
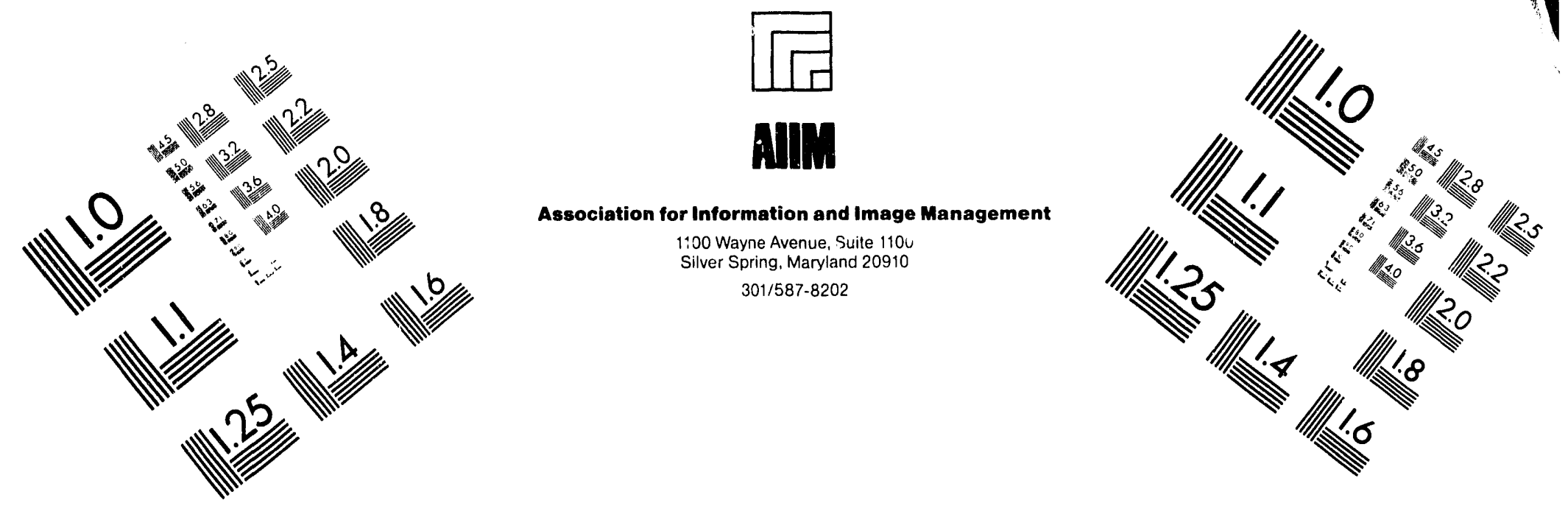

\title{
Centimeter
}

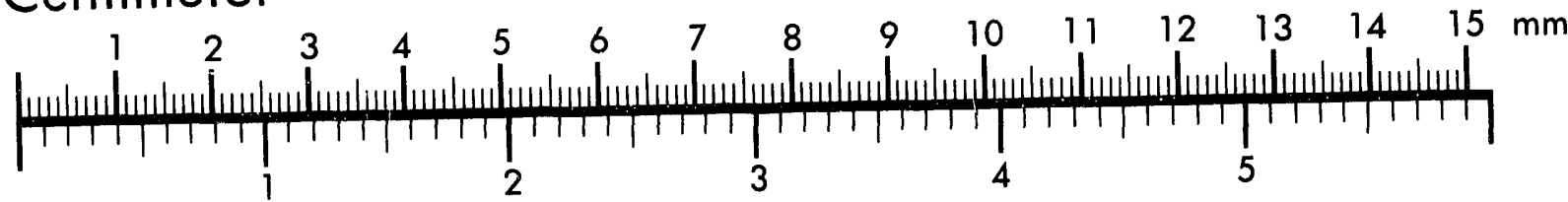
Inches
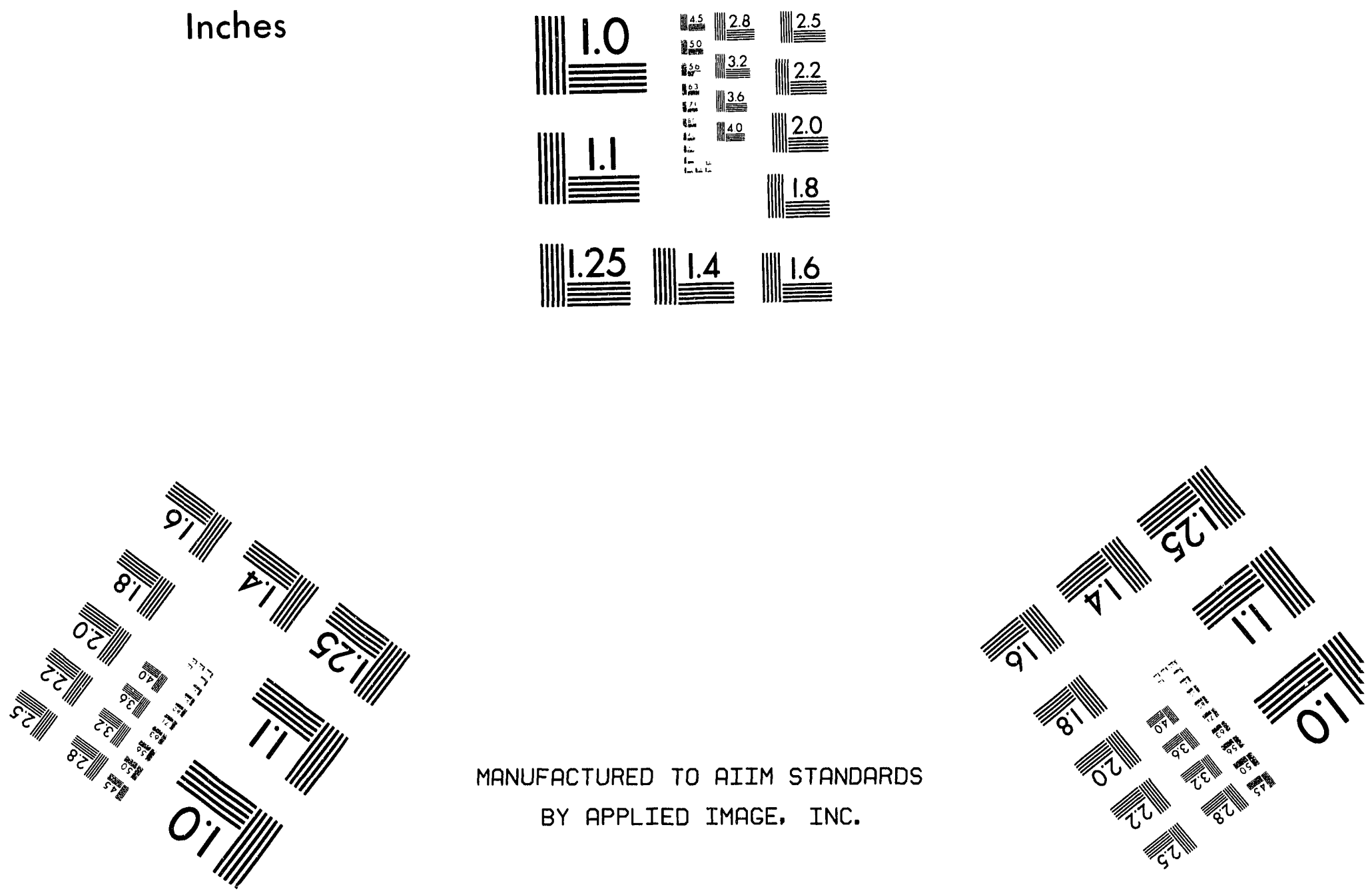

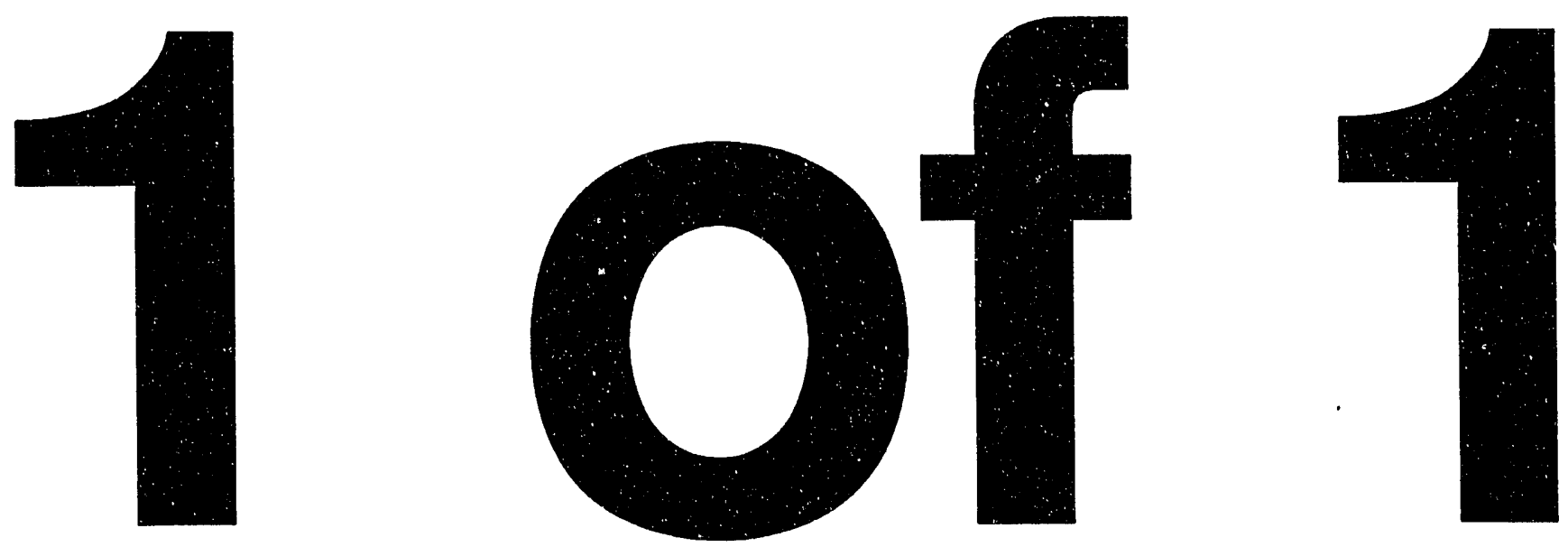
NUREG/CR-6013

\section{Methods Used for the Treatment of Non-Proportionally Damped Structural Systems}

Prepared by

J. P. Conoscente, O. R. Maslenikov, J. J. Johnson

EQE Engineering Consultants

Prepared for

U.S. Nuclear Regulatory Commission

$$
\begin{aligned}
& \text { RECEIVES } \\
& \text { JUN } 141993 \\
& \text { OSTI }
\end{aligned}
$$




\section{AVAILABILITY NOTICE}

Availability of Reference Materials Cited in NRC Publications

Most documents clted in NRC publications will be avallable from one of the following sources:

1. The NRC Publlc Document Room, 2120 L Street. NW., Lower Level, Washington, DC 20555

2. The Superintendent of Documents, U.S. Government Printing Office, P.O. Box 37082, Washington, DC 20013-7082.

3. The National Technical Information Service, Springfield, VA 22161

Although the listing that follows represents the malority of documents clted in NRC publications, it is not intended to be exhaustive.

Referenced documents avallable for Inspection and copying for a fee from the NRC Public Document Room include NRC correspondence and internal NRC memoranda; NRC bulletins, circulars, information notices, Inspection and investigation notlces; licensee event reports; vendor reports and correspondence; Commisslon papers; and applicant and licensee documents and correspondence.

The following documents in the NUREG series are available for purchase from the GPO Sales Program: formal NRC staff and contractor reports, NRC-sponsored conference proceedings, international agreement reports, grant publications, and NRC booklets and brochures. Also available are regulatory guides, NRC regulations in the Code of Federal Regulations. and Nuclear Regulatory Comrnission Issuances.

Documents avallable from the National Technical Information Service include NUREG-series reports and technical reports prepared by other Federal agencies and reports prepared by the Atomic Energy Commission. forerunner agency to the Nuclear Regulatory Commission.

Documents available from public and special technical libraries include all open literature items, such as books, Journal articles, and transactions. Federal Register notices, Federal and State legislation, and congressional reports can usually be obtained from these libraries.

Documents such as theses, dissertations, foreign reports and translations, and non-NRC conference proceedings are avallable for purchase from the organization sponsoring the publication cited.

Single copies of NRC draft reports are available free, to the extent of supply, upon written request to the Office of Administration. Distribution and Mail Services Section, U.S. Nuclear Regulatory Commission. Washington, DC 20555.

Coples of industry codes and standards used in a substantive manner in the NRC regulatory process are maintained at the NRC Library, 7920 Norfolk Avenue. Bethesda, Maryland, for use by the public. Codes and standards are usually copyrighted and may be purchased from the originating organization or, if they are American National Standards, from the American National Standards Institute, 1430 Broadway, New York, NY 10018.

\section{DISCLAIMER NOTICE}

This report was prepared as an account of work sponsored by an agency of the United Staies Government. Neither the United States Government nor any agency thereof, or any of their employees, makes any warranty. expressed or implied, or assumes any legal liability of responsibility for any third party's use, or the results of such use, of any information, apparatus, product or process disclosed in this report, or represents that its use by such third party would not infringe privately owned rights. 


\section{Methods Used for the Treatment of Non-Proportionally Damped Structural Systems}

Manuscript Completed: March 1993

Date Published: May 1993

Prepared by

J. P. Conoscente, O. R. Maslenikov, J. J. Johnson

EQE Engineering Consultants

44 Montgomery Street, Suite 3200

San Francisco, CA 94104

\section{Prepared for}

Division of Engineering

Office of Nuclear Regulatory Research

U.S. Nuclear Regulatory Commission

Washington, DC 20555

NRC FIN D1730 


\begin{abstract}
Non-proportional or non-classical damping is defined as a form of viscous damping that introduces coupling between the undamped modal coordinates of motion. Such problems have practical applications in the dynamic analysis of soil-structure systems, structure-equipment systems, and structural systems made of materials with different energy dissipation capacities.

Presented in this report is a review of the methods most commonly used in structural analysis for the solution of the dynamic response of systems with non-proportional damping. Both rigorous and approximate methods are described. Since rigorous methods usually require large computational efforts, approximate methods using undamped mode shapes are often preferred. In the study described here, the accuracy of three approximate methods was evaluated for three benchmark problems, with various parametric variations. Results were compared with the exact solution for different combinations of structural properties.
\end{abstract}

Based on these results, conclusions and recommendations are presented for the use of the selected approximate methods. 


\section{CONTENTS}

ABSTRACT $\ldots \ldots \ldots \ldots \ldots \ldots \ldots \ldots \ldots \ldots \ldots$ iii

TABLE OF CONTENTS ..................... v

EXECUTIVE SUMMARY $\ldots \ldots \ldots \ldots \ldots \ldots$ ix

PREFACE ...................... xi

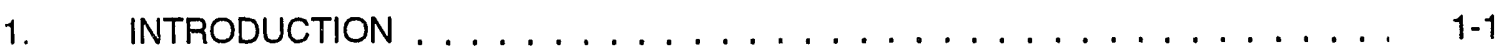

2. LITERATURE SEARCH AND IDENTIFICATION

OF AVAILABLE METHODS . . . . . . . . . . . . . . . . . . . 2-1

2.1 Rigorous Solution Methods . . . . . . . . . . . . . . . . 2-1

2.2 Approximate Solution Methods . . . . . . . . . . . . . . . . 2-5

2.2.1 Use of Equivalent Composite
Modal Damping Ratios . . . . . . . . . . . . . . . . . . 2-5

2.2.2 Methods Requiring Formulation $2-6$

3. SELECTION AND IMPLEMENTATION OF CANDIDATE METHODS . . . . . . $3-1$

3.1 Development of the Global Damping Matrix . . . . . . . . . . . . . . . 3-1

4. EVALUATION OF THE CANDIDATE METHODS . . . . . . . . . . . . . 4-1

4.1 Benchmark Problem $1 \ldots \ldots \ldots$ 4-1

4.2 Benchmark Problem $2 \ldots \ldots \ldots$ 4-3 . . . . . . . . . . . . .

4.3 Benchmark Problem $3 \ldots \ldots \ldots$ 4 . . . . . . . . . . . . .

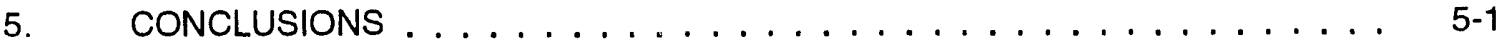

5.1 General Conclusions . . . . . . . . . . . . . . . . . . . 5-1

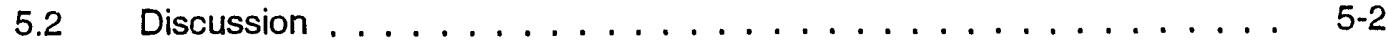

5.3 Recommendations . . . . . . . . . . . . . . . . . $5-4$

\section{APPENDICES}

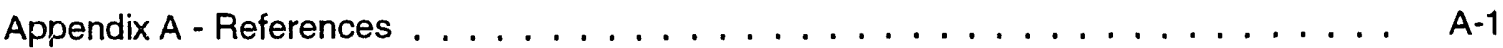

Appendix B - Benchmark Problem 3: Plots of Mode Shapes . . . . . . . . . . . . . B-1

\section{LIST OF TABLES}

4.1 Benchmark Problem 1

Summary of Fixed-Base Subsystem Properties . . . . . . . . . . . . . . . . 4 4-7

4.2 Benchmark Problem 1

Summary of Modal Frequencies and Damping Ratios . . . . . . . . . . . . . 4-8

4.3 Benchmark Problem 1

Summary of Maximum Percent Errors

in Maximum Relative Displacements 


\section{LIST OF TABLES (Continued)}

Section

4.4 Benchmark Problem 1

Summary of Maximum Percent Errors

in Maximum Relative Accelerations

4.5 Benchmark Problem 1

Summary of Maximum Percent Errors

in Maximum Member Forces . . . . . . . . . . . . . . . . . . . . . . . 4-12

4.6 Benchmark Problem 2

Summary of Fixed Base Subsystem Properties . . . . . . . . . . . . . . . . . . 4-13

4.7 Benchmark Problem 2

Summary of Modal Frequencies and Damping Ratios . . . . . . . . . . . . . . 4-14

4.8 Benchmark Problem 2

Summary of Maximum Percentage of Error

in Maximum Relative Displacements . . . . . . . . . . . . . . . . . . . 4-17

4.9 Benchmark Problem 2

Summary of Maximum Percentage of Error

in Maximum Member Forces . . . . . . . . . . . . . . . . . . . . . . . 4-18

4.10 Benchmark Problem 3, Case 1

Summary of Modal Damping Ratios for Modes Below $33 \mathrm{~Hz} \ldots \ldots$. . . . . . . . 4-19

4.11 Benchmark Problem 3, Case 1

Summary of Percentage of Error in Maximum Displacements . . . . . . . . . . . 4-20

4.12 Benchmark Problem 3, Case 1

Summary of Percentage of Error in Maximum Member

Forces in Internal Structure $\ldots \ldots \ldots \ldots$

4.13 Benchmark Problem 3, Case 1

Summary of Percentage of Error in Maximum Member

Forces in Piping System

4.14 Benchmark Problem 3, Case 2

Summary of Modal Damping Ratios for Modes Below $33 \mathrm{~Hz}$. . . . . . . . . . . .

4.15 Benchmark Problem 3, Case 2

Summary of Percentage of Error in Maximum Displacements . . . . . . . . . . .

4.16 Benchmark Problem 3, Case 2

Summary of Percentage of Error in Maximum Member

Forces in Internal Structure . . . . . . . . . . . . . . . . . .

4.17 Benchmark Problem 3, Case 2

Summary of Percentage of Error in Maximum Member

Forces in Piping System

4.18 Benchmark Problem 3, Case 2

Summary of Percentage of Error in Maximum Accelerations . . . . . . . . . . . 


\section{LIST OF TABLES (Continued)}

4.19 Benchmark Problem 3, Case 3

Summary of Modal Damping Ratios for Modes Below $33 \mathrm{~Hz} \ldots \ldots$. . . . . . . . 4-28

4.20 Benchmark Problem 3, Case 3

Summary of Percentage of Error in Maximum Displacements . . . . . . . . . . .

4.21 Benchmark Problem 3, Case 3

Summary of Percentage of Error in Maximum Member

Forces in Internal Structure . . . . . . . . . . . . . . . .

4.22 Benchmark Problem 3, Case 3

Summary of Percentage of Error in Maximum Member

Forces in Piping System . . . . . . . . . . . . . . . . . . .

\section{LIST OF FIGURES}

4.1 Response Spectra of Input Motions Used for

Benchmark Problems . . . . . . . . . . . . . . . . . . . . . . . . . 4-32

4.2 Sketch of Simplified Model for Benchmark Problem 1 . . . . . . . . . . . . 4-33

4.3 Sketch of Dynamic Model for Benchmark Problem $2 \ldots \ldots$ 4.34

4.4 Isometric View of Dynamic Model for Problem $3 \ldots \ldots \ldots$. . . . . . . . . . . . .

4.5a Benchmark Problem 3, Case 2

Comparison of Response at Node 24, X-Direction . . . . . . . . . . . . . . 4-36

4.5b Benchmark Problem 3, Case 2

Comparison of Response at Node 24, Y-Direction . . . . . . . . . . . . . . . . 4-37

4.5c Benchmark Problem 3, Case 2

Comparison of Response at Node 24, Z-Direction . . . . . . . . . . . . . . . 4-38

4.6a Benchmark Problem 3, Case 2

Comparison of Response at Node 32, X-Direction . . . . . . . . . . . . . . . . . . 4-39

4.6b Benchmark Problem 3, Case 2

Comparison of Response at Node 32, Y-Direction . . . . . . . . . . . . . . . . . 4-40

4.6c Benchmark Problem 3, Case 2

Comparison of Response at Node 32, Z-Direction . . . . . . . . . . . . . . 4-41

4.7a Benchmark Problem 3, Case 2

Comparison of Response at Node 42, X-Direction . . . . . . . . . . . . . . . . . 4-42

4.7b Benchmark Problem 3, Case 2

Comparison of Response at Node 42, Y-Direction . . . . . . . . . . . . . . . . 4-43

4.7c Benchmark Problem 3, Case 2

Comparison of Response at Node 42, Z-Direction . . . . . . . . . . . . . . . . . 4-44 


\section{EXECUTIVE SUMMARY}

Non-proportionally damped structures have practical app.ication in the dynamic analysis of soilstructure systems, structure-equipment systems, and structural systems made of materials with different energy dissipation capacities.

A compilation of the methods available in the literature to treat this type of structure is presented. Both rigorous and approximate methods are summarily described. Since rigorous methods usually require large computational effects and specific programs, approximate methods using classical undamped mode shapes are often used in practice. In the study described here, three commonly used approximate methods were evaluated for three sets of benchmark problems. The benchmark problems included a small- and a medium-size model of a structure made of different materials, and a large model of a structure-equipment system. Numerous parametric studies were performed to explore the accuracy of thie approximate methods over a wide range of variables.

Based on the results of the benchmark problems that were studied, the following conclusions were drawn:

- For all three problems, the errors in all responses produced by the approximate methods were generally less than $15 \%$. Although not trivial, this error was on the order of that assumed for standard engineering practice, and was within the accuracy of the damping values that were assumed. Therefore, even for the method producing the largest error for a given problem, the error was of acceptable order.

- For the two problems, in which the structures were represented with simplified models, the stiffness- and mass-weighted composite modal damping methods generally overestimated damping, thus producing underestimated responses.

- For the third problem, where the structural model was more complex, all three methods generally underestimated damping, thus producing conservative response estimates.

- For the first two problems, all tiree methods gave better approximations when the heavier lower stories had a larger damping ratio than the upper stories. This observation was in agreement with previous recommendations by Kusainov and Clough (Ref. 31) for the use of approximate methods for shear-type buildings made of different materials. For this case, the mass "eighted composite modal damping method produced the largest errors. This effect was not studied for the third pioblem.

For all three problems, errors tended to be larger for more heavily damped systems. Additionally, greater differences in assumed damping values produced greater errors. 
- Tuning or detuning the individual subsystems did not appear to have a predictable effect on the errors in the results. Tuned systems tended to have the largest errors for about half of the cases studied for the first two problems; most of these cases were for lighter upper systems.

- Overall, the method neglecting the off-diagonal terms of the generalized damping matrix appeared to produce the most accurate results. It produced small errors for the first two problems (generally less than $5 \%$ ) where the other two methods produced somewhat larger errors. It produced larger errors (10\% to $20 \%$ ) for the third problem, but these were essentially the same as those produced by the other methods. An attempt to explain the apparently superior performance of this method is provided below.

The poorer performance of the mass- and stiffness-weighted composite modal damping ratio methods for the two benchmark problems was found to be a consequence of the definition of subsystem damping. For small models, the idealization of structural damping by specific damping ratios for all modes of a subsystem results in a global damping matrix that does not fit the framework associated with the mass- and stiffness-weighted composite damping methods. Therefore, the following recommendations are made:

Use of the mass- or stiffness-weighted composite modal damping ratio method is recommended for systems of substructures with different damping characteristics, if the individual substructures are represented by refined models. These two methods are much easier to use and implement than the third approximate method, and they both give adequate approximations for large problems.

For most problems, the two methods are judged to be equivalent, with the exception of structures made of different materials for which the lower stories have higher energy-absorption capacity than the upper stories. For such systems, use of the stiffness-weighted composite modal damping ratio method is recommended.

- For systems of substructures with different damping characteristics represented by simple models (small number of lumped mass points and elements), the averaging process of the mass and stiffness weighted methods may not be very accurate, and use of the method neglecting the off-diagonal terms of the generalized damping matrix is recommended. However, it should be noted that this method requires considerably more effort than either of the other two when the damping of the individual subsystems is defined in terms of percentages of critical damping, as is the most common method of defining damping in the nuclear industry. When this procedure is used, the global damping matrix of the coupled system must first be assembled and then the generalized damping matrix must be calculated. Attention should be given to the method used to assemble the global damping matrix, as it may lead to a situation that violates the initial analysis assumptions. 


\section{PREFACE}

The study described in this report was conducted by EQE Engineering Consultants under contract to the U.S. Nuclear Regulatory Commission as part of the Structure Damping Research Program. Other reports prepared for this program include NUREG/CR-6012, "Stiffness and Damping Properties of a Low Aspect Ratio Shear Wall Building Based on Recorded Earthquake Responses," and NUREG/CR-6011. "Review of Structure Damping Values for Elastic Seismic Analysis of Nuclear Power Plants."

The USNRC project manager was Dr. James F. Costello. His support and guidance throughout the duration of this study are greatly appreciated. The contributions of the late Boris Browzin are also greatly appreciated. 


\section{INTRODUCTION}

The practical seismic response analysis of elastic structures is generally performed by the mode r. iperposition method. In most cases. the undamped eigen properties are calculated, and the equations of motion are transformed into the eigen-vectorial space. This transformation uncouples the equations of motion as long as damping does not cause any significant coupling between the modes. This type of damping is called proportional or classical. For this type of damping, the energy loss mechanisms modeled by damping are assumed to be homogeneous throughout the system. When large variations between energy-absorption mechanisms exist in a system, this system is said to have non-proportional or non-classical damping. Non-proportional damping can be defined as a form of damping that introduces coupling between the undamped modal coordinates of motion. In the seismic analysis of nuclear power plant stru-tures, such damping is found in soil-structure systems, structure-equipment systems, and structures made of different materials. The term damping as normally defined is "the means by which the response motion of a structural system is reduced as the result of energy loss, including material as well as geometrical nonlinear effects."

This study focuses on the procedures with which the damping of these systems can be modeled. It consists of the identification, review, and evaluation of analysis techniques that are currently available for use in the treatment of non-proportionally damped structural systems. For the purpose of this task, these systems are subdivided into two categories: soil-structure systems for which radiation as well as material damping are present, and assemblies of interacting subsystems with different damping characteristics. The focus of this report is the evaluation of commonly used approximate methods for the analysis of interacting subsystems.

Section 2 describes a literature search that was conducted to identify the available methods of treating non-proportional damping. Section 3 discusses the selection and implementation of candidate methods for further review and evaluation. Section 4 describes the benchmark problems that were used to evaluate the candidate methods and the results of the tests. Section 5 discusses conclusions and recommendations. 


\title{
2. LITERATURE SEARCH AND IDENTIFICATION OF AVAILABLE METHODS
}

\begin{abstract}
A literature review was performed to ascertain which methods have been proposed and used in the past for analyses of systems with non-proportional damping and to identify the types of problems for which such damping is assumed. A total of 37 papers were obtained and reviewed.

In the course of the literature review, a number of different solution methods were identified. These methods can be classified into two categories: rigorous solution methods and approximate solution methods. All of them can be used in either the time domain or the frequency domain. However, in practice, time-domain solution methods are usually used. The different methods are summarized below.
\end{abstract}

\subsection{Rigorous Solution Me thods}

Three rigorous methods were identified from the literature. These are direct integration, damped modal superposition (Foss method), and modal synthesis and are described in the subsections that follow. These methods produce so-called "exact" results, that is, results for which errors are limited to those caused by limitations in numerical accuracy. Use of these methods requires that the damping matrix be known in the physical coordinate system.

\section{Direct Integration}

For this method, the dynamic equations of motion are formulated in the global coordinates for the entire system as follows:

$$
\begin{array}{ll}
{[M]\{\dot{x}\}+[C]\{\dot{x}\}+[K]\{x\}=\{F(t)\}} \\
\text { where } \quad[M]=\text { the system mass matrix } \\
{[C]=\text { the system damping matrix }} \\
{[K]=\text { the system stiffness matrix }} \\
\{x\}=\text { the system displacement array } \\
\{F(t)\}=\text { is the forcing function }
\end{array}
$$

The coupled system of equations (1) is solved by step-by-step integration procedure alch as the Wilson-theta or the Newmark-beta methud.

\section{Damped Modal Superposition (Foss Method)}

The dynamic equations of a non-proportionally damped system can be uncoupled by a transformation to the damped modal coordinate system. This method was first proposed by Foss as follows. Equation (1) can be rewritten as:

$$
[A]\{\dot{Z}\}+[B]\{z]=[Y(t)]
$$


in which $[A]=\left[\begin{array}{cc}{[0]} & {[M]} \\ {[M]} & {[C]}\end{array}\right] \quad[B]=\left[\begin{array}{cc}-[M] & {[0]} \\ {[0]} & {[K]}\end{array}\right]$

and

$$
\{z\}=\left\{\begin{array}{l}
\{\dot{x}\} \\
\{x\}
\end{array}\right\} \quad[Y(t)]=\left\{\begin{array}{c}
\{0\} \\
{[F(t)\}}
\end{array}\right\}
$$

The solution of the homogeneous form of equation (2) may be taken as:

$$
\{z\}=\{Z\} e^{n t}
$$

with $\{Z\}=\left\{\begin{array}{c}r\{\phi\} \\ \{\phi\}\end{array}\right\}$

where $r=$ a characteristic value

$\{Z\}=$ the associated characteristic vector of $2 n$ elements

Combining equations (4),(5), and (6) yields:

$$
\{x\}=\{\phi\} e^{n t}
$$

Derivation of the characteristic values has been given in References 13 and 30 and yields $2 n$ complex values, two-by-two conjugate, as follows:

$$
\begin{aligned}
& r_{j}=p_{j}\left[-E_{j} \pm i\left(1-E_{j}^{2}\right)^{1 / 2}\right] \\
& \text { where } p_{j}=\text { the undamped circular natural frequency } \\
& E_{j}=\text { the modal damping ratio }
\end{aligned}
$$

The characteristic vectors $\left\{Z_{j}\right\}$ are also two-by-two conjugate and satisty the orthogonality relations:

$$
\begin{array}{ll}
\left\{Z_{j}\right\}^{t}[A]\left\{Z_{k}\right\}=0 & \text { for } j \neq k \\
\left\{Z_{j}\right\}^{t}[B]\left\{Z_{k}\right\}=0 & \text { for } j \neq k
\end{array}
$$

Since the eigenvalues and eigenvectors are two-by-two conjugate, the homogeneous solution of equation (1) will be:

$$
\begin{aligned}
& \{x\}_{h}=2 \operatorname{Re}\left[C_{j}\{\phi\} e^{r} j^{t}\right] \\
& \text { where } C j=\text { a complex constant dependent on the initial } \\
& \text { conditions }
\end{aligned}
$$

The particular solution is derived as for classically damped systems, by calculating the modal participation factors and the modal response vectors, and combining them. 
A different form for the solution of equation (2) is presented in References 33 and 43 . In this approach, the system displacement array $\{x\}$ is written as a combination of real mode shapes, rather than complex mode shapes as in equation (7).

\section{Modal Synthesis}

Modal synthesis is a Rayleigh-Ritz approach using systematically derived displacement functions. Several variations of modal synthesis have been proposed. They are similar in concept but differ in the type of substrusture riodes used.

All modal syntheses are based on the following concepts. The equations of motion for the complete structural system are written as in equation (1). Equations of similar form also apply to each separate substructure:

$$
\begin{aligned}
& {[m]_{S}\{\ddot{u}\}_{S}+[c]_{S}\{\dot{u}\}_{S}+[k]_{S}\{u\}_{S}=\{f(t)\}_{S}} \\
& \text { where }[\mathrm{m}]_{S},[\mathrm{c}]_{S},[\mathrm{k}]_{S}=\text { the substructure mass, damping, and } \\
& \text { stiffness matrices } \\
& \{u\}_{S} \quad=\text { the substructure displacement vector } \\
& \{f(t)\}_{S} \quad=\text { the substructure forcing function }
\end{aligned}
$$

Equations similar to equation (12) are written for all substructures, and are combined in the following single matrix form:

$$
\begin{aligned}
& {[m]\{\dot{u}\}+[c]\{\dot{u}\}+[k]\{u\}=\{f\}} \\
& \text { where }[\mathrm{m}]=\left[\begin{array}{lll}
{\left[\mathrm{m}_{1}\right.} & & \\
& {[\mathrm{m}]_{2}} & \\
& & {[\mathrm{~m}]_{\mathrm{s}}}
\end{array}\right] \\
& {[k]=\left[\begin{array}{lll}
{[k]_{1}} & & \\
& {[k]_{2}} & \\
& & {[k]_{S}}
\end{array}\right]} \\
& {[c]=\left[\begin{array}{lll}
{[c]_{1}} & & \\
& {[c]_{2}} & \\
& & {[c]_{S}}
\end{array}\right]} \\
& \{u\}=\left\{\begin{array}{c}
\{u\}_{1} \\
\{u\}_{2} \\
\{u\}_{s}
\end{array}\right\}
\end{aligned}
$$




$$
\{f\}=\left\{\begin{array}{c}
\{f(t)\}_{1} \\
\{f(t)\}_{2} \\
\{f(t)\}_{S}
\end{array}\right\}
$$

If there are $m$ components in the vector $\{u\}$ and $k$ equations of constraint relating them, then $n=$ $m-k$ is the order of $\{x\}$ in equation (1) (i.e., there are $n$ independent displacements). The vectors $\{u\}$ and $\{x\}$ are related as follows:

$$
\{u\}=[T]\{x\}
$$

where $[T]$ is of order $m X n$ with $m>n$

Substituting equation (19) into equation (13), premultiplying by $[T]^{t}$, and comparing to equation (1) yields the following identity:

$$
[C]=[T]^{t}[C][T]
$$

Equations similar to equation (20) can also be written for the mass and stiffness matrices.

To obtain the substiucture damping matrices, the substructure displacement vectors are broken down into three categories: rigid-body displacement vector, constraint displacement vector, and normal displacement vector. Each of these displacements is then defined in terms of a set of normalized displacement modes, as follows:

$$
\begin{aligned}
& \{u\}=\left\{u^{R}\right\}+\left\{u^{C}\right\}+\left\{u^{N}\right\} \\
& \{u\}=[Y]\{p\}
\end{aligned}
$$

where $[Y]=$ the modal matrix

The modal matrix $[Y]$ can be partioned into the different modes as follows:

$$
[Y]=\left[Y R_{][Y} C_{][Y} N_{]}\right.
$$

It follows that the damping matrix [c] can be written as:

$$
[c]=\left[\begin{array}{l}
c^{R R}{ }_{c} R C{ }_{c} R N \\
{ }_{c} \mathrm{CR}{ }_{c} \mathrm{CC}{ }_{c} \mathrm{CN} \\
c^{N R}{ }_{c} N C{ }_{c} N N
\end{array}\right]
$$

Solutions are rigorous only if the structure is described by all modes characterizing the behavior of independent substructures. However, in practice the common objective of these methods is to achieve an approximate formulation that will permit an accurate representation of system motion with the fewest substructure modes. 


\subsection{Approximate Solution Methods}

Classical modal superposition typically is used for the practical earthquake response analysis of linear elastic structures. In order to use this approach for non-proportionally damped systems, approximations must be made. The approximate methods can be classified into two main categories: (1) those for which no damping matrix is actually assembled but an equivalent modal composite damping ratio is used, and (2.) those requiring the formulation of the global damping matrix. Several methods that fall into these categories are described below.

\subsubsection{Use of Equivalent Composite Modal Damping Ratios}

\section{Stiffness-Weighted Composite Modal Damping (Biggs)}

This method computes the equivalent composite modal damping ratio as a weighted sum of the different component damping ratios. The weighting function for this method is the stiffness.

The composite modal damping ratios are calculated as follows:

$$
\begin{aligned}
& \underline{d}_{j}=\frac{\operatorname{Sum}\left(d_{i}\left[Y_{j}\right\}^{\top}\left[K_{i}\right]\left\{Y_{j}\right\}\right)}{\left\{Y_{j}\right\}^{\top}[K]\left\{Y_{j}\right\}} \\
& \text { where } \quad \underline{d}_{j}=\text { composite modal damping ratio for } j^{\text {th }} \text { mode } \\
& d_{i}=\text { component modal damping ratio for the } i^{\text {th }} \\
& \quad \text { element } \\
& {\left[K_{i}\right]=\text { stiffness matrix associated with element } i } \\
& {[K]=\text { system stiffness matrix } } \\
&\left\{Y_{j}\right\}=\text { mode shape for } j^{\text {th }} \text { mode }
\end{aligned}
$$

\section{Mass-Weighted Composite Modal Damping (Johnson-McCaffrey)}

This method computes the equivalent modal composite damping ratio as a weighted sum of the different component damping ratios, using the mass as a weighting function.

The composite modal damping ratios are calculated as follows:

$$
\begin{aligned}
& \underline{d}_{j}=-\frac{\operatorname{Sum}\left(d_{j}\left\{Y_{j}\right\}^{\top}\left[M_{j}\right]\left\{Y_{j}\right\}\right)}{\left\{Y_{j}\right\}^{\top}[M]\left\{Y_{j}\right\}} \\
& \text { where } \quad \underline{d}_{j}=\text { composite modal damping ratio for } j^{\text {th }} \text { mode } \\
& d_{i}=\text { component modal damping ratio for the } i^{\text {th }} \\
& \text { element } \\
& {\left[M_{i}\right]=\text { mass matrix associated } \text { with element } i} \\
& {[M]=\text { system mass matrix }} \\
& \left\{Y_{j}\right\}=\text { mode shape for } j^{\text {th }} \text { mode }
\end{aligned}
$$




\section{Energy-Weighted Composite Modal Damping (Roesset-Whitman-Dobry)}

This method computes the equivalent modal composite damping ratio as a weighted sum of the different component damping ratios, using the stored energy as a weighting function, combining both viscous and hysteretic damping effects.

The composite modal damping ratios are calculated as follows:

$$
\begin{aligned}
& \underline{d}_{i}=\frac{\operatorname{Sum}\left(E R_{i j} E_{s i j}\right)}{4 \pi \operatorname{Sum}\left(E_{s i j}\right)} \\
& \text { where } \underline{\text { di }}=\text { composite modal damping ratio for } j^{\text {th }} \text { mode } \\
& E s_{i j}=\text { energy stored in the } j^{\text {th }} \text { component of the } \\
& \text { system when the system deforms in the } \mathrm{ith}^{\text {th }} \text { mode } \\
& E R_{i j}=\text { ratio of the energy dissipated in the } j^{\text {th }} \\
& \text { component to the energy stored in the } \mathrm{j}^{\text {th }} \\
& \text { component }
\end{aligned}
$$

\section{Equivalent Modal Damping by Response Matching (Tsai)}

This method consists of matching the rigorous and normal mode solutions of the transfer function at certain structural locations simultaneously at all natural frequencies within the frequency range of interest. This method is discussed in References 3 and 4.

\subsubsection{Methods Requiring Formulation of the Global Damping Matrix}

\section{Neglecting Off-Diagonal Terms of Generalized Damping Matrix}

This method consists of forming the global damping matrix and transforming it into the undamped modal coordinates. If the system were proportionally damped, the obtained generalized damping matrix would be diagonal. However, when the system is non-proportionally damped, the generalized damping matrix will have non-zero off-diagonal terms.

The modal damping ratios are calculated as follows:

$$
\begin{aligned}
d_{i}=\frac{\left\{Y_{i}\right]^{T}[C]\left\{Y_{i}\right\}}{2 M_{i} W_{i}} \\
\text { where } \quad d_{i}=\text { modal damping ratio for } i^{\text {th }} \text { mode } \\
\left\{Y_{i}\right\}=\text { mode shape vector for } i^{\text {th }} \text { mode } \\
{[C]=\text { system damping matrix } } \\
M_{i}=\text { modal mass for } i^{\text {th }} \text { mode } \\
W_{i}=\text { circular frequency for } i^{\text {th }} \text { mode }
\end{aligned}
$$


The off-diagonal coupling term

$$
d_{i j}=\left\{Y_{i}\right\}^{\top}[C]\{Y j\} \text { with } i \neq j
$$

is generally non-zero, but is neglected. The method consists of forcing the system to have proportional damping by neglecting the off-diagonal terms.

\section{Clough/Mojtehedi Method}

This method consists of forming the global damping matrix, and transforming equation 1 1 ; into the undamped modal coordinates with a truncated set of the first $p$ lowest modes, as follows:

$$
\{\mathrm{X}\}=[\mathrm{Y}]\{\underline{u}\}
$$

where $\{x\}=$ the system displacement vector

$[Y]=$ a matrix containing the $q$ first modal vectors $(q<N$,

$\mathrm{N}=$ total number of modes)

$\{\underline{u}\}=$ corresponding truncated vector of modal coordinates

Substituting equation (30) into equation (1) anci pre-multiplying by $\left[Y^{\top}{ }^{\top}\right.$, yields:

$$
\begin{aligned}
& \{\underline{\underline{u}}\}+[\underline{C}]\{\underline{\underline{u}}\}+\left[\underline{W}^{2}\right]\{\underline{u}\}=\{\underline{F}\} \\
& \text { where } \quad[\underline{C}]=[Y]^{\top}[C][Y] \text { is fully populated } \\
& {\left[W^{2}\right]=\text { contains the first } q \text { circular frequencies }} \\
& \{\text { F }]=[Y]^{\top}\{F\}
\end{aligned}
$$

The coupled equations of equation (31) are then solved by direct integration techniques. This method reduces the problem from the direct integration of $\mathrm{N}$ coupled equations, to the integration of $q<N$ coupled equations. However, it is an approximate method since it only considers coupling between the first $q$ modes, and not all $\mathrm{N}$ modes. 


\section{SELECTION AND IMPLEMENTATION OF CANDIDATE METHODS}

Candidate solution methods were selected from those identified in the literature review. The approximate solution methods were evaluated by comparing their results from a series of benchmark problems with those produced by a rigorous method. The benchmark problems were for different cases of assemblies of interacting subsystems with different damping characteristics.

Regardless of the solution method used, the following assumptions were made:

(1) The system response is linear-elastic.

(2) The system can be divided into substructures that have proportional elastic damping properties.

(3) Damping was defined for each substructure as a ratio of critical damping at each natural mode of vibration, as specified in US NRC Regulatory Guide 1.61 (Ref. 38).

The rigorous method selected was the direct integration method. Results using this method were considered the standard against which the approximate methods would be evaluated.

Three approximate methods were selected for evaluation. These were:

(1) Stiffness-weighted composite modal damping ratio method.

(2) Mass-weighted composite modal damping ratio method.

(3) Neglecting the off-diagonal terms of the generalized damping matrix.

These methods were selected because of the frequency of usage in the literature and the ease of their implementation in existing available software. The first two approximate methods were already available in the program MODSAP (Ref. 39); the other two were developed by modifying existing software.

\subsection{Development of the Global Damping Matrix}

In order to evaluate the approximate methods, consistent problems of assemblies of interacting subsystems with different damping properties needed to be developed. For a given problem, proportional or classical damping for each substructure was assumed and was defined as a ratio of critical damping. This information was sufficient to define the damping for the first two approximate methods. However, for the third approximate method and for the rigorous method a global damping matrix that properly coupled the effects of the separate subsystems had to be defined.

The first step in the implementation procedure therefore consisted of developing a computer program to assemble the global damping matrix of a system made of multiple substructures. The 
method is described in References 8, 9, and 33. It uses the fixed-base dynamic properties and the rigid body or pseudostatic properties of each subsystem to back-calculate the global damping matrix.

Derivations of the method are given in the references mentioned above. The steps required were:

(1) Calculation of the natural modes of vibration of each substructure isolated one from another.

(2) For each substructure attached to another substructure, calculation of the substructure deflections due to a unit displacement at each fixedbase DOF. This led to an algorithm for the resolution of multi-support excitation. The approach adopted was the use of pseudostatic modes.

(3) Formulation of a diagonal fixed-base damping matrix containing the substructure fixed-base damping properties.

(4) Formulation of a transformation matrix using the fixed-base modes and the pseudostatic modes, allowing transformation from the fixed-base coordinate system to the coupled physical coordinate system.

(5) Transformation from the diagonal fixed-base damping matrix to the coupled damping matrix in the physical coordinate system.

Modifications were then made to MODSAP (Ref. 39) to incorporate the two remaining candidate methods. The first modification consisted of adding to MODSAP the capability to read an explicitly defined, fully populated damping matrix and to use the damping contributions in a stepby-step dynamic time-history analysis using the direct integration method.

The second modification to MODSAP consisted of adding the capability to calculate the diagonal terms of the fully populated generalized damping matrix and use them as composite modal damping ratios in a modal time-history analysis. 


\section{EVALUATION OF THE CANDIDATE METHODS}

The selected approximate methods were evaluated against the rigorous method for three test problems. Each problem consisted of a dynamic time-history response analysis of an assembly of substructures having dissimilar damping characteristics and subjected to base-excitation. For the first two problems, small models representative of real structures were selected. The models of the systems were kept simple enough to allow numerous parametric studies. Maximum displacements, accelerations, and member forces were obtained and errors in the approximate results were obtained as percentage differences from the rigorous results. The third benchmark problem was for a larger model representing a nuclear reactor building internal structure with a main steam line attached at several elevations. Because of the size of this problem, only a limited number of parametric studies were performed.

The base excitation that wis used for the three problems consisted of acceleration time histories whose spectra satisfy the speciral shape criteria set forth in the US NRC Regulatory Guide 1.60 (Ref. 40). Plots of the spectra of these time histories calculated at $5 \%$ oscillator damping are shown in Figure 4.1. The first two problems used only one component of base excitation; the spectrum of this time history is shown in Figure 4.1a. The third problem used all three components.

\subsection{Benchmark Problem 1}

The first benchmark problem consisted of a dynamic time-history analysis of a structure comprising of two substructures having different damping characteristics. The seismic input consisted of a single a'celeration time history: the spectrum of this motion is shown in Figure 4.1a. The structural nodel consisted of a modification of a dynamic model of an auxiliary building for a nuclear power plant. The building was a reinforced concrete structure up to 27.5 feet above grade and steel frame to a height of 66 feet, rectangular in plan (150 by 110 feet) and supported at grade by a 4-foot-thick basemat. The building was modeled with four mass points located eccentrically at the floor and roof elevations. The fundamental modes of vibration of the concrete substructure were about $22 \mathrm{~Hz}$ in each horizontal direction; for the steel-frame superstructure they were about. $6 \mathrm{~Hz}$.

This model was simplified for the purpose of this study to a one-dimensional mass-spring system shown in Figure 4.2. In addition to this simplification, the stiffness of the substructure was reduced by a factor of 18 in order to bring the frequencies of the substructure into the amplified frequency range of the input motion.

Dynamic analyses were performed for 18 cases, for which the frequency and mass of the steel superstructure, as well as the damping ratios of both subsystems, were varied. The different combinations of subsystem properties are summarized in Table 4.1. A summary of the modal frequencies and damping ratios used for the analyses is contained in Table 4.2.

Analyses were performed using modal time-history analysis methods with mass-proportional and stiffness-proportional composite modal damping and modal damping ratios obtained from the diagonal terms of the generalized damping matrix of the coupled system (referred to here as 
neglecting off-diagonal damping terms). Maximum displacements and accelerations relative to the model base and maximum member forces were obtained. These results were compared to the respective results from the direct integration analysis, and the maximum percentages of errors at any mass point or element in each subsystem are summarized in Tables 4.3 through 4.5 .

Based on the data shown in the tables, the following observations were made for this problem:

- In general, the errors in all responses produced by the approximate methods were less than $15 \%$. The method neglecting off-diagonal damping terms produced the lowest errors by far, generally less than $1.5 \%$; stiffness-proportional damping errors were generally between $4 \%$ and $12 \%$. Mass-proportional damping errors were generally less than about $14 \%$, varying from less than $1 \%$ to over $20 \%$.

- Overall, errors from the mass- and stiffness-proportional damping methods tended to be unconservative (i.e., to underpredict response); the method neglecting off-diagonal terms, on average, tended to be unbiased. The tendency for the mass- and stiffness-proportional damping results to underpredict or overpredict response appears to correlate well with the first mode damping ratios in Table 4.2; both methods tended to produce higher first mode damping than the method neglecting off-diagonal damping terms.

- Mass-proportional damping errors were sensitive to the assumed subsystem damping. For Cases 7 to 12, for which the upper system had $7 \%$ damping and the lower system had $4 \%$ damping, the massproportional damping method gave errors ranging from about $10 \%$ to $20 \%$; for the other cases, where the damping in the upper system was less than that in the lower system, mass-proportional damping produced errors generally below $5 \%$. The other two methods did not appear to be affected by differences in subsystern damping.

- The effect of increasing the mass of the upper system by a factor of 2 was to increase the errors in the mass-proportional and stiffnessproportional damping methods by factors of 1 and $1 / 2$ to 2 . No significant effect was seen for the other method.

- The effect of tuning and detuning the two subsystems did not appear to have a significant effect on the accuracy of any of the methods. For a given mass and damping configuration, changing the stiffness of the upper system to change its frequency resulted in differences in accuracy, but there did not appear to be any significant trend.

- For a given analysis, the errors in the two subsystems were not significantly different.

- For the configuration most closely resembling the actual structure (Case 1), the errors from all methods were less than $8 \%$. 


\subsection{Benchmark Problem 2}

This problem is similar to Problem 1 in that it consisted of a dynamic time-history analysis of a structure comprising of two substructures having different damping characteristics. The seismic input was the same as that used in Problem 1. The structural model was of a reactor building for a nuclear power plant. The building was a reinforced concrete structure up to 143 feet above its basemat, and a steel frame with metal siding and decking above this level. The building was modeled with six mass points located at different elevations in the building as shown in Figure 4.3. Each mass point had a horizontal and rotational degree of freedom. The fixed-base fundamental mode of vibration of the concrete substructure was about $7.5 \mathrm{~Hz}$; for the steel-frame superstructure it was about $11.6 \mathrm{~Hz}$. This model configuration was used for the first analysis case for this problem.

Dynamic analyses were performed for 18 cases, for which the frequency and mass of the steel superstructure, as well as the damping ratios of both subsystems, were varied. The different combinations of subsystem fixed-base properties are summarized in Table 4.6. The frequencies and calculated modal damping ratios of the coupled models used for each of the cases are shown in Table 4.7.

Analyses were performed using the approximate and rigorous methods previously described. Maximum displacements relative to the model base and maximum member forces were obtained. The results from the approximate methods were compared to the respective results from the direct integration analysis. The maximum percentages of errors at any mass point or element in each subsystem are summarized in Tables 4.8 and 4.9 .

The trends seen in the results of Problem 1 were also observed for this problem.

- Generally, the errors produced by all methods were less than about $15 \%$ Overall, the method neglecting off-diagonal damping terms produced the greatest accuracy, with the majority of errors less than $3 \%$. The massproportional and stiffness-proportional damping methods produced about the same accuracy overall, with most errors less than $12 \%$ to $13 \%$; the largest errors for these methods were about $18 \%$ to $23 \%$.

As was the case for Problem 1, errors tended to be unconservative for the mass- and stiffness-proportional damping methods, while the method neglecting off-diagonal damping terms generally appeared to be unbiased. Again, the results seem to correlate with the damping ratios calculated for the first mode of each analysis; for all analysis cases, the mass- and stiffness-proportional damping methods calculated damping ratios that were greater than those calculated by the method neglecting off-diagonal terms.

- Mass-proportional damping errors were again sensitive to the damping ratios assumed for each subsystem. For Cases 7 to 12 (upper system $7 \%$ and lower system $4 \%$ ), the errors ranged to over $20 \%$, generally 2 to 3 times the errors for Cases 1 to 6 . The other two methods did not show a similar sensitivity. 
- Generally, the effect of reducing the subsystem damping ratios (Cases 13 to 18 ), was to reduce the errors in all methods.

- The effect of increasing the mass of the upper subsystem from 0.013 to 0.130 of the lower subsystem was to increase errors in the mass- and stiffness-proportional damping results by factors varying from 2 to 4 times; the method neglecting off-diagonal damping terms showed a decrease of about the same amount.

- Changing the stiffness of the upper subsystem did not appear to have a predictable effect on the accuracy of any of the methods. Errors tended to increase for the cases where the subsystems were tuned.

- The errors in the two subsystems did not appear to correlate as well as was the case for Problem 1; for a given case, the errors in the lower subsystem were not necessarily of the same magnitude as those in the upper subsystem.

- For the combination of subsystem properties modeling the actual structure (Case 1), the errors from all methods were less than about $4 \%$.

\subsection{Benchmark Problem 3}

For the third benchmark problem, a more realistic model of a typical structure with nonproportional damping was selected. The structure consisted of a piping system spanning several floors of the internal structure of a reactor building. A sketch of the model is shown in Fig. 4-4.

The primary system is the reinforced concrete internal structure, which extends about 50 feet above the basemat to the operating floor. Its major components are the biological shield surrounding the reactor pressure vessel and the ring wall. The two structures are tied together at the operating floor. Both are offset slightly from the containment building centerline. The total weight of the internal structure is about $26,000 \mathrm{kips}$. The model of the internal structure comprised two lumped mass beam models with beam elements connecting 10 mass points located at appropriate intervals between the basemat and operating floor, modeling the biological shield and ring wall. Seven additional nodes were rigidly linked to the beam models to serve as support points for the piping system. Six degrees of freedom were modeled for each node point, giving a total of 102 degrees of freedom for the internal structure.

The secondary system was a main steam line extending from the top of one of the steam generators, about 85 feet above the basemat, to a penetration in the containment about 11 feet above the basemat. The steam line consisted of a 30 -inch-diameter run of pipe having a total length of about 140 feet from steam generator to penetration. The piping system was supported at seven locations including the end points. The total weight of the piping systern was about 64 kips. The piping system was modeled with 28 pipe elements connecting 29 node points. The two end points were assumed to be anchored to the internal structure and basemat; intermediate supports were modeled with a combination of spring and stiffness elements. The piping system model contained 162 dynamic degrees of freedom. 
For the purposes of this study, the piping system support points were connected to the internal structure by rigid links. For modeling its support off the steam generator, the flexibility of the steam generator could have been included, but was not readily available and was therefore omitted.

The seismic input for this problem consisted of three simultaneous components of earthquake motion, shown in Figure 4.1.

Because of the size of this problem, only three cases were analyzed. For all cases, the mass and stiffness properties of both systems were held constant; only the damping in each system was varied. The damping ratios defined for each of the cases is tabulated below. Note that the Case 2 values correspond to those in Regulatory Guide 1.61 (Ref. 38) for SSE excitation.

$\begin{array}{ll}\begin{array}{c}\text { Internal } \\ \text { Structure }\end{array} & \begin{array}{c}\text { Piping } \\ \text { System }\end{array}\end{array}$

$\begin{array}{lll}\text { Case 1 } & 0.05 & 0.02 \\ \text { Case 2 } & 0.07 & 0.03 \\ \text { Case 3 } & 0.10 & 0.01\end{array}$

For all approximate methods of analysis, 250 out of a possible 264 modes were used to minimize errors due to missing mass effects. Figures B-1 through B-16 in Appendix B show isometric plots of the mode shapes of the first 16 modes, which cover all frequencies below $33 \mathrm{~Hz}$. These plots give an indication of what portions of the coupled system participated most for each mode.

For each analysis case, maximum displacements were calculated for all locations in the primary structure. Maximum member forces were calculated for all members in the biological shield and ring wall and at all elbows in the piping system. Additionally, for Case 2, maximum accelerations and response spectra were calculated at the operating floor and at several selected locations on the piping system.

\section{CASE 1}

For Case 1 , the damping in the pipiny system was defined to be $2 \%$, while that in the internal structure was $5 \%$. The modal damping ratios that were calculated for this case are summarized for frequencies below $33 \mathrm{~Hz}$ in Table 4.10. As can be seen from the table, the calculated values varied only slightly between the different methods; the largest difference is about $8 \%$ and the average was less than $1 \%$. The results obtained from the three approximate methods were compared with those from the rigorous method by calculating the percentage of difference (i.e., divided by the rigorous solution values) for each response component. The maxima, means, and standard deviations of the individual errors are shown in Tables 4.11 through 4.13. Mean values and their standard deviations were calculated two ways: the first was based on the algebraic mean of the individual errors (positive values indicate that approximate results were higher, negative values indicate the reverse); the second was based on the absolute mean. The reason for this was to get an indication of whether the approximate methods were producing conservative or unconservative results. As can be seen from the tables, the errors in the primary system were small; for maximum displacements they were $1 \%$ or less; for member forces they averaged about $0.5 \%$, although there were some errors as large as $12 \%$. Errors in member forces in the piping system were larger than in the internal structure, the average being about $5 \%$ with maximum errors of about $15 \%$. Generally, all three methods produced the same degree of accuracy; differences in accuracy were too small to be considered of any significance. 


\section{CASE ?}

For Case 2, the damping in the piping system was 3\%, while for the internal structure it was $7 \%$. The modal damping ratios that were calctlated for this case are summarized for frequencies below $33 \mathrm{~Hz}$ in Table 4.14. As was true for Case 1, the calculated values varied only slightly between the different methods; the largest difference was about $9 \%$ and the average was less than $1 \%$. The comparison of results from the three approximate methods with those from the rigorous methor are shown in Tables 4.15 through 4.17. The errors for this case were almost identical to those obtained in Case 1.

Maximum absolute accelerations and re:sponse spectra at various locations were also obtained for this case. Mean values and standard deviations of the errors in maximum accelerations are shown in Table 4.18. The mean errors were less than $3 \%$ for all methods, and the $84 \%$ NEP (mean-plus-one-standard-deviation) values were less than $6 \%$. Maximum errors were less than $10 \%$.

Response spectra were obtained for $5 \%$ damping at the same locations as the maximum accelerations. The spectra on the internal structure were virtually identical except for the spectral peak for the top of the ring wall w:here errors of about $5 \%$ occurred. The comparisons of spectra on the piping system are shown in Figures 4-5 through 4-7. The errors at these locations averaged about $9 \%$ with maximum errors of about $15 \%$ to $20 \%$.

Inspection of the results from this case showed that most of the errors were conservative (i.e., showed greater response). Furthermore, no appreciable differences could be seen in the accuracy of the different appruximate methods.

\section{CASE 3}

For Case 3, the damping in the piping system was $1 \%$, while for the internal structure it was $10 \%$, representing an extreme case of dissimilarity in damping characteristics between the two systems. The modal damping ratios that were calculated for this case are summarized for frequencies below $33 \mathrm{~Hz}$ in Table 4.19. As was true for Case 1 , the calculated values for these frequencies varied little between the different methods; the largest difference is less than $3 \%$ and the average is less than $1 \%$. The comparison of results from the three approximate methods with those from the rigorous method are shown in Tables 4.20 through 4.22. The errors in maximum displacements were only slightly larger than those obtained in the other cases. Errors in maximum forces in the internal structure were about double those from the others, with average errors of about $1 \%$ and maximum errors of about $20 \%$. For forces in the piping system, errors were 2 to 3 times as large as for the other cases, averaging about $15 \%$ with maximum errors as high as $37 \%$. There was no distinguishable difference in accuracy between the differeni methods.

In all cases, the errors produced by all methods tended to be conservative. This can be seen from the algebraic means which are all positive. In particular, for the case having the highest errors (the piping system forces for Case 3), while the absolute mean errors were about $15 \%$, the algebraic errors were about $12 \%$, indicating that the great majority of the individual errors were conservative. This was further supported by a review of the individual errors which showed that while $2 / 3$ of the errors were over $10 \%$, over $90 \%$ of them were conservative. 
Table 4.1 Benchmark problem 1

Summary of fixed-base subsystem properties

\begin{tabular}{|c|c|c|c|c|c|c|}
\hline \multirow[b]{2}{*}{$\begin{array}{l}\text { Case } \\
\text { No. }\end{array}$} & \multicolumn{2}{|c|}{ Masses } & \multicolumn{2}{|c|}{ Frequencies } & \multicolumn{2}{|c|}{ Damping Ratios } \\
\hline & $\begin{array}{l}\text { Lower } \\
\text { System }\end{array}$ & $\begin{array}{l}\text { Upper } \\
\text { System }\end{array}$ & $\begin{array}{l}\text { Lower } \\
\text { System }\end{array}$ & $\begin{array}{l}\text { Upper } \\
\text { System }\end{array}$ & $\begin{array}{l}\text { Lower } \\
\text { System }\end{array}$ & $\begin{array}{c}\text { Upper } \\
\text { System }\end{array}$ \\
\hline 1 & 606.6 & 107.0 & 6.09 & 6.09 & 0.07 & 0.04 \\
\hline 2 & 606.6 & 107.0 & 6.09 & 3.04 & 0.07 & 0.04 \\
\hline 3 & 606.6 & 107.0 & 6.09 & 12.18 & 0.07 & 0.04 \\
\hline 4 & 606.6 & 214.1 & 6.09 & 6.09 & 0.07 & 0.04 \\
\hline 5 & 606.6 & 214.1 & 6.09 & 3.04 & 0.07 & 0.04 \\
\hline 6 & 606.6 & 214.1 & 6.09 & 12.18 & 0.07 & 0.04 \\
\hline 7 & 606.6 & 107.0 & 6.09 & 6.09 & 0.04 & 0.07 \\
\hline 8 & 606.6 & 107.0 & 6.09 & 3.04 & 0.04 & 0.07 \\
\hline 9 & 606.6 & 107.0 & 6.09 & 12.18 & 0.04 & 0.07 \\
\hline 10 & 606.6 & 214.1 & 6.09 & 6.09 & 0.04 & 0.07 \\
\hline 11 & 606.6 & 214.1 & 6.09 & 3.04 & 0.04 & 0.07 \\
\hline 12 & 606.6 & 214.1 & 6.09 & 12.18 & 0.04 & 0.07 \\
\hline 13 & 606.6 & 107.0 & 6.09 & 6.09 & 0.05 & 0.02 \\
\hline 14 & 606.6 & 107.0 & 6.09 & 3.04 & 0.05 & 0.02 \\
\hline 15 & 606.6 & 107.0 & 6.09 & 12.18 & 0.05 & 0.02 \\
\hline 16 & 606.6 & 214.1 & 6.09 & 6.09 & 0.05 & 0.02 \\
\hline 17 & 606.6 & 214.1 & 6.09 & 3.04 & 0.05 & 0.02 \\
\hline 18 & 606.6 & 214.1 & 6.09 & 12.18 & 0.05 & 0.02 \\
\hline
\end{tabular}


Table 4.2 Benchmark problem 1

Summary of modal frequencies and damping ratios

\begin{tabular}{|c|c|c|c|c|c|}
\hline $\begin{array}{l}\text { Case } \\
\text { No. }\end{array}$ & $\begin{array}{c}\text { Mode } \\
\text { No. }\end{array}$ & Frequency & $\begin{array}{l}\text { Mass- } \\
\text { Proportional } \\
\text { Damping }\end{array}$ & $\begin{array}{l}\text { Stiffness- } \\
\text { Proportional } \\
\text { Damping }\end{array}$ & $\begin{array}{c}\text { Neglecting } \\
\text { Off-Diagonal } \\
\text { Damping Terms }\end{array}$ \\
\hline \multirow[t]{4}{*}{1} & 1 & 5.329 & 0.0603 & 0.0666 & 0.0580 \\
\hline & 2 & 6.204 & 0.0434 & 0.0432 & 0.0440 \\
\hline & 3 & 15.370 & 0.0682 & 0.0696 & 0.0674 \\
\hline & 4 & 38.830 & 0.0481 & 0.0406 & 0.0500 \\
\hline \multirow[t]{4}{*}{2} & 1 & 3.038 & 0.0400 & 0.0402 & 0.0399 \\
\hline & 2 & 5.394 & 0.0628 & 0.0691 & 0.0607 \\
\hline & 3 & 14.830 & 0.0637 & 0.0650 & 0.0617 \\
\hline & 4 & 20.300 & 0.0535 & 0.0457 & 0.0584 \\
\hline \multirow[t]{4}{*}{3} & 1 & 5.412 & 0.0635 & 0.0699 & 0.0619 \\
\hline & 2 & 12.230 & 0.0405 & 0.0403 & 0.0406 \\
\hline & 3 & 15.460 & 0.0684 & 0.0697 & 0.0680 \\
\hline & 4 & 77.170 & 0.0475 & 0.0401 & 0.0479 \\
\hline \multirow[t]{4}{*}{4} & 1 & 4.848 & 0.0575 & 0.0679 & 0.0536 \\
\hline & 2 & 6.211 & 0.0420 & 0.0419 & 0.0427 \\
\hline & 3 & 15.090 & 0.0679 & 0.0696 & 0.0666 \\
\hline & 4 & 43.420 & 0.0526 & 0.0407 & 0.0568 \\
\hline \multirow[t]{4}{*}{5} & 1 & 3.030 & 0.0401 & 0.0404 & 0.0397 \\
\hline & 2 & 4.911 & 0.0585 & 0.0686 & 0.0549 \\
\hline & 3 & 14.610 & 0.0652 & 0.0663 & 0.0628 \\
\hline & 4 & 22.680 & 0.0562 & 0.0446 & 0.0644 \\
\hline \multirow[t]{4}{*}{6} & 1 & 4.916 & 0.0593 & 0.0698 & 0.0560 \\
\hline & 2 & 12.260 & 0.0408 & 0.0405 & 0.0409 \\
\hline & 3 & 15.200 & 0.0679 & 0.0695 & 0.0671 \\
\hline & 4 & 86.170 & 0.0520 & 0.0402 & 0.0541 \\
\hline \multirow[t]{4}{*}{7} & 1 & 5.329 & 0.0497 & 0.0434 & 0.0377 \\
\hline & 2 & 6.204 & 0.0666 & 0.0667 & 0.0680 \\
\hline & 3 & 15.370 & 0.0418 & 0.0404 & 0.0388 \\
\hline & 4 & 38.830 & 0.0619 & $0.06 \Omega 4$ & 0.0823 \\
\hline \multirow[t]{4}{*}{8} & 1 & 3.038 & 0.0700 & 0.0698 & 0.0695 \\
\hline & 2 & 5.394 & 0.0472 & 0.0409 & 0.0356 \\
\hline & 3 & 14.830 & 0.0463 & 0.0450 & 0.0421 \\
\hline & 4 & 20.300 & 0.0565 & 0.0643 & 0.0798 \\
\hline \multirow[t]{4}{*}{9} & 1 & 5.412 & 0.0465 & 0.0401 & 0.0354 \\
\hline & 2 & 12.230 & 0.0695 & 0.0697 & 0.0700 \\
\hline & 3 & 15.460 & 0.0416 & 0.0403 & 0.0394 \\
\hline & 4 & 77.170 & 0.0625 & 0.0699 & 0.0816 \\
\hline
\end{tabular}


Table 4.2 (Continued)

\begin{tabular}{|c|c|c|c|c|c|}
\hline $\begin{array}{c}\text { Case } \\
\text { No. }\end{array}$ & $\begin{array}{c}\text { Mode } \\
\text { No. }\end{array}$ & Frequency & $\begin{array}{l}\text { Mass- } \\
\text { Proportional } \\
\text { Damping }\end{array}$ & $\begin{array}{l}\text { Stifiness- } \\
\text { Proportional } \\
\text { Damping }\end{array}$ & $\begin{array}{c}\text { Neglecting } \\
\text { Off-Diagonal } \\
\text { Damping Terms }\end{array}$ \\
\hline \multirow[t]{4}{*}{10} & 1 & 4.848 & 0.0525 & 0.042 .1 & 0.0331 \\
\hline & 2 & 6.211 & 0.0680 & 0.0681 & 0.0694 \\
\hline & 3 & 15.090 & 0.0421 & 0.0404 & 0.0384 \\
\hline & 4 & 43.420 & 0.0574 & 0.0693 & 0.0924 \\
\hline \multirow[t]{4}{*}{11} & 1 & 3.030 & 0.0699 & 0.0696 & 0.0689 \\
\hline & 2 & 4.911 & 0.0515 & 0.0414 & 0.0329 \\
\hline & 3 & 14.610 & 0.0448 & 0.0437 & 0.0409 \\
\hline & 4 & 22.680 & 0.0538 & 0.0654 & 0.0909 \\
\hline \multirow[t]{4}{*}{12} & 1 & 4.916 & 0.0507 & 0.0402 & 0.0321 \\
\hline & 2 & 12.260 & 0.0692 & 0.0695 & 0.0701 \\
\hline & 3 & 15.200 & 0.0421 & 0.0405 & 0.0391 \\
\hline & 4 & 86.170 & 0.0580 & 0.0698 & 0.0914 \\
\hline \multirow[t]{4}{*}{13} & 1 & 5.329 & 0.0403 & 0.0466 & 0.0406 \\
\hline & 2 & 6.204 & 0.0234 & 0.0233 & 0.0237 \\
\hline & 3 & 15.370 & 0.0482 & 0.0496 & 0.0481 \\
\hline & 4 & 38.830 & 0.0281 & 0.0205 & 0.0259 \\
\hline \multirow[t]{4}{*}{14} & 1 & 3.038 & 0.0200 & 0.0202 & 0.0200 \\
\hline & 2 & 5.394 & 0.0428 & 0.0491 & 0.0432 \\
\hline & 3 & 14.830 & 0.0437 & 0.0450 & 0.0428 \\
\hline & 4 & 20.300 & 0.0335 & 0.0257 & 0.0333 \\
\hline \multirow[t]{4}{*}{15} & 1 & 5.412 & 0.0435 & 0.0499 & 0.0442 \\
\hline & 2 & 12.230 & 0.0205 & 0.0203 & 0.0205 \\
\hline & 3 & 15.460 & 0.0484 & 0.0497 & 0.0485 \\
\hline & 4 & 77.170 & 0.0275 & 0.0201 & 0.0244 \\
\hline \multirow[t]{4}{*}{16} & 1 & 4.848 & 0.0375 & 0.0479 & 0.0378 \\
\hline & 2 & 6.211 & 0.0220 & 0.0219 & 0.0223 \\
\hline & 3 & 15.090 & 0.0479 & 0.0496 & 0.0475 \\
\hline & 4 & 43.420 & 0.0326 & 0.0207 & 0.0297 \\
\hline \multirow[t]{4}{*}{17} & 1 & 3.030 & 0.0201 & 0.0204 & 0.0200 \\
\hline & 2 & 4.911 & 0.0385 & 0.0486 & 0.0389 \\
\hline & 3 & 14.610 & 0.0452 & 0.0463 & 0.0440 \\
\hline & 4 & 22.680 & 0.0362 & 0.0246 & 0.0362 \\
\hline \multirow[t]{4}{*}{18} & 1 & 4.916 & 0.0393 & 0.0498 & 0.0400 \\
\hline & 2 & 12.260 & 0.0208 & 0.0205 & 0.0207 \\
\hline & 3 & 15.200 & 0.0479 & 0.0495 & 0.0478 \\
\hline & 4 & 86.170 & 0.0320 & 0.0202 & 0.0276 \\
\hline
\end{tabular}


Table 4.3 Benchmark problem 1

Summary of maximum percentage of error

in maximum relative displacements

\begin{tabular}{|c|c|c|c|c|c|c|}
\hline \multirow[b]{2}{*}{$\begin{array}{c}\text { Case } \\
\text { No. }\end{array}$} & \multicolumn{2}{|c|}{$\begin{array}{l}\text { Mass } \\
\text { Proportional } \\
\text { Damping }\end{array}$} & \multicolumn{2}{|c|}{$\begin{array}{l}\text { Stiffness } \\
\text { Proportional } \\
\text { Damping }\end{array}$} & \multicolumn{2}{|c|}{$\begin{array}{c}\text { Neglecting } \\
\text { Off-Diagonal } \\
\text { Damping Terms }\end{array}$} \\
\hline & $\begin{array}{l}\text { Lower } \\
\text { System }\end{array}$ & $\begin{array}{l}\text { Upper } \\
\text { System }\end{array}$ & $\begin{array}{l}\text { Lower } \\
\text { System }\end{array}$ & $\begin{array}{l}\text { Upper } \\
\text { System }\end{array}$ & $\begin{array}{l}\text { Lower } \\
\text { System }\end{array}$ & $\begin{array}{c}\text { Upper } \\
\text { System }\end{array}$ \\
\hline 1 & 0.84 & 3.56 & 6.04 & 7.26 & 1.44 & 2.51 \\
\hline 2 & 1.72 & 1.56 & 6.82 & 5.28 & 0.08 & 0.10 \\
\hline 3 & 1.44 & 1.44 & 6.67 & 5.28 & 0.03 & 0.39 \\
\hline 4 & 2.86 & 3.21 & 10.70 & 10.72 & 0.70 & 0.60 \\
\hline 5 & 3.19 & 3.21 & 11.12 & 11.18 & 0.13 & 0.13 \\
\hline 6 & 2.99 & 3.03 & 10.94 & 11.19 & 0.01 & 0.05 \\
\hline 7 & 12.24 & 12.23 & 7.04 & 7.02 & 2.08 & 3.45 \\
\hline 8 & 10.05 & 10.05 & 4.72 & 4.72 & 0.04 & 0.10 \\
\hline 9 & 9.71 & 9.97 & 4.23 & 4.43 & 0.02 & 0.15 \\
\hline 10 & 18.95 & 18.97 & 10.08 & 10.09 & 0.59 & 1.04 \\
\hline 11 & 21.30 & 21.36 & 11.47 & 11.49 & 0.10 & 0.56 \\
\hline 12 & 21.92 & 22.21 & 11.40 & 11.55 & 0.03 & 0.01 \\
\hline 13 & 1.92 & 1.77 & 3.84 & 4.08 & 1.62 & 1.47 \\
\hline 14 & 0.48 & 0.37 & 5.15 & 5.19 & 0.03 & 0.08 \\
\hline 15 & 0.63 & 0.62 & 5.14 & 5.31 & 0.01 & 0.15 \\
\hline 16 & 1.07 & 1.01 & 9.39 & 9.42 & 0.73 & 0.66 \\
\hline 17 & 0.61 & 0.65 & 11.54 & 11.56 & 0.09 & 0.02 \\
\hline 18 & 0.94 & 1.06 & 11.25 & 11.59 & 0.03 & 0.09 \\
\hline
\end{tabular}


Table 4.4 Benchmark problem 1

Summary of maximum percentage of error

in maximum relative accelerations

\begin{tabular}{|c|c|c|c|c|c|c|}
\hline \multirow[b]{2}{*}{$\begin{array}{c}\text { Case } \\
\text { No. }\end{array}$} & \multicolumn{2}{|c|}{$\begin{array}{c}\text { Mass } \\
\text { Proportional } \\
\text { Damping }\end{array}$} & \multicolumn{2}{|c|}{$\begin{array}{l}\text { Stiffness } \\
\text { Proportional } \\
\text { Damping }\end{array}$} & \multicolumn{2}{|c|}{$\begin{array}{c}\text { Neglecting } \\
\text { Off-Diagonal } \\
\text { Damping Terms }\end{array}$} \\
\hline & $\begin{array}{l}\text { Lower } \\
\text { System }\end{array}$ & $\begin{array}{l}\text { Upper } \\
\text { System }\end{array}$ & $\begin{array}{l}\text { Lower } \\
\text { System }\end{array}$ & $\begin{array}{l}\text { Upper } \\
\text { System }\end{array}$ & $\begin{array}{l}\text { Lower } \\
\text { System }\end{array}$ & $\begin{array}{l}\text { Upper } \\
\text { System }\end{array}$ \\
\hline 1 & 0.46 & 4.22 & 4.83 & 7.99 & 2.02 & 3.19 \\
\hline 2 & 1.37 & 1.55 & 6.18 & 5.45 & 0.32 & 0.17 \\
\hline 3 & 1.13 & 1.04 & 5.98 & 5.17 & 0.22 & 0.36 \\
\hline 4 & 2.21 & 3.28 & 7.94 & 8.50 & 0.92 & 1.47 \\
\hline 5 & 4.44 & 3.50 & 8.93 & 9.14 & 0.46 & 0.25 \\
\hline 6 & 1.30 & 2.87 & 6.23 & 11.18 & 0.12 & 0.13 \\
\hline 7 & 13.58 & 8.96 & 8.05 & 5.20 & 2.37 & 2.88 \\
\hline 8 & 11.65 & 5.20 & 5.73 & 4.24 & 0.09 & 2.68 \\
\hline 9 & 11.01 & 7.12 & 5.01 & 4.27 & 0.04 & 1.10 \\
\hline 10 & 20.14 & 20.15 & 10.83 & 10.83 & 0.68 & 1.24 \\
\hline 11 & 21.16 & 20.58 & 10.59 & 10.62 & 0.19 & 2.26 \\
\hline 12 & 21.98 & 21.98 & 10.58 & 10.59 & 0.10 & 0.22 \\
\hline 13 & 2.38 & 2.32 & 4.38 & 4.97 & 2.03 & 2.08 \\
\hline 14 & 0.72 & 0.02 & 5.49 & 3.08 & 0.16 & 0.08 \\
\hline 15 & 0.81 & 0.94 & 5.33 & 2.98 & 0.14 & 0.70 \\
\hline 16 & 0.98 & 1.03 & 10.23 & 10.21 & 0.59 & 0.64 \\
\hline 17 & 0.46 & 0.66 & 11.52 & 11.39 & 0.17 & 0.18 \\
\hline 18 & 0.95 & 0.94 & 12.08 & 12.08 & 0.05 & 0.25 \\
\hline
\end{tabular}


Table 4.5 Benchmark problem 1

Summary of maximum percentage of error in maximum member forces

\begin{tabular}{|c|c|c|c|c|c|c|}
\hline \multirow[b]{2}{*}{$\begin{array}{c}\text { Case } \\
\text { No. }\end{array}$} & \multicolumn{2}{|c|}{$\begin{array}{c}\text { Mass } \\
\text { Proportional } \\
\text { Damping }\end{array}$} & \multicolumn{2}{|c|}{$\begin{array}{c}\text { Stiffness } \\
\text { Proportional } \\
\text { Damping }\end{array}$} & \multicolumn{2}{|c|}{$\begin{array}{c}\text { Neglecting } \\
\text { Off-Diagonal } \\
\text { Damping Terms }\end{array}$} \\
\hline & $\begin{array}{l}\text { Lower } \\
\text { System }\end{array}$ & $\begin{array}{l}\text { Upper } \\
\text { System }\end{array}$ & $\begin{array}{l}\text { Lower } \\
\text { System }\end{array}$ & $\begin{array}{l}\text { Upper } \\
\text { System }\end{array}$ & $\begin{array}{l}\text { Lower } \\
\text { System }\end{array}$ & $\begin{array}{l}\text { Upper } \\
\text { System }\end{array}$ \\
\hline 1 & 0.84 & 1.44 & 6.03 & 5.37 & 1.35 & 0.40 \\
\hline 2 & 1.65 & 1.82 & 6.82 & 5.30 & 0.08 & 0.55 \\
\hline 3 & 1.40 & 1.57 & 6.66 & 4.68 & 0.03 & 2.39 \\
\hline 4 & 3.08 & 4.00 & 11.23 & 11.73 & 0.70 & 0.72 \\
\hline 5 & 3.32 & 2.72 & 10.80 & 9.08 & 0.15 & 0.34 \\
\hline 6 & 3.09 & 2.98 & 11.33 & 11.28 & 0.02 & 0.70 \\
\hline 7 & 12.36 & 11.91 & 7.10 & 6.44 & 2.08 & 1.21 \\
\hline 8 & 10.26 & 9.62 & 4.86 & 4.77 & 0.06 & 0.62 \\
\hline 9 & 9.81 & 9.90 & 4.28 & 4.36 & 0.02 & 0.48 \\
\hline 10 & 19.51 & 19.99 & 10.40 & 10.60 & 0.63 & 1.68 \\
\hline 11 & 21.89 & 22.13 & 11.77 & 11.82 & 0.12 & 0.27 \\
\hline 12 & 22.41 & 22.93 & 11.64 & 12.20 & 0.04 & 0.56 \\
\hline 13 & 1.92 & 0.36 & 4.01 & 5.98 & 1.61 & 0.71 \\
\hline 14 & 0.47 & 0.18 & 5.25 & 5.25 & 0.03 & 0.50 \\
\hline 15 & 0.63 & 2.49 & 5.19 & 5.27 & 0.00 & 2.29 \\
\hline 16 & 1.08 & 0.34 & 9.76 & 10.85 & 0.73 & 0.17 \\
\hline 17 & 0.64 & 0.67 & 11.89 & 9.33 & 0.09 & 0.13 \\
\hline 18 & 1.01 & 1.03 & 11.54 & 12.14 & 0.05 & 0.55 \\
\hline
\end{tabular}


Table 4.6 Benchmark problem 2

Summary of fixed-base subsystem properties

\begin{tabular}{|c|c|c|c|c|c|c|}
\hline \multirow[b]{2}{*}{$\begin{array}{c}\text { Case } \\
\text { No. }\end{array}$} & \multicolumn{2}{|c|}{ Masses } & \multicolumn{2}{|c|}{ Frequencies } & \multicolumn{2}{|c|}{ Damping Ratios } \\
\hline & $\begin{array}{l}\text { Lower } \\
\text { System }\end{array}$ & $\begin{array}{l}\text { Upper } \\
\text { System }\end{array}$ & $\begin{array}{l}\text { Lower } \\
\text { System }\end{array}$ & $\begin{array}{l}\text { Upper } \\
\text { System }\end{array}$ & $\begin{array}{l}\text { Lower } \\
\text { System }\end{array}$ & $\begin{array}{l}\text { Upper } \\
\text { System }\end{array}$ \\
\hline 1 & 2651. & 34.4 & 7.47 & 11.63 & 0.07 & 0.04 \\
\hline 2 & 2651. & 34.4 & 7.47 & 7.47 & 0.07 & 0.04 \\
\hline 3 & 2651 & 34.4 & 7.47 & 4.80 & 0.07 & 0.04 \\
\hline 4 & 2651. & 344.1 & 7.47 & 11.63 & 0.07 & 0.04 \\
\hline 5 & 2651. & 344.1 & 7.47 & 7.47 & 0.07 & 0.04 \\
\hline 6 & 2651. & 344.1 & 7.47 & 4.80 & 0.07 & 0.04 \\
\hline 7 & 2651. & 34.4 & 7.47 & 11.63 & 0.04 & 0.07 \\
\hline 8 & 2651. & 34.4 & 7.47 & 7.47 & 0.04 & 0.07 \\
\hline 9 & 2651. & 34.4 & 7.47 & 4.80 & 0.04 & 0.07 \\
\hline 10 & 2651. & 344.1 & 7.47 & 11.63 & 0.04 & 0.07 \\
\hline 11 & 2651. & 344.1 & 7.47 & 7.47 & 0.04 & 0.07 \\
\hline 12 & 2651. & 344.1 & 7.47 & 4.80 & 0.04 & 0.07 \\
\hline 13 & 2651. & 34.4 & 7.47 & 11.63 & 0.05 & 0.02 \\
\hline 14 & 2651. & 34.4 & 7.47 & 7.47 & 0.05 & 0.02 \\
\hline 15 & 2651. & 34.4 & 7.47 & 4.80 & 0.05 & 0.02 \\
\hline 16 & 2651. & 344.1 & 7.47 & 11.63 & 0.05 & 0.02 \\
\hline 17 & 2651 & 344.1 & 7.47 & 7.47 & 0.05 & 0.02 \\
\hline 18 & 2651. & 344.1 & 7.47 & 4.80 & 0.05 & 0.02 \\
\hline
\end{tabular}


Table 4.7 Benchmark problem 2

Summary of modal frequencies and damping ratios

\begin{tabular}{|c|c|c|c|c|c|}
\hline $\begin{array}{c}\text { Case } \\
\text { No. }\end{array}$ & $\begin{array}{c}\text { Mode } \\
\text { No. }\end{array}$ & Frequency & $\begin{array}{l}\text { Mass- } \\
\text { Proportional } \\
\text { Damping }\end{array}$ & $\begin{array}{l}\text { Stiffness- } \\
\text { Proportional } \\
\text { Damping }\end{array}$ & $\begin{array}{c}\text { Neglecting } \\
\text { Off-Diagonal } \\
\text { Damping Terms }\end{array}$ \\
\hline \multirow[t]{6}{*}{1} & 1 & 7.209 & 0.0670 & 0.0690 & 0.0660 \\
\hline & 2 & 11.820 & 0.0428 & 0.0419 & 0.0428 \\
\hline & 3 & 20.330 & 0.0682 & 0.0684 & 0.0685 \\
\hline & 4 & 26.270 & 0.0424 & 0.0415 & 0.0428 \\
\hline & 5 & 30.950 & 0.0696 & 0.0694 & 0.0699 \\
\hline & 6 & 42.470 & 0.0700 & 0.0700 & 0.0700 \\
\hline \multirow[t]{6}{*}{2} & 1 & 6.758 & 0.0537 & 0.0568 & 0.0512 \\
\hline & 2 & 8.153 & 0.0558 & 0.0534 & 0.0579 \\
\hline & 3 & 16.600 & 0.0415 & 0.0416 & 0.0412 \\
\hline & 4 & 20.620 & 0.0691 & 0.0684 & 0.0700 \\
\hline & 5 & 30.880 & 0.0700 & 0.0699 & 0.0701 \\
\hline & 6 & 42.470 & 0.0700 & 0.0700 & 0.0700 \\
\hline \multirow[t]{6}{*}{3} & 1 & 4.730 & 0.0405 & 0.0413 & 0.0395 \\
\hline & 2 & 7.467 & 0.0681 & 0.0681 & 0.0688 \\
\hline & 3 & 10.780 & 0.0414 & 0.0408 & 0.0417 \\
\hline & 4 & 20.450 & 0.0700 & 0.0698 & 0.0704 \\
\hline & 5 & 30.870 & 0.0700 & 0.0700 & 0.0701 \\
\hline & 6 & 42.470 & 0.0700 & 0.0700 & 0.0700 \\
\hline \multirow[t]{6}{*}{4} & 1 & 5.801 & 0.0558 & 0.0670 & 0.0497 \\
\hline & 2 & 12.680 & 0.0523 & 0.0498 & 0.0505 \\
\hline & 3 & 19.980 & 0.0604 & 0.0613 & 0.0621 \\
\hline & 4 & 28.500 & 0.0577 & 0.0549 & 0.0586 \\
\hline & 5 & 32.490 & 0.0637 & 0.0593 & 0.0684 \\
\hline & 6 & 42.510 & 0.0700 & 0.0699 & 0.0701 \\
\hline \multirow[t]{6}{*}{5} & 1 & 5.336 & 0.0500 & 0.0605 & 0.0419 \\
\hline & 2 & 9.337 & 0.0551 & 0.0508 & 0.0597 \\
\hline & 3 & 16.520 & 0.0497 & 0.0499 & 0.0478 \\
\hline & 4 & 22.440 & 0.0654 & 0.0604 & 0.0728 \\
\hline & 5 & 31.080 & 0.0699 & 0.0694 & 0.0712 \\
\hline & 6 & 42.480 & 0.0700 & 0.0700 & 0.0701 \\
\hline \multirow[t]{6}{*}{6} & 1 & 4.252 & 0.0426 & 0.0488 & 0.0359 \\
\hline & 2 & 7.462 & 0.0582 & 0.0583 & 0.0619 \\
\hline & 3 & 11.620 & 0.0496 & 0.0454 & 0.0522 \\
\hline & 4 & 20.940 & 0.0696 & 0.0680 & 0.0743 \\
\hline & 5 & 30.930 & 0.0700 & 0.0698 & 0.0707 \\
\hline & 6 & 42.470 & 0.0700 & 0.0700 & 0.0700 \\
\hline
\end{tabular}


Table 4.7 (Continued)

\begin{tabular}{|c|c|c|c|c|c|}
\hline $\begin{array}{c}\text { Case } \\
\text { No. }\end{array}$ & $\begin{array}{l}\text { Mode } \\
\text { No. }\end{array}$ & Frequency & $\begin{array}{l}\text { Mass- } \\
\text { Propiortional } \\
\text { Damping }\end{array}$ & $\begin{array}{l}\text { Stiffness- } \\
\text { Proportional } \\
\text { Damping }\end{array}$ & $\begin{array}{c}\text { Neglecting } \\
\text { Off-Diagonal } \\
\text { Damping Terms }\end{array}$ \\
\hline \multirow[t]{6}{*}{7} & 1 & 7.209 & 0.0430 & 0.0410 & 0.0387 \\
\hline & 2 & 11.820 & 0.0672 & 0.0681 & 0.0692 \\
\hline & 3 & 20.330 & 0.0418 & 0.0416 & 0.0422 \\
\hline & 4 & 26.270 & 0.0676 & 0.0685 & 0.0699 \\
\hline & 5 & 30.950 & 0.0404 & 0.0406 & 0.0411 \\
\hline & 6 & 42.470 & 0.0400 & 0.0400 & 0.0400 \\
\hline \multirow[t]{6}{*}{8} & 1 & 6.758 & 0.0563 & 0.0532 & 0.0480 \\
\hline & 2 & 8.153 & 0.0542 & 0.0567 & 0.0616 \\
\hline & 3 & 16.600 & 0.0685 & 0.0684 & 0.0682 \\
\hline & 4 & 20.620 & 0.0409 & 0.0416 & 0.0435 \\
\hline & 5 & 30.880 & 0.0400 & 0.0400 & 0.0402 \\
\hline & 6 & 42.470 & 0.0400 & 0.0400 & 0.0400 \\
\hline \multirow[t]{6}{*}{9} & 1 & 4.730 & 0.0695 & 0.0687 & 0.0671 \\
\hline & 2 & 7.467 & 0.0419 & 0.0419 & 0.0430 \\
\hline & 3 & 10.780 & 0.0686 & 0.0692 & 0.0702 \\
\hline & 4 & 20.450 & 0.0400 & 0.0402 & 0.0411 \\
\hline & 5 & 30.870 & 0.0400 & 0.0400 & 0.0401 \\
\hline & 6 & 42.470 & 0.0400 & 0.0400 & 0.0400 \\
\hline \multirow[t]{6}{*}{10} & 1 & 5.801 & 0.0542 & 0.0430 & 0.0307 \\
\hline & 2 & 12.680 & 0.0577 & 0.0602 & 0.0632 \\
\hline & 3 & 19.980 & 0.0496 & 0.0487 & 0.0516 \\
\hline & 4 & 28.500 & 0.0523 & 0.0551 & 0.0602 \\
\hline & 5 & 32.490 & 0.0463 & 0.0507 & 0.0625 \\
\hline & 6 & 42.510 & 0.0400 & 0.0401 & 0.0404 \\
\hline \multirow[t]{6}{*}{$1^{t}$} & 1 & 5.336 & 0.0600 & 0.0495 & 0.0345 \\
\hline & 2 & 9.337 & 0.0549 & 0.0592 & 0.0708 \\
\hline & 3 & 16.520 & 0.0603 & 0.0601 & 0.0588 \\
\hline & 4 & 22.440 & 0.0446 & 0.0496 & 0.0657 \\
\hline & 5 & 31.080 & 0.0401 & 0.0406 & 0.0432 \\
\hline & 6 & 42.480 & 0.0400 & 0.0400 & 0.0402 \\
\hline \multirow[t]{6}{*}{12} & 1 & 4.252 & 0.0674 & 0.0612 & 0.0499 \\
\hline & 2 & 7.462 & 0.0518 & 0.0517 & 0.0583 \\
\hline & 3 & 11.620 & 0.0604 & 0.0646 & 0.0727 \\
\hline & 4 & 20.940 & 0.0404 & 0.0420 & 0.0509 \\
\hline & 5 & 30.930 & 0.0400 & 0.0402 & 0.0414 \\
\hline & 6 & 42.470 & 0.0400 & 0.0400 & 0.0401 \\
\hline
\end{tabular}


Table 4.7 (Continued)

\begin{tabular}{|c|c|c|c|c|c|}
\hline $\begin{array}{l}\text { Case } \\
\text { No. }\end{array}$ & $\begin{array}{l}\text { Mode } \\
\text { No. }\end{array}$ & Frequency & $\begin{array}{l}\text { Mass- } \\
\text { Proportional } \\
\text { Damping }\end{array}$ & $\begin{array}{l}\text { Stiffness- } \\
\text { Proportional } \\
\text { Damping }\end{array}$ & $\begin{array}{c}\text { Neglecting } \\
\text { Off-Diagonal } \\
\text { Damping Terms }\end{array}$ \\
\hline \multirow[t]{6}{*}{13} & 1 & 7.209 & 0.0470 & 0.0490 & 0.0470 \\
\hline & 2 & 11.820 & 0.0228 & 0.0219 & 0.0224 \\
\hline & 3 & 20.330 & 0.0482 & 0.0484 & 0.0484 \\
\hline & 4 & 26.270 & 0.0224 & 0.0215 & 0.0223 \\
\hline & 5 & 30.950 & 0.0496 & 0.0494 & 0.0497 \\
\hline & 6 & 42.470 & 0.0500 & 0.0500 & 0.0500 \\
\hline \multirow[t]{6}{*}{14} & 1 & 6.758 & 0.0337 & 0.0368 & 0.0331 \\
\hline & 2 & 8.153 & 0.0358 & 0.0333 & 0.0362 \\
\hline & 3 & 16.600 & 0.0215 & 0.0216 & 0.0213 \\
\hline & 4 & 20.620 & 0.0491 & 0.0484 & 0.0494 \\
\hline & 5 & 30.880 & 0.0500 & 0.0499 & 0.0500 \\
\hline & 6 & 42.470 & 0.0500 & 0.0500 & 0.0500 \\
\hline \multirow[t]{6}{*}{15} & 1 & 4.730 & 0.0205 & 0.0213 & 0.0202 \\
\hline & 2 & 7.467 & 0.0481 & 0.0481 & 0.0484 \\
\hline & 3 & 10.780 & 0.0214 & 0.0208 & 0.0214 \\
\hline & 4 & 20.450 & 0.0500 & 0.0498 & 0.0501 \\
\hline & 5 & 30.870 & 0.0500 & 0.0500 & 0.0500 \\
\hline & 6 & 42.470 & 0.0500 & 0.0500 & 0.0500 \\
\hline \multirow[t]{6}{*}{16} & 1 & 5.801 & 0.0358 & 0.0470 & 0.0351 \\
\hline & 2 & 12.680 & 0.0323 & 0.0298 & 0.0298 \\
\hline & 3 & 19.980 & 0.0404 & 0.0413 & 0.0415 \\
\hline & 4 & 28.500 & 0.0377 & 0.0349 & 0.0370 \\
\hline & 5 & 32.490 & 0.0437 & 0.0393 & 0.0446 \\
\hline & 6 & 42.510 & 0.0500 & 0.0499 & 0.0500 \\
\hline \multirow[t]{6}{*}{17} & 1 & 5.336 & 0.0300 & 0.0405 & 0.0280 \\
\hline & 2 & 9.337 & 0.0351 & 0.0308 & 0.0360 \\
\hline & 3 & 16.520 & 0.0297 & 0.0299 & 0.0284 \\
\hline & 4 & 22.440 & 0.0454 & 0.0404 & 0.0476 \\
\hline & 5 & 31.080 & 0.0499 & 0.0494 & 0.0504 \\
\hline & 6 & 42.480 & 0.0500 & 0.0500 & 0.0500 \\
\hline \multirow[t]{6}{*}{18} & 1 & 4.252 & 0.0226 & 0.0288 & 0.0203 \\
\hline & 2 & 7.462 & 0.0382 & 0.0383 & 0.0401 \\
\hline & 3 & 11.620 & 0.0296 & 0.0254 & 0.0294 \\
\hline & 4 & 20.940 & 0.0496 & 0.0480 & 0.0515 \\
\hline & 5 & 30.930 & 0.0500 & 0.0498 & 0.0503 \\
\hline & 6 & 42.470 & 0.0500 & 0.0500 & 0.0500 \\
\hline
\end{tabular}


Table 4.8 Benchmark problem 2 Summary of maximum percentage of error in maximum relative displacements

\begin{tabular}{|c|c|c|c|c|c|c|}
\hline \multirow[b]{2}{*}{$\begin{array}{c}\text { Case } \\
\text { No. }\end{array}$} & \multicolumn{2}{|c|}{$\begin{array}{c}\text { Mass } \\
\text { Proportional } \\
\text { Damping }\end{array}$} & \multicolumn{2}{|c|}{$\begin{array}{c}\text { Stiffness } \\
\text { Proportional } \\
\text { Damping }\end{array}$} & \multicolumn{2}{|c|}{$\begin{array}{c}\text { Neglecting } \\
\text { Off-Diagonal } \\
\text { Damping Terms }\end{array}$} \\
\hline & $\begin{array}{l}\text { Lower } \\
\text { System }\end{array}$ & $\begin{array}{l}\text { Upper } \\
\text { System }\end{array}$ & $\begin{array}{l}\text { Lower } \\
\text { System }\end{array}$ & $\begin{array}{l}\text { Upper } \\
\text { System }\end{array}$ & $\begin{array}{l}\text { Lower } \\
\text { System }\end{array}$ & $\begin{array}{l}\text { Upper } \\
\text { System }\end{array}$ \\
\hline 1 & 0.42 & 1.90 & 1.41 & 2.73 & 0.39 & 1.37 \\
\hline 2 & 4.20 & 3.12 & 3.51 & 5.87 & 4.78 & 0.81 \\
\hline 3 & 0.65 & 1.37 & 0.64 & 1.47 & 0.45 & 1.35 \\
\hline 4 & 5.07 & 5.36 & 13.59 & 14.07 & 0.80 & 0.19 \\
\hline 5 & 6.31 & 7.50 & 14.10 & 16.13 & 0.77 & 0.20 \\
\hline 6 & 4.99 & 9.96 & 9.88 & 17.72 & 0.89 & 0.07 \\
\hline 7 & 5.29 & 5.56 & 3.00 & 3.09 & 0.07 & 0.04 \\
\hline 8 & 6.66 & 8.20 & 5.91 & 5.50 & 4.73 & 0.65 \\
\hline 9 & 0.59 & 1.95 & 0.57 & 1.76 & 0.63 & 2.39 \\
\hline 10 & 20.76 & 21.67 & 12.08 & 14.03 & 0.14 & 0.04 \\
\hline 11 & 19.83 & 21.64 & 12.65 & 13.31 & 0.56 & 0.31 \\
\hline 12 & 6.77 & 13.68 & 6.02 & 10.19 & 3.05 & 0.78 \\
\hline 13 & 0.35 & 0.66 & 1.62 & 1.65 & 0.34 & 0.48 \\
\hline 14 & 4.10 & 1.76 & 3.78 & 5.17 & 4.14 & 1.23 \\
\hline 15 & 0.57 & 1.11 & 0.61 & 2.43 & 0.27 & 0.62 \\
\hline 16 & 0.45 & 1.01 & 11.09 & 11.31 & 0.60 & 0.18 \\
\hline 17 & 1.03 & 1.96 & 8.77 & 11.49 & 0.58 & 0.17 \\
\hline 18 & 2.33 & 4.16 & 7.77 & 13.81 & 0.61 & 0.04 \\
\hline
\end{tabular}


Table 4.9: Benchmark problem 2

Summary of maximum percentage of error

in maximum member forces

\begin{tabular}{|c|c|c|c|c|c|c|}
\hline \multirow[b]{2}{*}{$\begin{array}{l}\text { Case } \\
\text { No. }\end{array}$} & \multicolumn{2}{|c|}{$\begin{array}{c}\text { Mass } \\
\text { Proportional } \\
\text { Damping }\end{array}$} & \multicolumn{2}{|c|}{$\begin{array}{c}\text { Stiffness } \\
\text { Proportional } \\
\text { Damping }\end{array}$} & \multicolumn{2}{|c|}{$\begin{array}{c}\text { Neglecting } \\
\text { Off-Diagonal } \\
\text { Damping Terms }\end{array}$} \\
\hline & $\begin{array}{l}\text { Lower } \\
\text { System }\end{array}$ & $\begin{array}{l}\text { Upper } \\
\text { System }\end{array}$ & $\begin{array}{l}\text { Lower } \\
\text { System }\end{array}$ & $\begin{array}{l}\text { Upper } \\
\text { System }\end{array}$ & $\begin{array}{l}\text { Lower } \\
\text { System }\end{array}$ & $\begin{array}{l}\text { Upper } \\
\text { System }\end{array}$ \\
\hline 1 & 0.51 & 3.52 & 1.55 & 4.10 & 0.43 & 3.03 \\
\hline 2 & 4.67 & 1.47 & 4.41 & 3.25 & 5.10 & 0.04 \\
\hline 3 & 0.74 & 1.03 & 0.77 & 1.44 & 0.50 & 1.06 \\
\hline 4 & 5.72 & 4.25 & 13.99 & 10.27 & 0.95 & 0.49 \\
\hline 5 & 7.98 & 6.95 & 14.41 & 12.10 & 0.87 & 0.71 \\
\hline 6 & 8.91 & 10.00 & 16.30 & 17.55 & 1.02 & 0.13 \\
\hline 7 & 5.77 & 3.63 & 3.30 & 2.33 & 0.22 & 0.26 \\
\hline 8 & 11.55 & 5.10 & 9.36 & 3.33 & 7.57 & 0.53 \\
\hline 9 & 0.63 & 4.93 & 0.61 & 4.72 & 1.37 & 4.20 \\
\hline 10 & 23.35 & 18.44 & 14.80 & 11.39 & 0.18 & 0.24 \\
\hline 11 & 20.48 & 18.42 & 14.35 & 13.66 & 0.79 & 0.37 \\
\hline 12 & 14.75 & 18.38 & 10.39 & 12.65 & 2.94 & 0.34 \\
\hline 13 & 0.38 & 1.55 & 2.53 & 2.05 & 0.37 & 1.26 \\
\hline 14 & 4.26 & 2.46 & 3.98 & 6.51 & 4.29 & 1.77 \\
\hline 15 & 0.66 & 0.57 & 0.68 & 2.04 & 0.56 & 0.61 \\
\hline 16 & 1.15 & 1.07 & 11.63 & 8.14 & 0.67 & 0.55 \\
\hline 17 & 1.83 & 2.31 & 11.39 & 8.73 & 0.64 & 0.61 \\
\hline 18 & 3.48 & 3.56 & 12.34 & 12.17 & 0.71 & 0.14 \\
\hline
\end{tabular}


Table 4.10 Benchmark problem 3, case 1

Summary of modal damping ratios for modes below $33 \mathrm{~Hz}$

\begin{tabular}{rrrrr}
\hline $\begin{array}{c}\text { Mode } \\
\text { No. }\end{array}$ & Frequency & $\begin{array}{c}\text { Mass- } \\
\text { Proportional } \\
\text { Damping }\end{array}$ & $\begin{array}{c}\text { Stiffness- } \\
\text { Proportional } \\
\text { Damping }\end{array}$ & $\begin{array}{c}\text { Neglecting } \\
\text { Off-Diagonal } \\
\text { Damping Terms }\end{array}$ \\
\hline 1 & 9.69 & 0.02008 & 0.02012 & 0.02007 \\
2 & 10.22 & 0.04992 & 0.04991 & 0.05003 \\
3 & 10.81 & 0.05000 & 0.05000 & 0.05001 \\
4 & 12.67 & 0.04990 & 0.04993 & 0.05038 \\
5 & 14.86 & 0.02012 & 0.02018 & 0.02015 \\
6 & 16.54 & 0.02002 & 0.02006 & 0.01998 \\
7 & 19.14 & 0.02000 & 0.02001 & 0.02001 \\
8 & 22.55 & 0.03940 & 0.03948 & 0.03990 \\
9 & 22.68 & 0.03060 & 0.03055 & 0.03069 \\
10 & 24.36 & 0.04737 & 0.04768 & 0.05145 \\
11 & 25.47 & 0.02243 & 0.02228 & 0.02227 \\
12 & 26.63 & 0.04997 & 0.04997 & 0.05004 \\
13 & 26.76 & 0.04715 & 0.04728 & 0.05040 \\
14 & 26.86 & 0.04999 & 0.04999 & 0.05000 \\
15 & 27.17 & 0.02237 & 0.02232 & 0.02227 \\
16 & 31.08 & 0.02052 & 0.02043 & 0.02047
\end{tabular}


Table 4.11 Benchmark problem 3, case 1

Summary of percentage of error in maximum displacements

\begin{tabular}{ccc}
\hline Mass & Stiffness & Neglecting \\
Proportional & Proportional \\
Damping & Damping & $\begin{array}{c}\text { Off-Diagonal } \\
\text { Damping Terms }\end{array}$ \\
\hline
\end{tabular}

Algebraic Errors

Mean Error

Std Deviation

Mean + Std Deviation

Absolute Errors

Mean Error

Std Deviation

Mean + Std Deviation

Maximum Positive Error

Maximum Negative Error
$+0.231$

0.354

0.585

0.274

0.320

0.594

1.007

- 0.177
$+0.223$

0.342

0.565

0.266

0.308

0.574

0.974

0.177
$+0.078$

0.202

0.280

0.148

0.157

0.305

0.521

0.152 
Table 4.12 Benchmark problem 3, case 1 Summary of percentage of error in maximum member forces in internal structure

$\longrightarrow$

\begin{tabular}{ccc}
$\begin{array}{c}\text { Mass } \\
\begin{array}{c}\text { Proportional } \\
\text { Damping }\end{array}\end{array}$ & $\begin{array}{c}\text { Stiffness } \\
\text { Proportional } \\
\text { Damping }\end{array}$ & $\begin{array}{c}\text { Neglecting } \\
\text { Off-Diagonal } \\
\text { Damping Terms }\end{array}$ \\
\hline
\end{tabular}

Algebraic Errors

\section{Mean Error}

Std Deviation

Mean + Std Deviation

Absolute Errors

Mean Error

Std Deviation

Mean + Std Deviation

Maximum Positive Error

Maximum Negative Error
$+0.612$

1.774

2.386

0.697

1.742

2.439

11.724
$-\quad 0.662$

11.495

- 0.662

1.707

2.388
$+0.379$

1.405

1.784

0.458

1.381

1.839

9.257

- 0.432 
Table 4.13 Benchmark problem 3, case 1

Summary of percentage of error in maximum member forces

in piping system

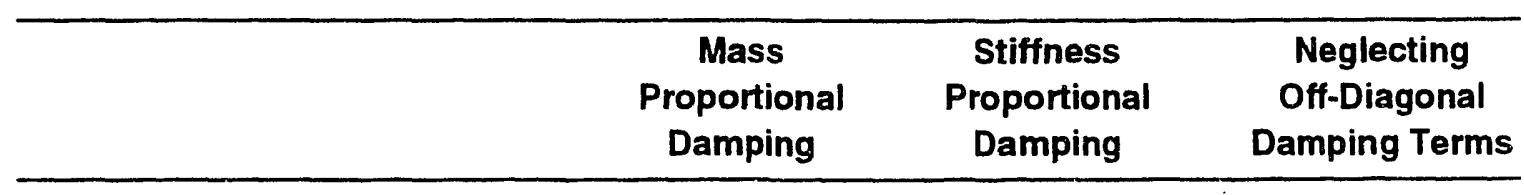

Algebraic Errors

Mean Error

Std Deviation

Mean + Std Deviation

Absolute Errors

Mean Error

Std Deviation

Mean + Std Deviation

Maximum Positive Error

Maximum Negative Error
$+3.342$

5.094

8.436

4.892

3.606

8.498

15.699

- 10.971
$+3.274$

5.127

8.401

4.896

5.191

3.450

8.481

8.641

14.626

- 11.543 
Table 4.14 Benchmark problem 3, case 2

Summary of modal damping ratios for modes below $33 \mathrm{~Hz}$

\begin{tabular}{rrrrr}
\hline $\begin{array}{c}\text { Mode } \\
\text { No. }\end{array}$ & Frequency & $\begin{array}{c}\text { Mass- } \\
\text { Proportional } \\
\text { Damping }\end{array}$ & $\begin{array}{c}\text { Stiffness- } \\
\text { Proportional } \\
\text { Damping }\end{array}$ & $\begin{array}{c}\text { Neglecting } \\
\text { Off-Diagonal } \\
\text { Damping Terms }\end{array}$ \\
\hline 1 & 9.69 & 0.03011 & 0.03016 & 0.03010 \\
2 & 10.22 & 0.06989 & 0.06989 & 0.07007 \\
3 & 10.81 & 0.07000 & 0.07000 & 0.07001 \\
4 & 12.67 & 0.06987 & 0.06991 & 0.07058 \\
5 & 14.86 & 0.03016 & 0.03025 & 0.03021 \\
6 & 16.54 & 0.03003 & 0.03007 & 0.02997 \\
7 & 19.14 & 0.03000 & 0.03001 & 0.03002 \\
8 & 22.55 & 0.05586 & 0.05598 & 0.05661 \\
9 & 22.68 & 0.04414 & 0.04406 & 0.04427 \\
10 & 24.36 & 0.06649 & 0.06690 & 0.07259 \\
11 & 25.47 & 0.03323 & 0.03304 & 0.03302 \\
12 & 26.63 & 0.06996 & 0.06996 & 0.07006 \\
13 & 26.76 & 0.06620 & 0.06638 & 0.07106 \\
14 & 26.86 & 0.06999 & 0.06999 & 0.07000 \\
15 & 27.17 & 0.03315 & 0.03310 & 0.03302 \\
16 & 31.08 & 0.03069 & 0.03058 & 0.03063
\end{tabular}


Table 4.15 Benchmark problem 3, case 2

Summary of percentage of error in maximum displacements

\begin{tabular}{ccc}
\hline Mass & Stiffness & Neglecting \\
Proportional & Proportional \\
Damping & Damping & $\begin{array}{c}\text { Off-Diagonal } \\
\text { Damping Terms }\end{array}$ \\
\hline
\end{tabular}

Algebraic Errors

Mean Error

Std Deviation

Mean + Std Deviation

Absolute Errors

Mean Error

Std Deviation

Mean + Std Deviation

Maximum Positive Error

Maximum Negative Error
$+0.225$

0.377

0.602

0.228

0.375

0.603

1.164

- 0.029
$+0.218$

0.365

0.583

$+0.082$

0.216

0.298

0.133

0.189

0.321

0.363

0.584

1.124

0.602

- 0.029

- 0.176 
Table 4.16 Benchmark problem 3, case 2

Summary of percentage of error in maximum member forces

in internal structure

\begin{tabular}{ccc}
\hline Mass & Stiffness & Neglecting \\
Proportional & Proportional \\
Damping & Damping & $\begin{array}{c}\text { Off-Diagonal } \\
\text { Damping Terms }\end{array}$ \\
\hline
\end{tabular}

Algebraic Errors

Mean Error

Std Deviation

Mean + Std Deviation

Absolute Errors

Mean Error

Std Deviation

Mean + Std Deviation

Maximum Positive Error

Maximum Negative Error
$+0.630$

1.766

2.395

0.684

1.745

2.429

11.599

- 0.900
$+0.616$

1.736

2.351

0.668

1.716

2.384

11.411

- 0.825
$+0.413$

1.475

1.888

0.452

1.464

1.916

9.768

- 0.321 
Table 4.17 Benchmark problem 3, case 2

Summary of percentage of error in maximum member forces

in piping system

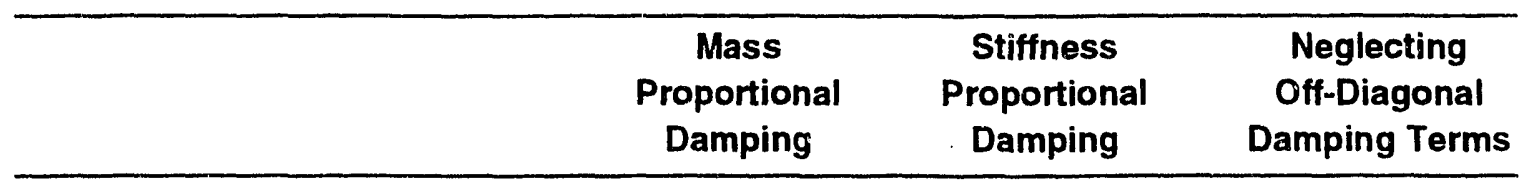

Algebraic Errors

Mean Error

$+2.869$

6.347

$+2.822$

6.386

$+2.455$

Std Deviation

9.215

9.207

7.054

Mean + Std Deviation

9.215

9.508

Absolute Errors

Mean Error

5.693

3.970

5.702

6.015

Std Deviation

9.663

3.985

4.379

Mean + Std Deviation

16.285

16.459

10.394

Maximum Positive Error

- 11.490

- 11.355

17.431

Maximum Negative Error

$-11.490$

- 16.499 
Table 4.18 Benchmark problem 3, case 2

Summary of percentage of error in maximum accelerations

\begin{tabular}{ccc}
\hline Mass & Stiffness & Neglecting \\
Proportional & Proportional \\
Damping & Damping & $\begin{array}{c}\text { Off-Diagonal } \\
\text { Damping Terms }\end{array}$ \\
\hline
\end{tabular}

Algebraic Errors

Mean Error

Std Deviation

Mean + Std Deviation

Absolute Errors

\section{Mean Error}

Std Deviation

Mean + Std Deviation

Maximum Positive Error

Maximum Negative Error
$+1.658$

3.893

5.551

2.826

3.150

5.976

7.799

- 9.077
$+1.651$

3.851

5.502

2.795

3.121

5.916

7.690

- 8.976
3.155

5.878

7.143

$+1.491$

3.892

5.383

9.077 
Table 4.19 Benchmark problem 3, case 3

Summary of modal damping ratios for modes below $33 \mathrm{~Hz}$

\begin{tabular}{rrrrr}
\hline $\begin{array}{c}\text { Mode } \\
\text { No. }\end{array}$ & Frequency & $\begin{array}{c}\text { Mass- } \\
\text { Proportional } \\
\text { Damping }\end{array}$ & $\begin{array}{c}\text { Stiffness- } \\
\text { Proportional } \\
\text { Damping }\end{array}$ & $\begin{array}{c}\text { Neglecting } \\
\text { Off-Diagonal } \\
\text { Damping Terms }\end{array}$ \\
\hline 1 & 9.69 & 0.01025 & 0.01037 & 0.01027 \\
2 & 10.22 & 0.09976 & 0.09974 & 0.09981 \\
3 & 10.81 & 0.10000 & 0.09999 & 0.10000 \\
4 & 12.67 & 0.09971 & 0.09980 & 0.09999 \\
5 & 14.86 & 0.01036 & 0.01055 & 0.01041 \\
6 & 16.54 & 0.01007 & 0.01017 & 0.01008 \\
7 & 19.14 & 0.01001 & 0.01002 & 0.01002 \\
8 & 22.55 & 0.06819 & 0.06845 & 0.06855 \\
9 & 22.68 & 0.04181 & 0.04164 & 0.04178 \\
10 & 24.36 & 0.09210 & 0.09303 & 0.09453 \\
11 & 25.47 & 0.01728 & 0.01683 & 0.01701 \\
12 & 26.63 & 0.09991 & 0.09992 & 0.09995 \\
13 & 26.76 & 0.09146 & 0.09185 & 0.09324 \\
14 & 26.86 & 0.09998 & 0.09998 & 0.09999 \\
15 & 27.17 & 0.01710 & 0.01697 & 0.01699 \\
16 & 31.08 & 0.01155 & 0.01130 & 0.01139
\end{tabular}


Table 4.20 Benchmark problem 3, case 3

Summary of percentage of error in maximum displacements

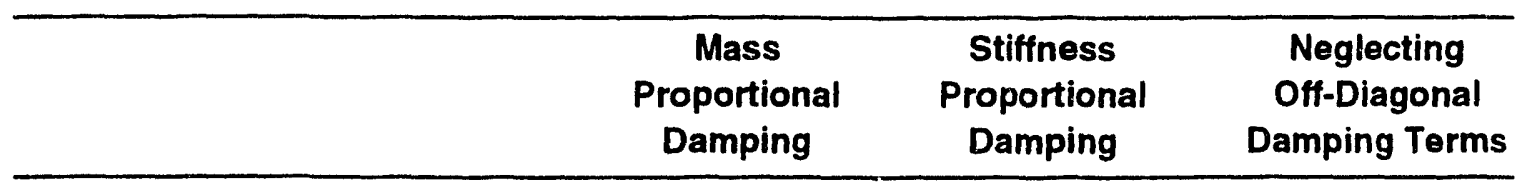

Algebraic Errors

Mean Error

Std Deviation

Mean + Std Deviation

Absolute Errors

Mean Error

Std Deviation

Mean + Std Deviation

Maximum Positive Error

Maximum Negative Error
$+0.201$

0.487

0.688

0.325

0.411

0.737

1.365

- 0.444
$+0.185$

0.471

0.656

0.316

0.393

0.708

1.293

- 0.444
$+0.156$ 0.447 0.604

0.300

0.364

0.664

1.193

- 0.472 
Table 4.21 Benchmark problem 3, case 3

Summary of percentage of error in maximum member forces in internal structure

\begin{tabular}{ccc}
\hline Mass & Stiffness & Neglecting \\
Proportional & Proportional & Off-Diagonal \\
Damping & Damping & Damping Terms \\
\hline
\end{tabular}

Algebraic Errors

Mean Error

Std Deviation

Mean + Std Deviation

Absolute Errors

Mean Error

Std Deviation

Mean + Std Deviation

Maximum Positive Error

Maximum Negative Error
$+0.924$

3.216

4.140

1.165

3.134

4.300

20.534

- 1.396
$+0.880$

3.091

3.971

$+0.846$

3.087

3.932

1.111

2.999

4.111

4.138

19.688

19.630

- 1.222 
Table 4.22 Benchmark problem 3, case 3

Summary of percentage of error in maximum member forces in piping system

\begin{tabular}{ccc}
\hline Mass & Stiffness & Neglecting \\
Proportional & Proportional \\
Damping & Damping & $\begin{array}{c}\text { Off-Diagonal } \\
\text { Damping Terms }\end{array}$ \\
\hline
\end{tabular}

Algebraic Errors

Mean Error

Std Deviation

Mean + Std Deviation

Absolute Errors

Mean Error

Std Deviation

Mean + Std Deviation

Maximum Positive Error

Maximum Negative Error
11.861

13.496

25.357

15.130

9.627

24.757

37.418

- 28.720
11.709

13.313

25.022

11.921

13.455

25.376
14.989

9.405

24.393

36.998

- 28.824
15.175

9.572

24.747

37.383

- 28.876 


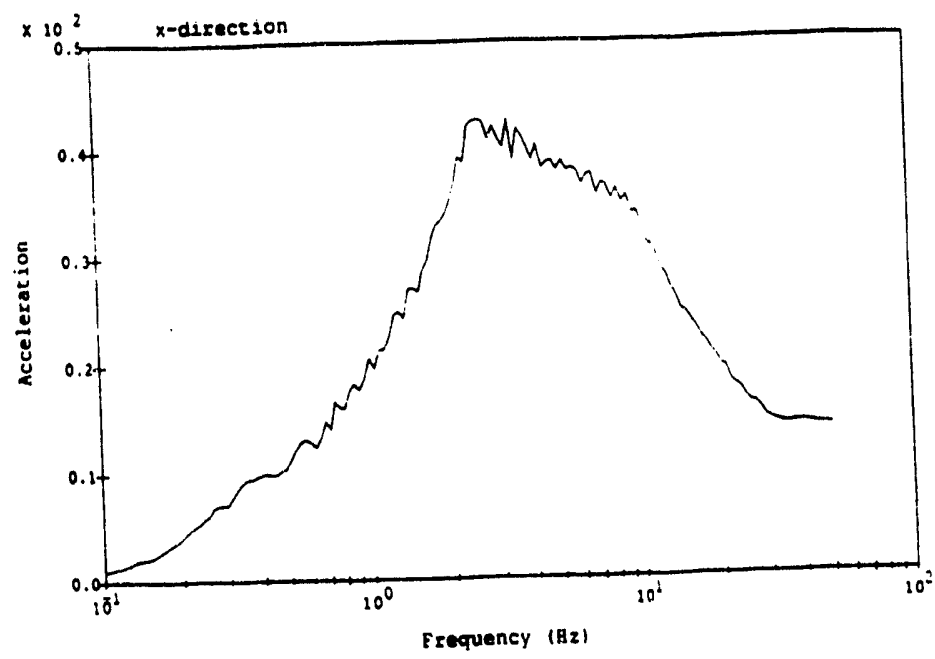

a

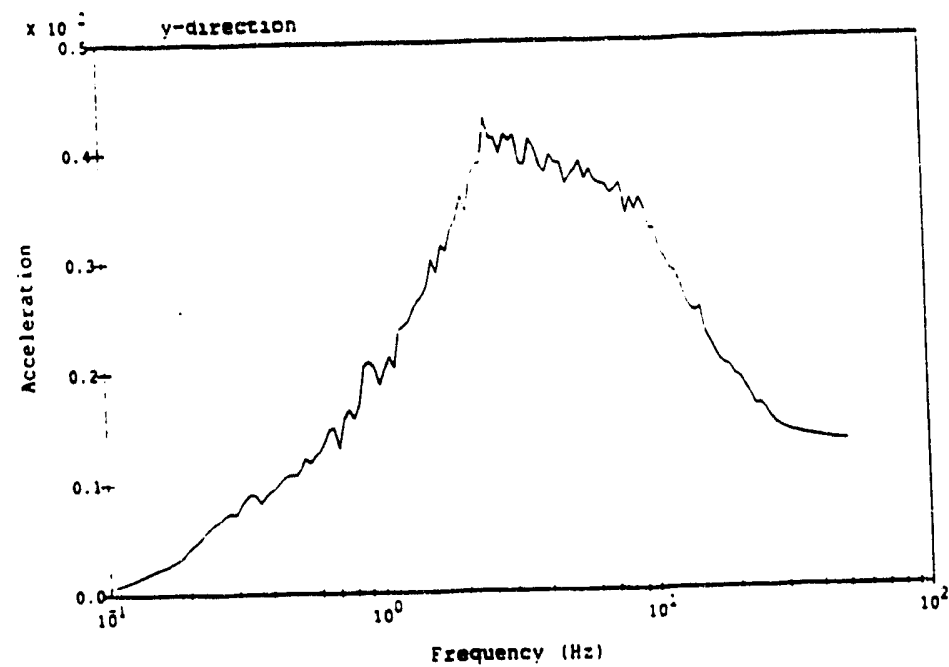

b

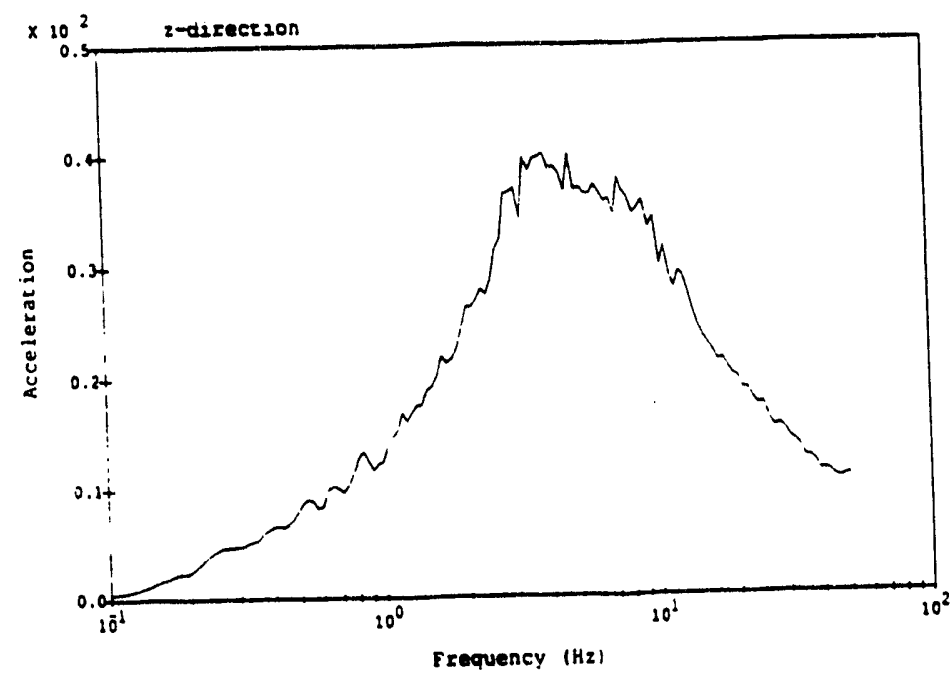

c

Nores:

Specra calculared Usang

St Oscildator Dampang

Accelerations are in $\mathrm{tr} / \mathrm{sec} / \mathrm{sec}$ units.

Figure 4.1 Response spectra of input motions used for benchmark problems 


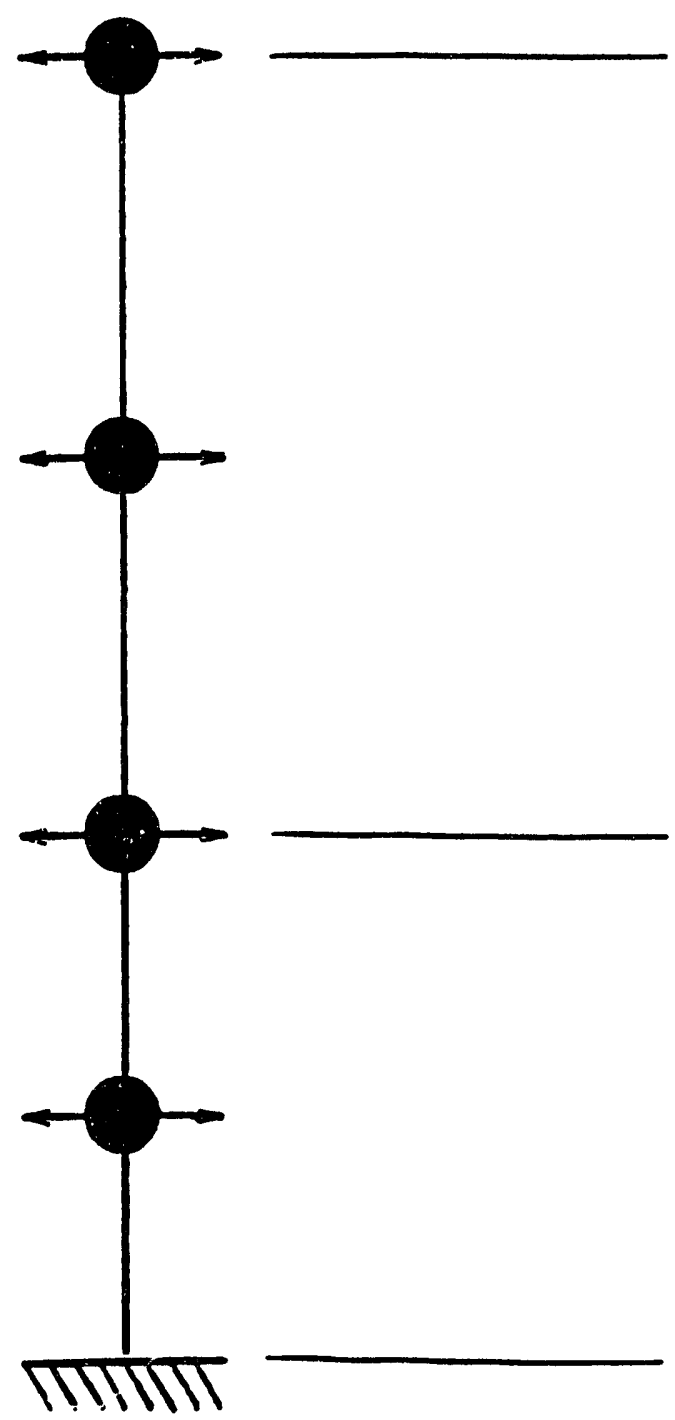

Figure 4.2 Sketch of simplified model for benchmark problem 1 


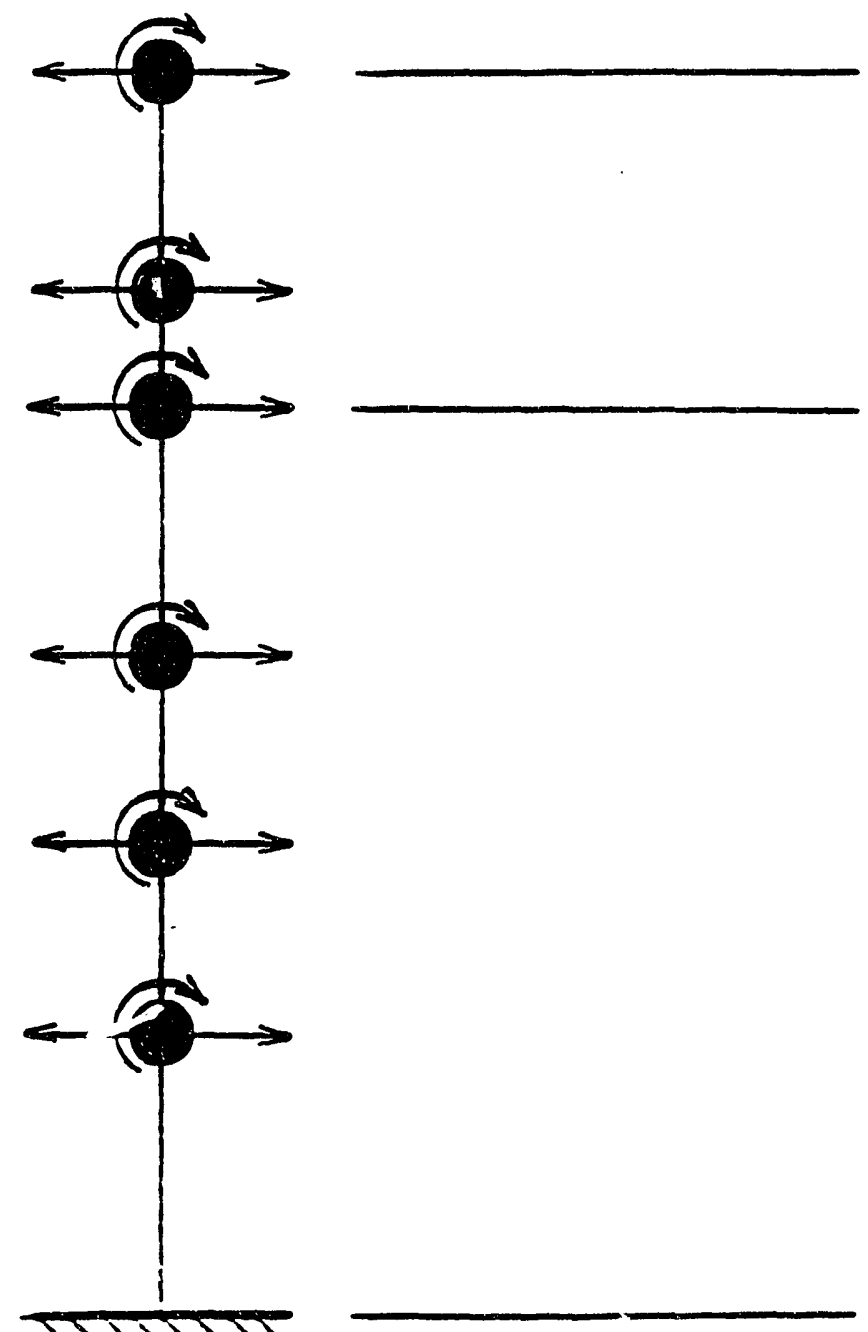

Figure 4.3 Sketch of dynamic model for benchmark problem 2 


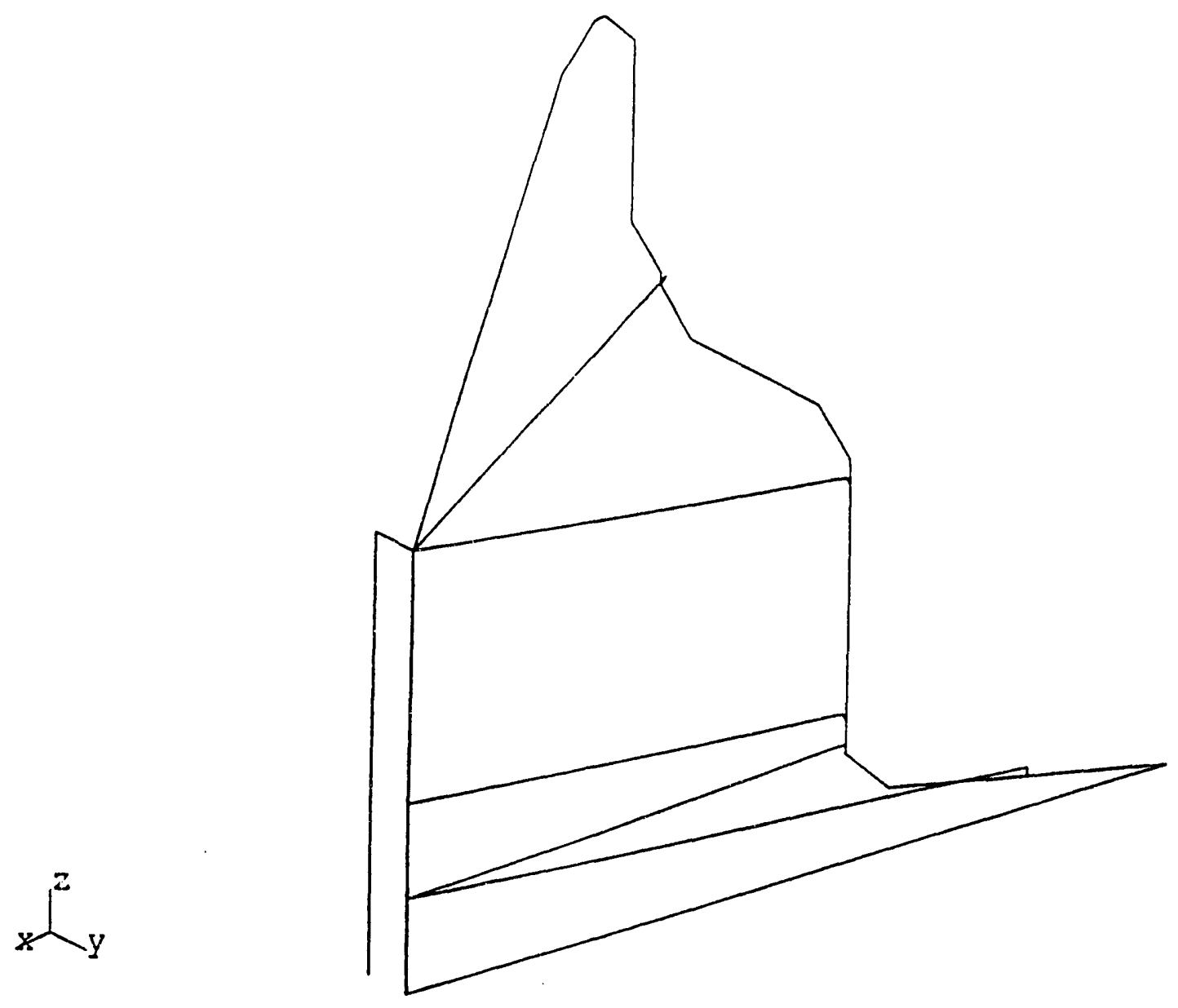

Figure 4.4 Isometric view of dynamic model for problem 3

4-35

NUREG/CR-6013 


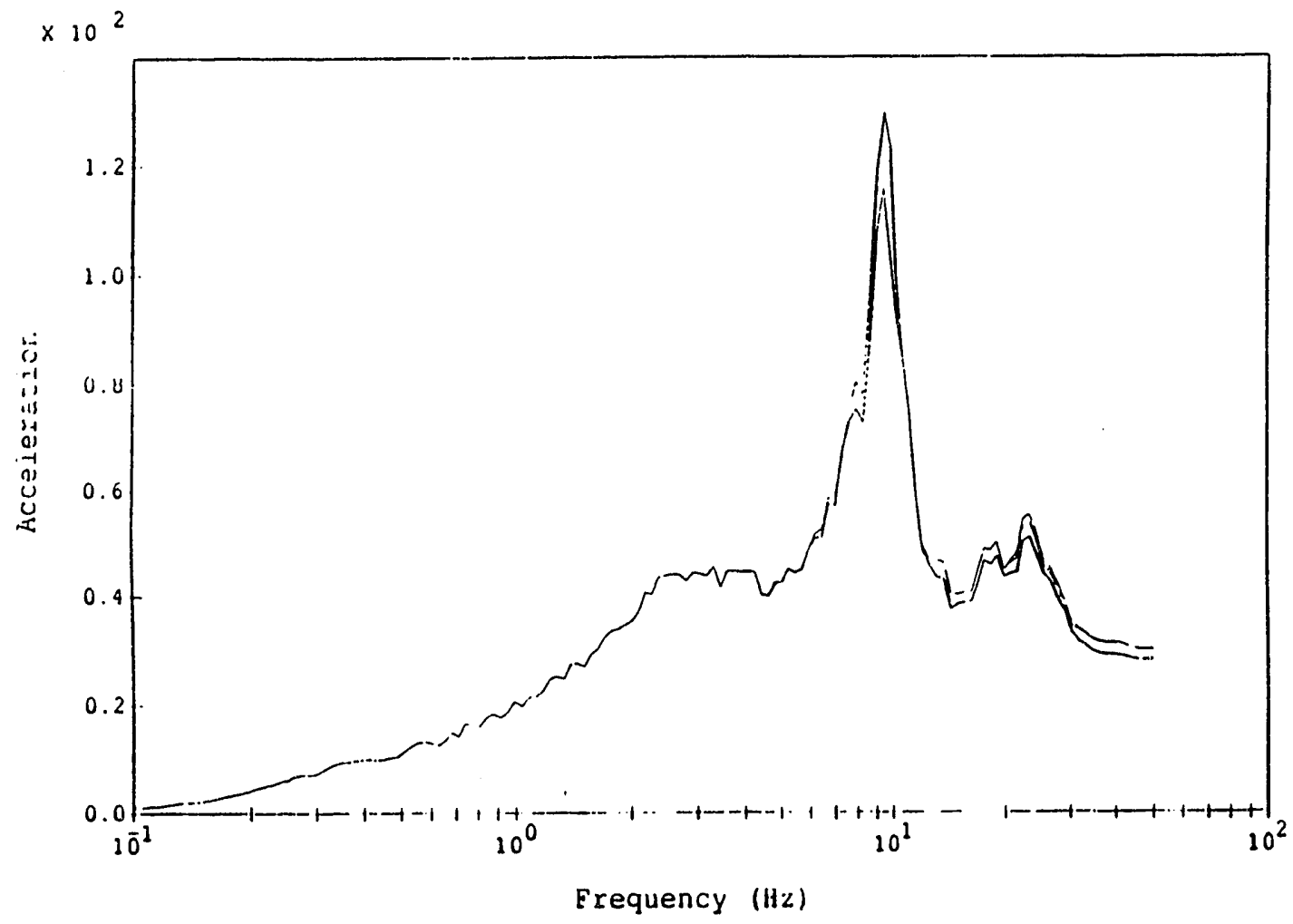

Legend:

Notes:

Direct Integration
$\begin{aligned} & \text { Mass-Proportional } \\ & \text { Damping }\end{aligned}$

Figure 4.5a Benchmark problem 3, case 2

Comparison of response at Node 24, X-Direction 


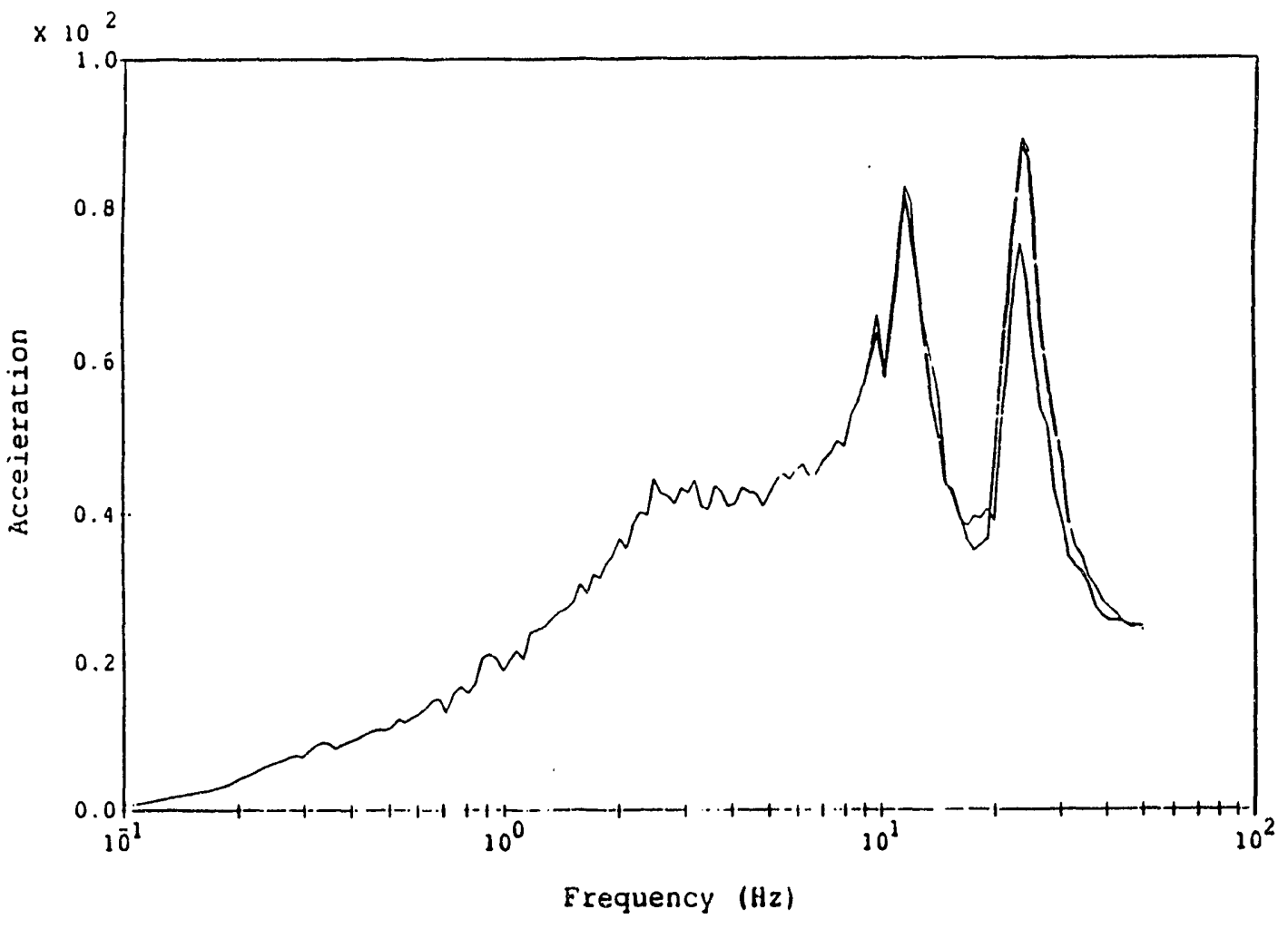

Legend:

Direct Integration

Notes:

Mass-Proportional

Dampjing

Stiffness-

Proportional Damp'g _.......

Neglect off-Diagonal

Damping Terms

Spectra Calculated Using

$5 q$ Oscillator Damping

Acculerations are in $\mathrm{ft} / \mathrm{sec} / \mathrm{sec}$ units.

Figure 4.5b Benchmark problem 3, case 2

Comparison of response at Node 24, Y-Direction 


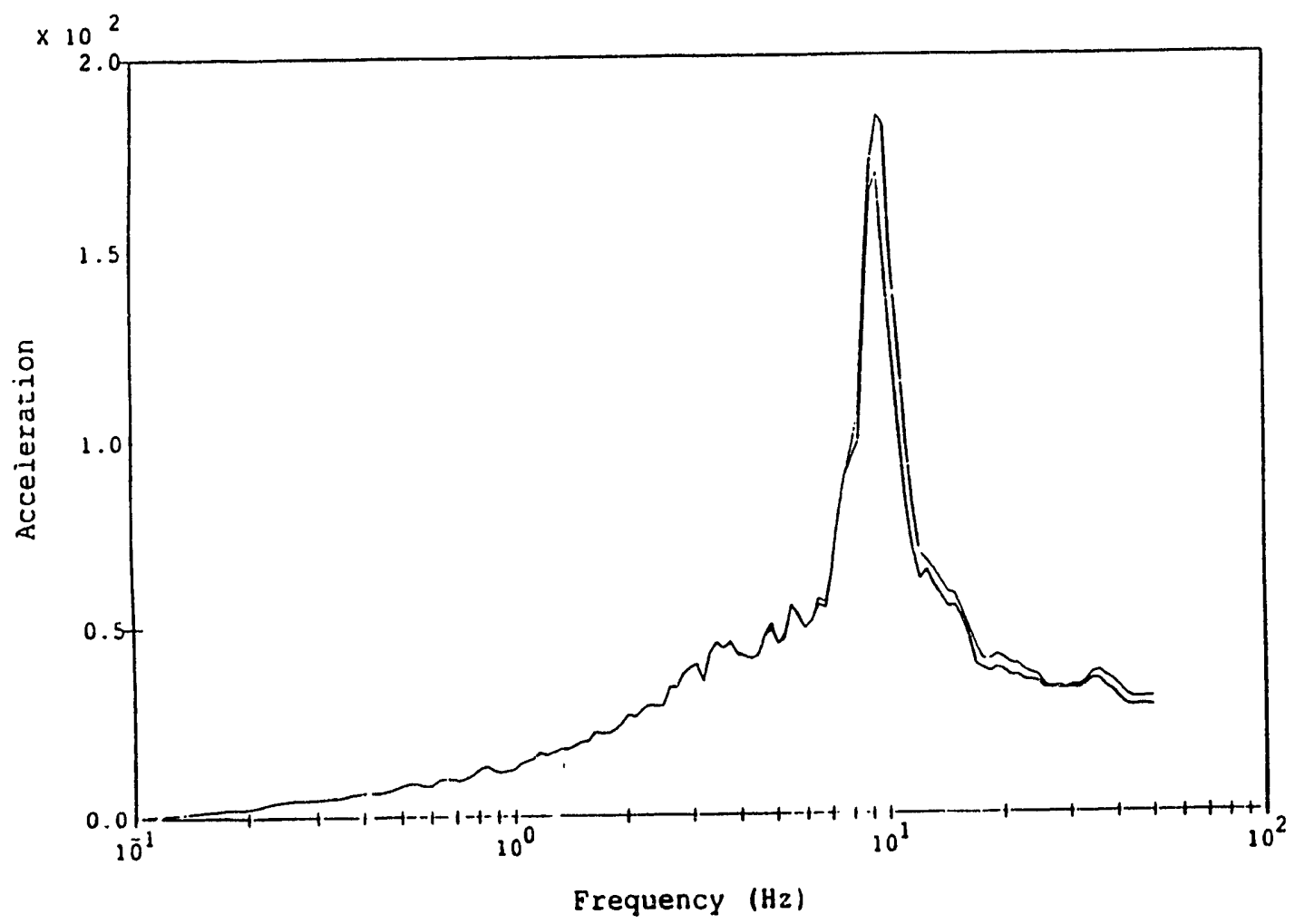

Legend:

Direct Integration Mass-Proportional Damping

Stiffness-

Proportional Damp'g Neglect off-Diagonal

Damping Terms

Notes:

Spectra Calculated Using

5\% Oscillator Damping

Accelerations are in $\mathrm{ft} / \mathrm{sec} / \mathrm{sec}$ units.

Figure 4.5c Benchmark problem 3, case 2

Comparison of response at Node 24, Z-Direction 


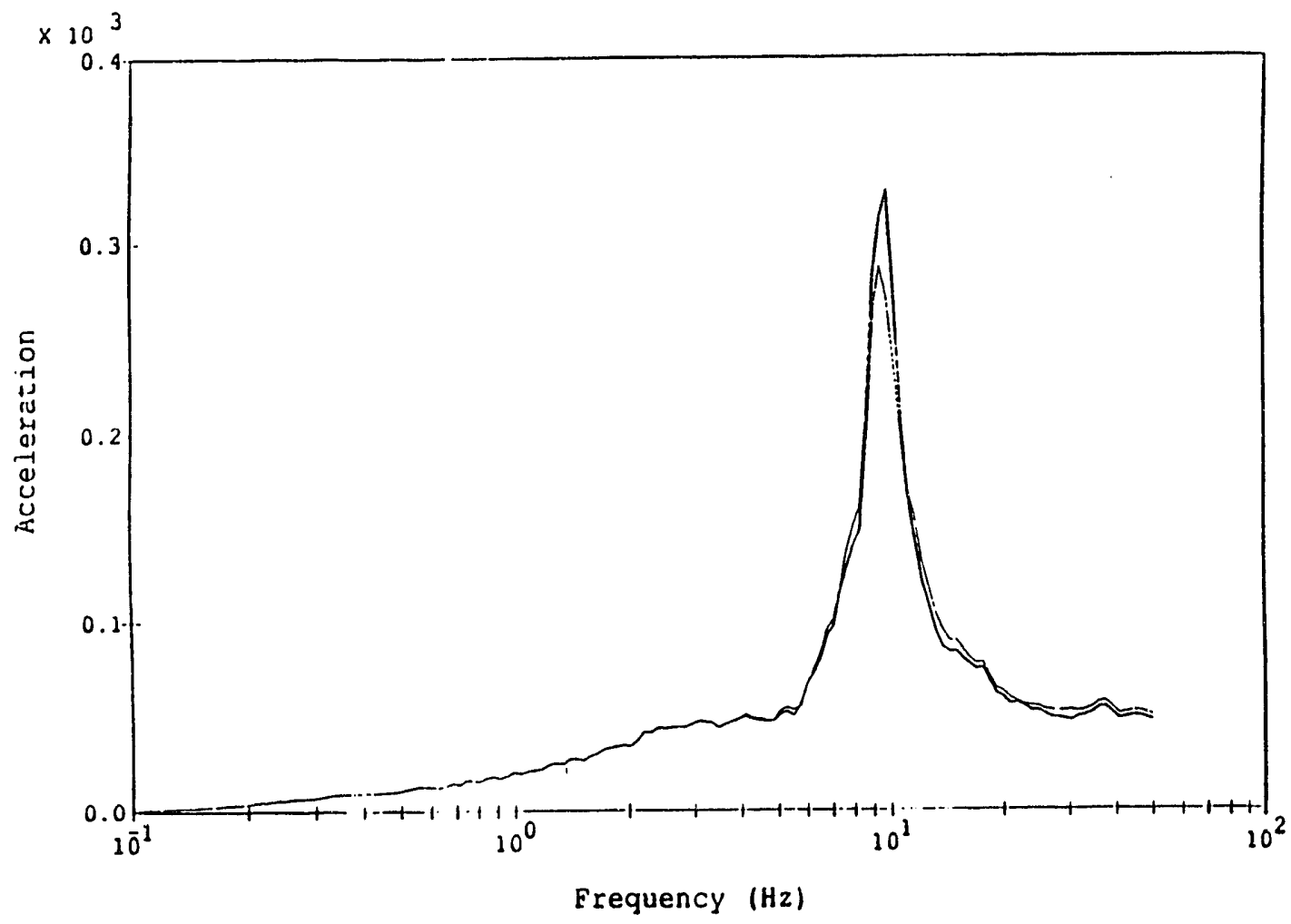

Legend:

Notes:

Direct Integration

Spectra Calculated Using

Mass-Proportional

Damping

Stiffness-

Proportional Damp'

Neglect off-Diagonal

Damping Terms

Figure 4.6a Benchmark problem 3, case 2

Comparison of response at Node 32, X-Direction 


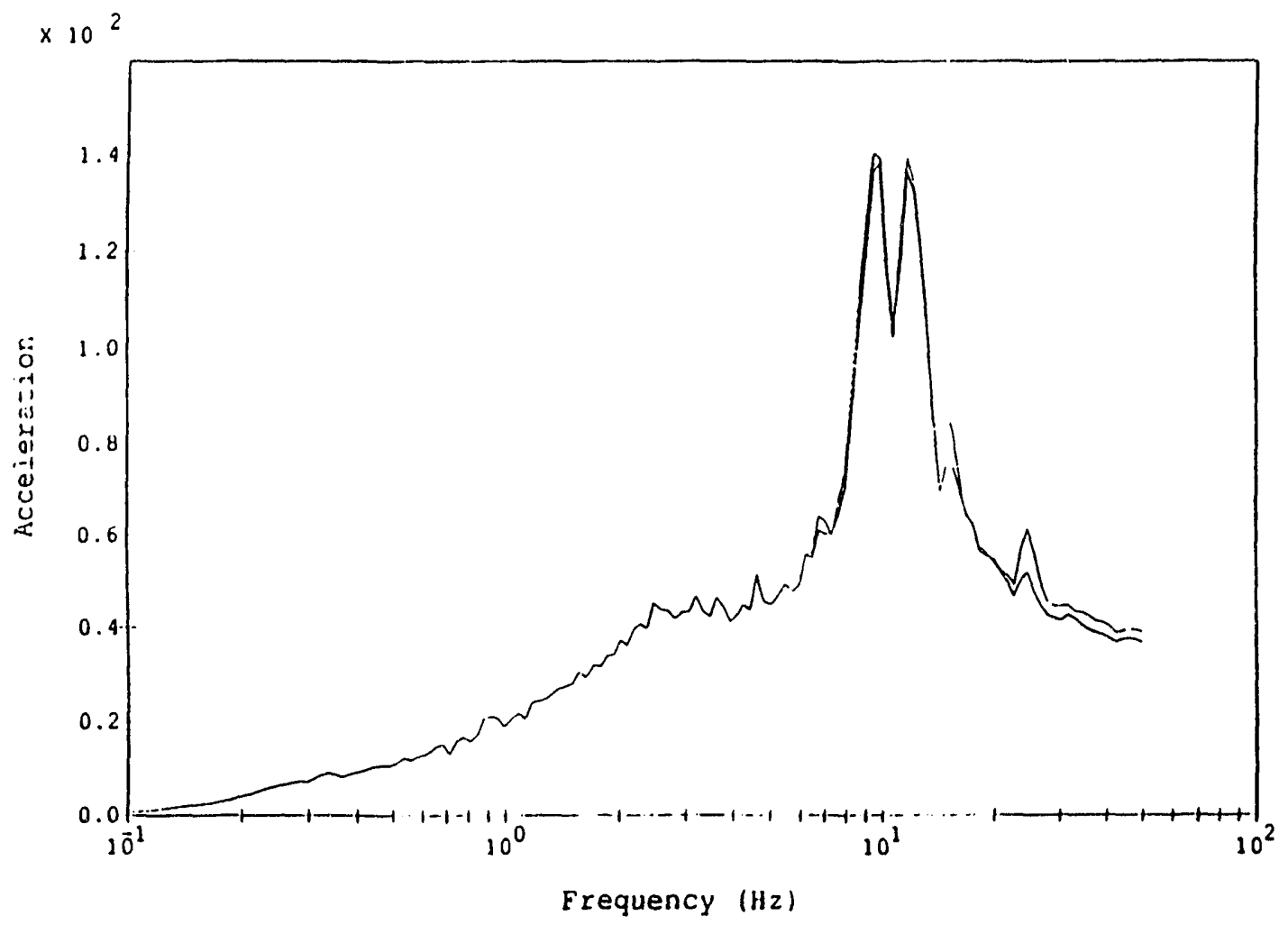

Legend:

Direct Integration
$\begin{aligned} & \text { Mass-Proportional } \\ & \text { Damping }\end{aligned}$
$\begin{aligned} & \text { Stiffness- } \\ & \text { Proportional Damp'g }\end{aligned}$
$\begin{aligned} & \text { Neglect Off-Diagonal } \\ & \text { Damping Terms }\end{aligned}$

Figure 4.6b Benchmark problem 3, case 2

Comparison of response at Node 32, Y-Direction 


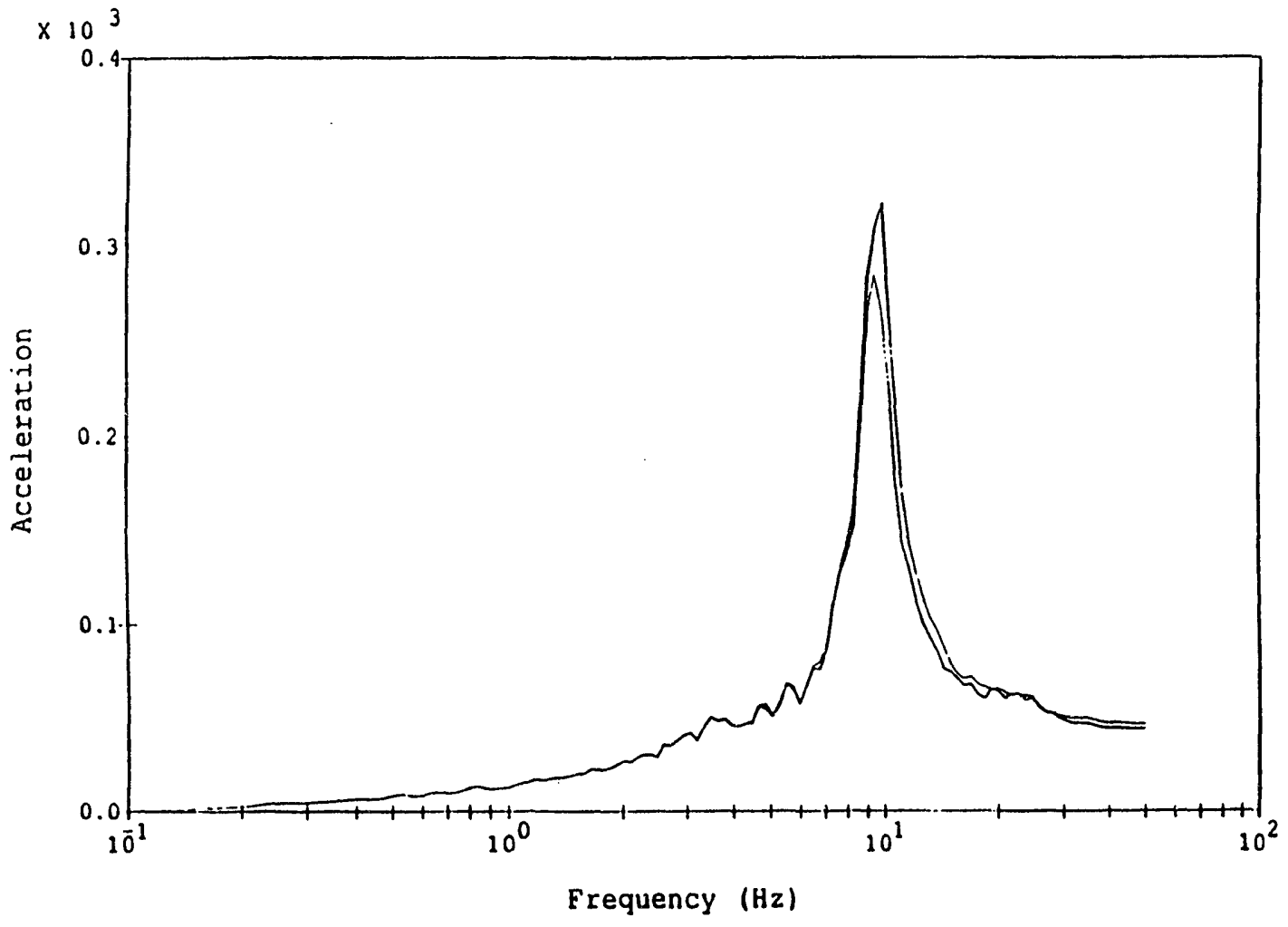

Legend:

Direct Integration

Mass-Proportional

Damping

Stiffness-

Proportional Damp'g .........

Notes:

Spectra Calculated Using

58 Oscillator Damping

Accelerations are in $\mathrm{fL} / \mathrm{sec} / \mathrm{sec}$ units.

Neglect of $f-D i a g o n a l$

Damping Terms

Figure 4.6c Benchmark problem 3, case 2

Comparison of response at Node 32, Z-Direction 


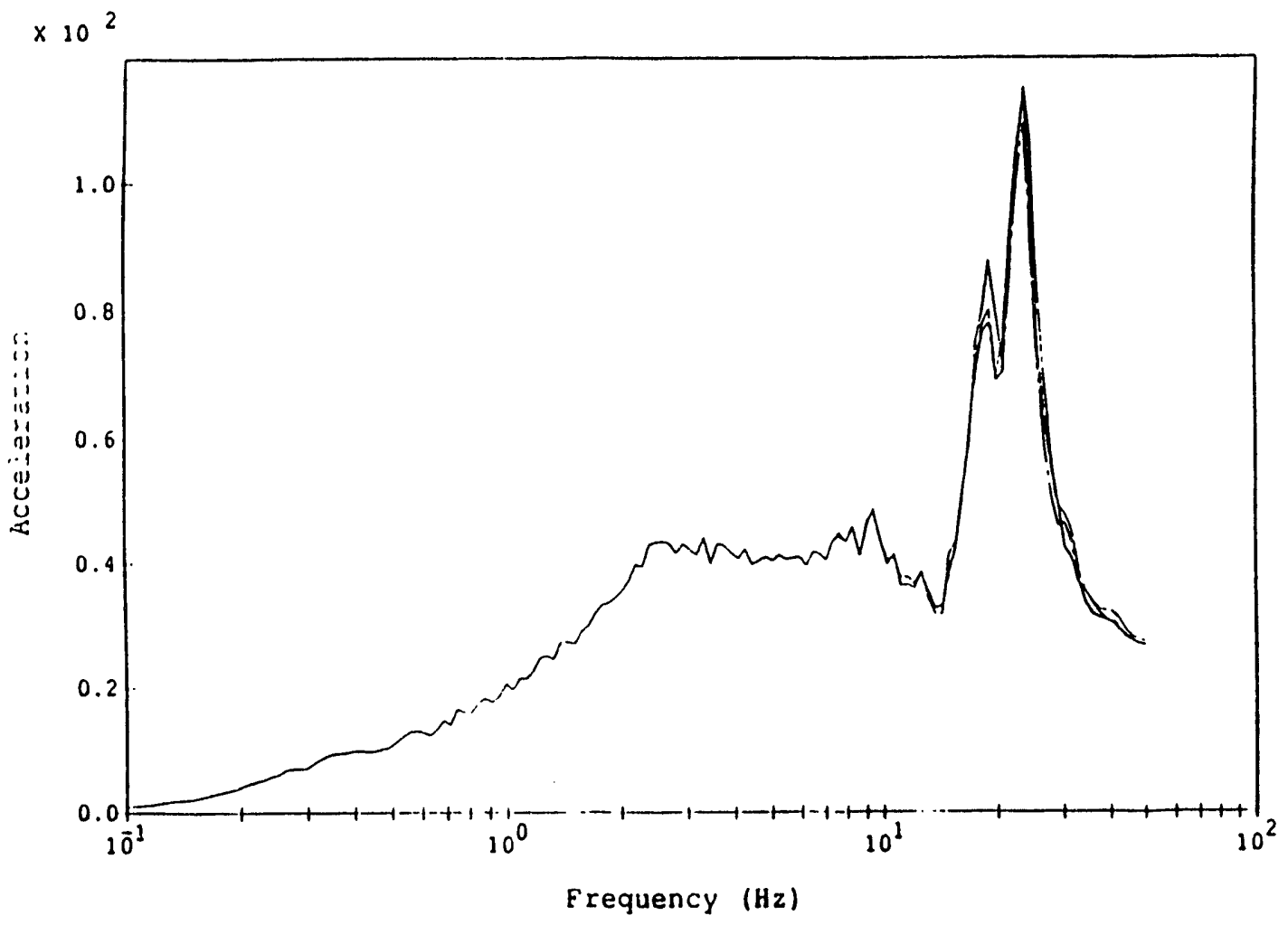

Legend:

Notes:

Direct Integration
Mass-Proportional
Damping

Figure 4.7a Benchmark problem 3, case 2

Comparison of response at Node 42, X-Direction 

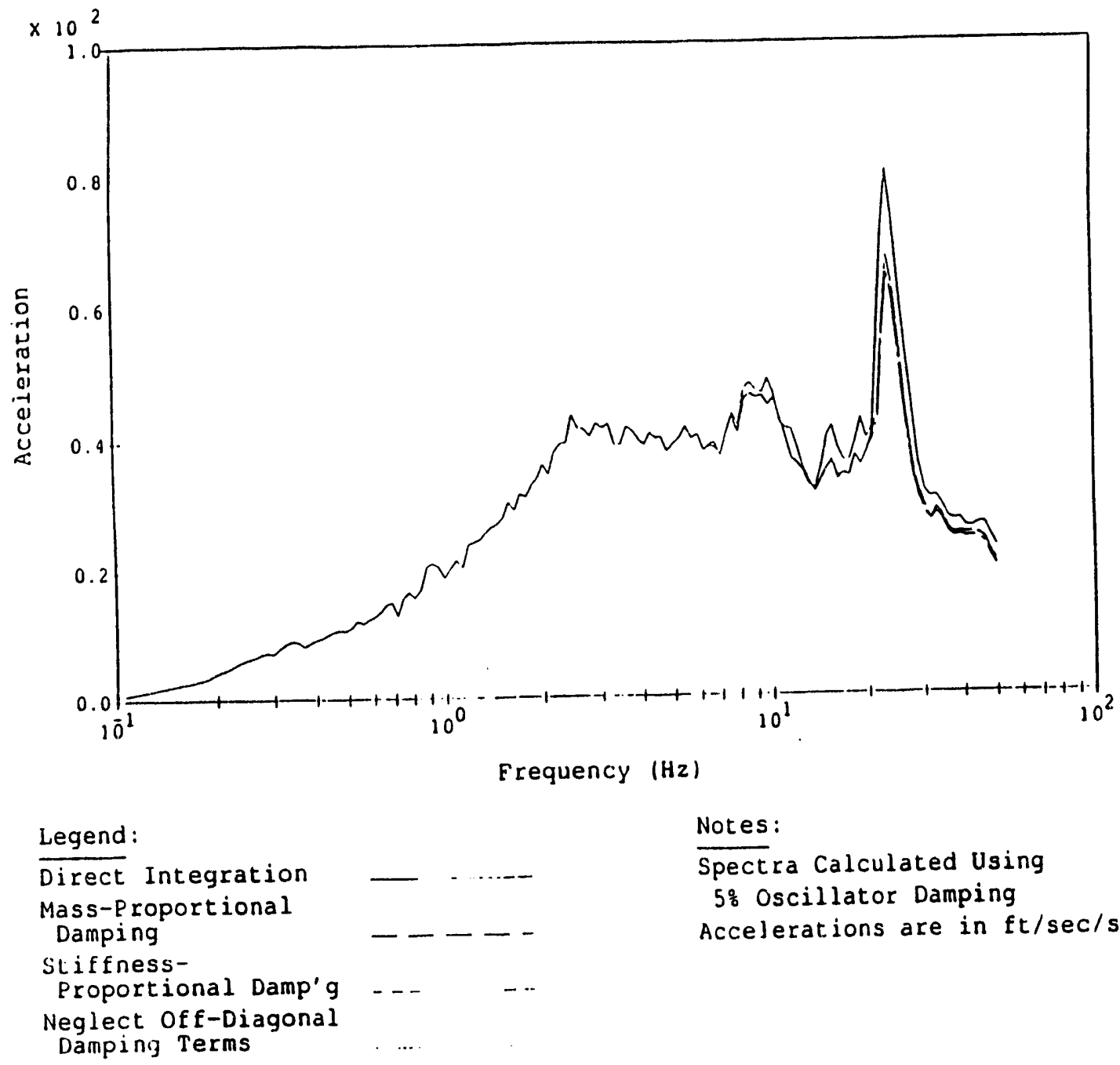

Notes:

Spectra Calculated Using

5\% Oscillator Damping

Accelerations are in $\mathrm{ft} / \mathrm{sec} / \mathrm{sec}$ units.

Figure 4.7b Benchmark problem 3, case 2

Comparison of response at Node 42, Y-Direction 


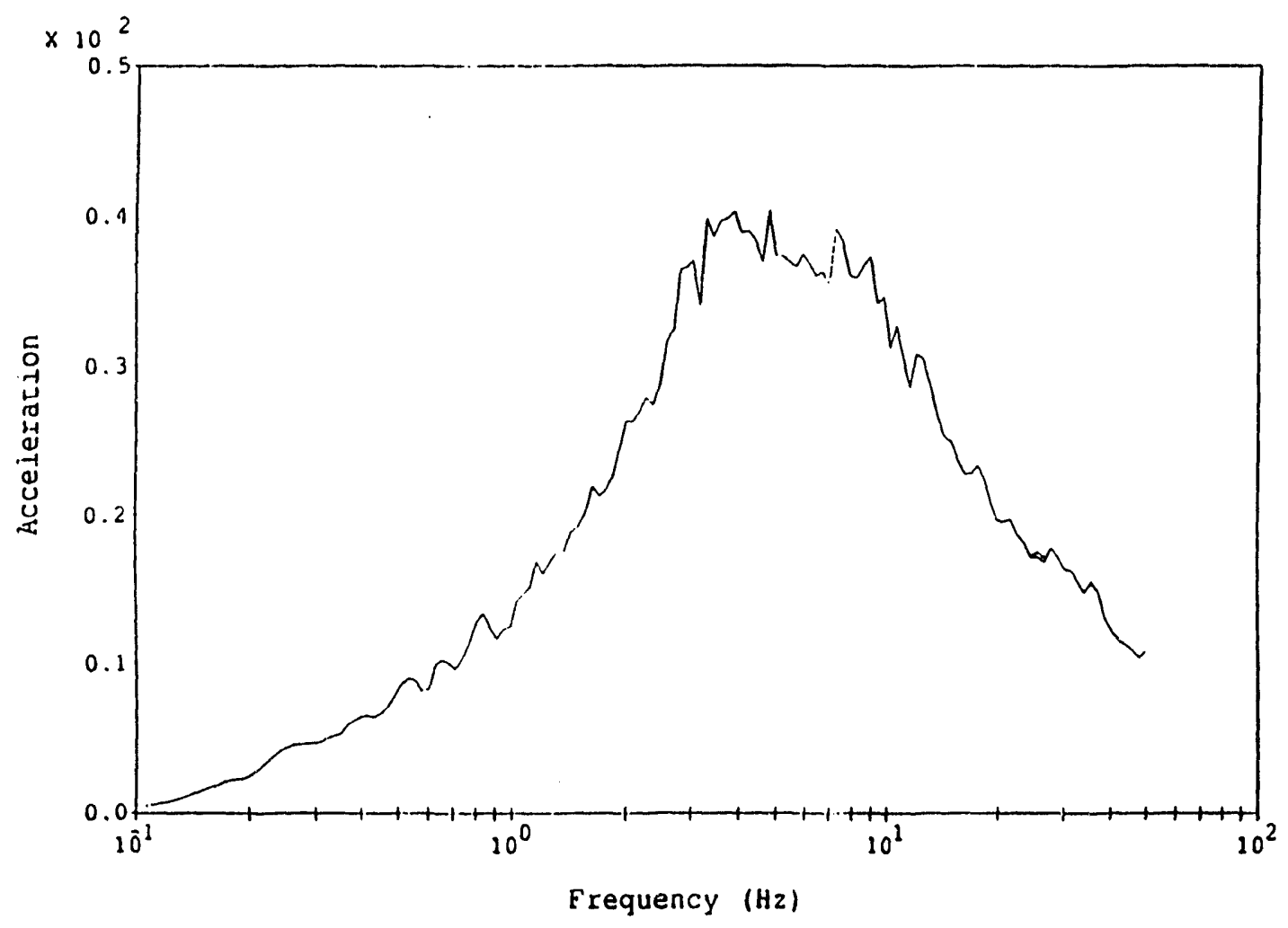

Legend:

Direct Integration Mass-Proportional

Damping

Stiffness-

Proportional Damp'g

Neglect off-Diagonal

Damping Terms

Notes:

Spectra Calculated Using

58 Oscillator Damping

Accelerations are in $\mathrm{ft} / \mathrm{sec} / \mathrm{sec}$ units.

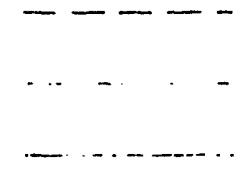

Figure 4.7c Benchmark problem 3, case 2

Comparison of response at Node 42, Z-Direction 


\section{CONCLUSIONS}

\subsection{General Conclusions}

Several analysis techniques for modeling systems with non-proportional damping were identified and reviewed through a general literature review. Three approximate methods (stiffnessweighted composite modal damping. mass-weighted composite modal damping, and neglecting off-diagonal terms of the generalized damping matrix) were selected for evaluation based on their frequency of usage in the literature and their ease of implementation for practical problems. The three approximate methods were compared with a selected rigorous method (direct integration) to evaluate the errors associated with each. Three realistic benchmark problems, drawn from actual analyses, were used for this purpose.

Based on the results of the benchmark problems that were studied, the following conclusions were drawn:

- For all three problems. the errors in all responses produced by the approximate methods were generally less than $15 \%$. Although not trivial, this error was on the order of that assumed for standard engineering practice, and was within the accuracy of the damping values that were assumed. Therefore, even for the method producing the largest error for a given problem, the error was of acceptable order.

- For the first two problems, in which the structures were represented with simplified models, the stiffness- and mass-weighted composite modal damping methods generally overestimated damping, thus producing underestimated responses.

- For the third problem, where the structural model was more complex, all three methods generally underestimated damping, thus producing conservative response estimates.

- For the first two problems, all three methods gave better approximations when the heavier lower stories had a larger damping ratio than the upper stories. This observation was in agreement with previous recommendations by Kusainov and Clough (Ref. 31) for the use of approximate methods for shear-type buildings made of different materials. For this case, the mass-weighted composite modal damping method produced the largest errors. This effect was not studied for the third problem.

- For all three problems, errors tended to be larger for more heavily damped systems. Additionally, as observed for the third problem, greater differences in assumed damping values produced greater errors. 
- Tuning or detuning the individual subsystems did not appear to have a predictable effect on the errors in the results. Tuned systems tended to have the largest errors for about half of the cases studied for the first two problems; most of these cases were for lighter upper systems.

- Overall, the method neglecting the off-diagonal terms of the generalized damping matrix appeared to produce the most accurate results. It produced small errors for the first two problems (generally less than $5 \%$ ) where the other two methods produced somewhat larger errors. It produced larger errors ( $10 \%$ to $20 \%$ ) for the third problem, but these were essentially the same as those produced by the other methods. An attempt to explain the apparently superior performance of this method is provided below.

\subsection{Discussion}

The method neglecting the off-diagonal terms of the generalized damping matrix outperformed the other two methods for the first two problems, but the three methods gave similar results for the third problem. The difference in the performance of the approximate methods for the different models was further investigated. The larger model (third problem) was different from the others in three ways, which may contribute to this difference: first, the mass ratio of the piping system to the supporting structure (0.0025) was much smaller than for any other configuration studied; second, the model contained a much greater degree of refinement; and third, the piping system was supported at seven locations, producing significant pseudostatic response.

The first difference was dismissed, since substructure mass ratio was taken as one of the parameters for variation for the first two problems. Although the mass ratio was always greater than 0.0025 , the methods' performance trends were similar regardless of the mass ratio of the secondary substructure to the supporting substructure.

The difference in pseudostatic response was also dismissed as the reason for the difference in performance. Pseudostatic response would have a tendency to reduce errors associated with all the approximate methods, but it would not change the trend.

Therefore, the principal factor was judged to be the difference in modeling refinement. This is a consequence of the method adopted to form the global damping matrix. Indeed, the method described in Section 3.1 requires that the modal damping ratio be given for the subsystem modes, a finite number. However, the damping ratio is assumed to be identical for all modes of a subsystem, as per Reference 38.

For a large model, that assumption is valid since the number of subsystem natural frequencies is large, and the global damping matrix assembled by the method described in Section 3.1 accurately reflects that assumption. In addition, because of the large number of lumped mass points and elements, the weighted average obtained by the mass and stiffness methods is more refined and gives better results. Therefore, for a large model, the three methods give approximations of the same order of accuracy. 
For a small model, the number of lumped mass points and elements is small and the weighted average obtained by the mass and stiffness methods is more crude. Furthermore, the number of subsystem frequencies is small, and the assumption that the modal damping ratio is the same for all modes is no longer true. In order to further explain this, consider Rayleigh damping. The damping matrix of a classically damped system may be written as (Ref. 42):

$$
\begin{aligned}
& C=M^{*} S U M_{b}\left(A_{b}\left[M^{-1} K\right]^{b}\right)=\operatorname{SUM}_{b}\left(C_{b}\right) \\
& \text { where } \quad \begin{aligned}
C= & \text { the damping matrix } \\
M= & \text { the mass matrix } \\
K= & \text { the stifiness matrix } \\
A_{b}= & \text { an arbitrary proportionality factor } \\
b= & \text { an integer positive or negative, and } \\
& \text { dependent on the number of frequencies where } \\
& \text { damping is defined }
\end{aligned}
\end{aligned}
$$

For a given frequency, the associated damping ratio may be derived as follows (Ref. 42):

$$
\begin{aligned}
& d_{n}=\frac{1}{2^{*} W_{n}} \operatorname{Sum}_{b}\left(A_{b} W_{n}^{2 b}\right) \\
& \text { where } \quad \begin{array}{l}
d_{n}=\text { the damping ratio for mode } n \\
W_{n}=\text { the circular frequency for mode } n
\end{array}
\end{aligned}
$$

Thus, if the damping is defined at only two modes, b only takes two values, and the dampingversus-frequency curve may have sharp valleys and troughs. If the damping is defined at a large number of modes, the relationship in equation (33) will be a polynomial of high order, which, at the limit, will be a straight line if the number of frequencies is infinite.

In consequence, for a small model, such as those for problems 1 and 2 , the global damping matrix assembled by the method described in Section 3.1 does not accurately represent the assumption that all substructure modes have the same damping ratio. For a large model, such as the one in problem 3 , the damping matrix gives a fairly good representation of this assumption, depending on the relative size of the model. When using the mass- and stiffness-weighted composite modal damping l. lethods for systems of substructures having Regulatory Guide (R.G.) 1.61 damping, the averaging process implies that the composite damping ratio is between the values of the substructure damping ratios. For systems of substructures where Rayleigh damping does not approximate a straight line, this is no longer true. One of the results is that two substructures with proportional damping conforming to R.G. 1.61 will in general not combine into a proportionally damped structure, even if the two substructures have the same damping ratio.

This explains in part why the mass- and stiffness-weighted composite modal damping ratio methods performed so poorly for the first two problems. The "realistic" benchmark method (direct integration) used a damping matrix that did not fit the framework associated with these approximate methods. The method neglecting the off-diagonal terms of the generalized damping matrix used the same damping matrix as the benchmark method, and therefore had the same assumptions concerning modal damping. Whether the substructure Rayleigh damping curves 
approximated a straight line or not, the damping used for that method and the benchmark method was identical.

\subsection{Recommendations}

Use of the mass- or stiffness-weighted composite modal damping ratio methods is recommended for systems of substructures with different damping characteristics, if the individual substructures are represented by refined models. These two methods are much easier to use and implerient than the third approximate method, and they both give adequal? approximations for large problems.

For most problems, the two methods are judged to be equivalent, with the exception of structures made of different materials for which the lower stories have higher energy-absorption capacity than the upper stories. For such systems, use of the stiffness-weighted composite modal damping ratio method is recommended.

For systems of substructures with different damping characteristics represented by simple models (small number of lumped mass points and elements), the averaging process of the mass- and stiffness-weighted methods may not be very accurate, and use of the method negle ing the off-diagonal terms of the generalized damping matrix is recommended. However, it should be noted that this method requires considerably more effort than either of th s other two when the damping of the individual subsystems is defined in term of percentages of critical damping, as is the most common method of defining damping in the nuclear industry. When this procedure is used, the global damping matrix of the coupled system must first be assembled and then the generalized damping matrix must be calculated. Attention should be given to the method used to assemble the global damping matrix, as it may lead to a situation that violates the initial analysis assumptions. 
APPENDIX A

REFERENCES 


\section{REFERENCES}

1. Brusa, L. et al., "A Numerical Method for Vibration Analysis of Composite Structures with Different Damping Capacities", 3rd International Conference on Structural Mechanics Reactor Technology, Vol.4, Paper K 4/5, London, UK, September 1975.

2. Stevenson, J.D., "Structural Damping Values as a Function of Dynamic Response Stress and Deformation Levels", Nuclear Engineering and Design 60, 211-237, 1980.

3. Tsai, N.C., "Modal Damping for Soil-Structure Interaction", Journal of the Engineering Mechanics Division, ASCE, Vol.100, No.EM2, 323-341, April 1974.

4. Coats Jr., D.W., "Damping in Building Structures During Earthquakes", NUREG/CR3006, UCRL-53043, January 1989.

5. Clough, R.W., and S. Mojtahedi, "Earthquake Response Analysis Considering NonProportional Damping", Earthquake Engineering and Structural Dynamics, Vol.4, 489496, 1976.

6. Idriss, I.M. et al., "Quad-4: A Computer Program for Evaluating the Seismic Response of Soil Structures by Variable Damping Finite Element Procedures", Report No. EERC 73. 16, University of California, Berkeley CA, July 1973.

7. Grant, J.E., and A.T. Jones, "Generation and Properties of Banded Viscous Darnping Matrices," Sandia Laboratories, SCL-DC-710093, March 1972.

8. W.C. Hurty, "Dynamic Analysis of Structural Systems Using Component Modes", AAIA Journal, Vol.3, No.4, 678-685, April 1965.

9. Pajuhesh, J., and A.H. Hadjian, "Determination of Composite Damping Matrices", 5th World Conference on Earthquake Engineering, Rome, Italy, 1973.

10. J.M. Roesset, R.V. Whitman, R. Dobry, "Modal Analysis for Structures with Foundation Interaction", Journal of the Structural Division, ASCE, Vol.99, No.ST3, March 1973.

11. Chiu, K.D., and H.J. Kuo, "Modal Damping in Dynamic Analysis of Structures", Conference on Structural Design of Nuclear Plant Facilities, ASCE, Vol.2, 499-514, Chicago, IL, December 1973.

12. Caughey, T.K., "Classical Normal Modes in Damped Linear Systems", Journal of Applied Mechanics, 269-271, June 1960.

13. Foss, K.A., "Coordinates Which Uncouple the Equations of Damped Linear Dynamic Systems", Transactions of the American Society of Mechanical Engineers, Vol.82, 361$364,1960$. 
14. Brusa, L. , Ciacci, R., and F. Restelli, "A Simplified Procedure for Evaluating Modal Damping Factors in Structures with Widely Varying Damping Capacities", 4th International Conference on Structural Mechanics Reactor Technology, Vol.K(a), Paper K3/10, San Francisco, CA, August 1977.

15. Danish, R., Delinic, K., and K. Veselic, "Quadratic Eigenvalue Solver for Modal Response Analysis of Non- Proportionally Damped Elastic Structures", 7th International Conference on Structural Mechanics Reactor Technology, Vol.K(a), Paper K3/1, Chicago, IL, August 1983.

16. Duncan, P.E., and R. Eatock Taylor, "A Note on the Dynamic Analysis of NonProportionally Damped Systems", Earthquake Engineering and Structural Dynamics, Vol.7, No.1, 99-105, 1979.

17. Trail-Nash, R.W., "Modal Methods in Dynamics of Systems with Non-Classical Damping", Earthquake Engineering and Structural Dynamics, Vol.9, No.2, 153-169, 1981.

18. Cella, A., Greco, A., and R. Leo, "Diagonalization Methods for Viscous and Hysteretic Damping Matrices", 7th International Conference on Structural Mechanics Reactor Technology, Vol.K(a), Paper K3/2, Chicago, IL, August 1983.

19. Krapf, K.G., and H. Wolfel, "Limitations of Modal Analysis of Damped Structures", 7th International Conference on Structural Mechanics Reactor Technology, Vol.K(a), Paper K3/3, Chicago, IL, August 1983.

20. Hadjian, A.H., Masri, S.F., and A.F. Saud, "A Review of Methods of Equivalent Damping Estimation from Experimental Data", Journal of Pressure Vessel Technology, ASME, Vol.109, 236-243, May 1987.

21. Warburton, G.B., and S.R. Soni, "Errors in response calculation for non-classically damped structures", Earthquake Engineering and Structural Dynamics, Vol.5, No.4, 365$376,1977$.

22. Inman, D.J., "Dynamics of Asymmetric Non-Conservative Systems", Journal of Applied Mechanics, ASME, Vol.50, March 1983.

23. Fawzy, I., and R.E.D. Bishop, "On the Nature of Response in Non-Conservative Systems", Journal of Sound and Vibration, Vol.55, No.4, 475-485, December 1977.

24. Ahmadian, M., and D.J. Inman, "Modal Analysis in Non-Conservative Dynamic Systems", Proceedings of the 2nd International Modal Analysis Conference, Vol.1, 340-344, Orlando, FL, 1984.

25. Maybee, J.S., "Normal and Quasi-Normal Modes in Damped Linear Dynamic Systems", Journal of Applied Mechanics, ASME, Vol.88, 413-416, 1966.

26. Craig Jr., R.R., and Y.T. Chung, "Generalized Substructure Coupling Procedure for Damped Systems", AAlA Journal, Vol.20, No.3, March 1982. 
27. Hale, A.L., "A Family of Subspace Iteration Algorithms for the Eigensolution of Large Structural Systems Composed of Substructures", Proceedings of the 1st International Modal Analysis Conference, 500-507, Orlando, FL, November 1982.

28. Hasselman, T.K., "Modal Coupling in Lightly Damped Structures", AAIA Journal, Vol.14, No.11, 1627-1628, November 1976.

29. Bechtel Group, Inc., "Piping System Damping Evaluation", EPRI NP-6035, Project 26352, October.1988.

30. Veletsos, A.S., and C.E. Ventura, "Modal Analysis of Non-Classically Damped Linear Systems", Earthquake Engineering and Structural Dynamics, Vol.14, No.2, 217-243, 1986.

31. Kusainov, A.A., and R.W. Clough, "Alternatives to Standard Mode Superposition for Analysis of Non-Classically Damped Systems", EERC Report No. UCB/EERC-88/09, University of California, Berkeley, CA, June 1988.

32. Suarez, L.E., and M.P. Singh, "Eigenproperties of Non-Classically Damped Primary Structure and Oscillator Systems", Journal of Applied Mechanics, ASME, Vol.54, September 1987.

33. Gupta, A.K., and J.W. Jaw, "Seismic Response of Non-Classically Damped Structures", Nuclear Engineering and Design, Vol.91, No.2, 153-159, 1986.

34. Gupta, A.K., J.W. Jaw, "Response Spectrum Method for Non-Classically Damped Systems" Nuclear Engineering and Design, Vol.91, No.2, 161-169, 1986.

35. Singh, A.K., "Dynamic Analysis Using Modal Synthesis", Journal of the Power Division, 131-140, April 1978.

36. Hasselman, T.K., "Damping Synthesis from Substructure Tests", AAIA Journal, Vol.14, No.10, 1409-1418, October 1976.

37. Hasselman, T.K., and G.C. Hart, "A Minimization Method for Treating Convergence in Modal Synthesis", AAIA Joumal, Vol.12, No.3, 316-323, March 1974.

38. United States Atomic Energy Commission, "Damping Values for Seismic Design of Nuclear Power Plants", Regulatory Guide 1.61, October 1973.

39. Johnson, J.J., "MODSAP. A Modified Version of the Structural Analysis Program SAP IV for the Static and Dynamic Response of Linear and Localized Nonlinear Structures", General Atomics, National Technical Information Services No.GA-A14006, June 1976.

40. United States Atomic Energy Commission, "Design Response Spectra for Seismic Design of Nuclear Power Plants", Regulatory Guide 1.60, Rev.1, December 1973. 
41. Maslenikov, O.R., and J.J. Johnson, et al. "SMACS. A System of Computer Programs for Probabilistic Seismic Analysis of Structures and Subsystems", UCID-20413, Vol.2, March 1985.

42. Clough, R.W., and J. Penzien, "Dynamics of Structures", pp 194-196, McGraw-Hill Book Company, 1975.

43. Gupta, A.K., "Response Spectrum Method in Seismic Analysis and Design of Structures," pp 66-138, Blackwell Scientific Publications, 1990. 
APPENDIX B

BENCHMARK PROBLEM 3:

PLOTS OF MODE SHAPES 


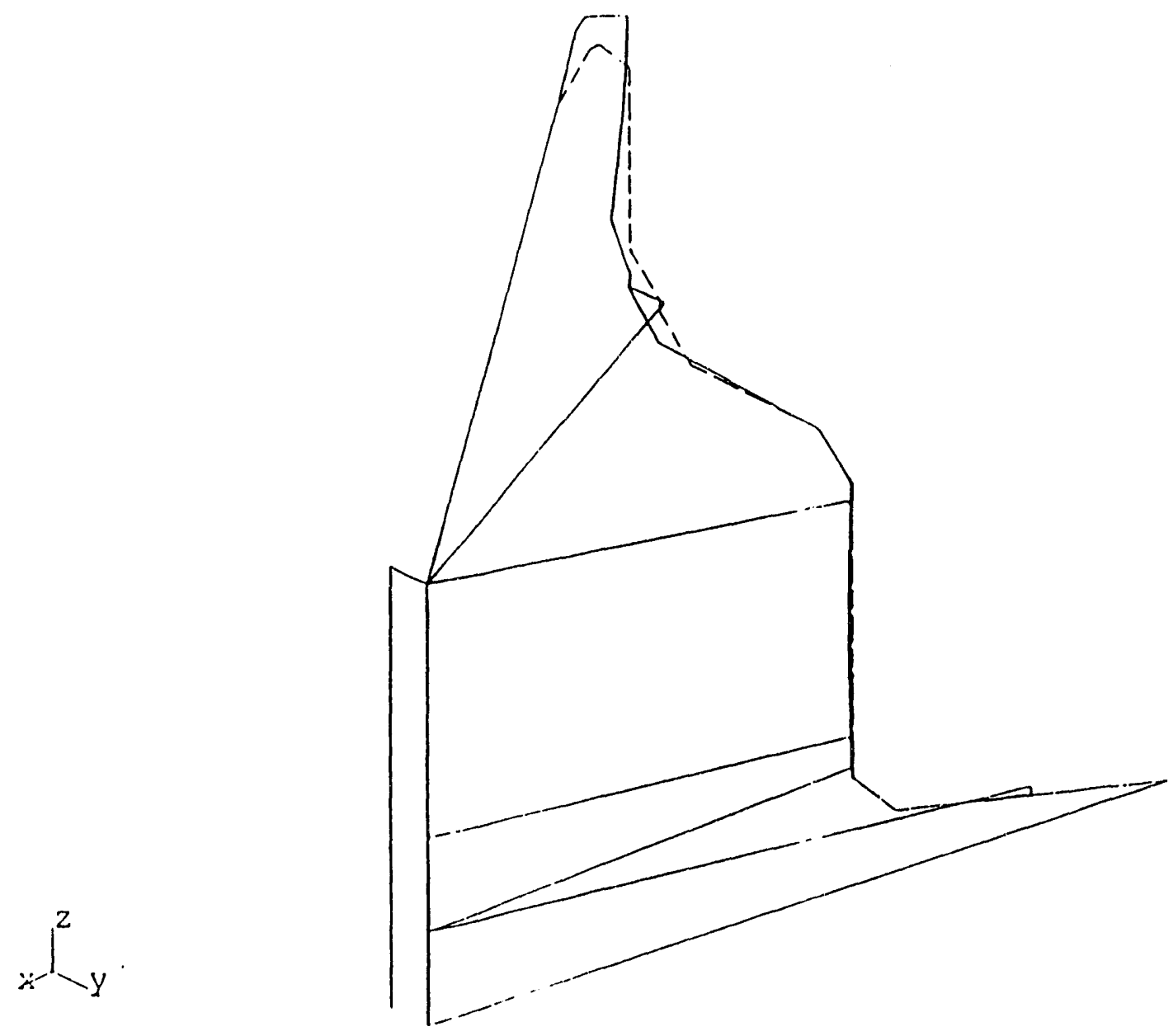

BENCHMARK PROBLEM 3: COUPLED MODEL

Mode 1, Erequency $=9.689 \mathrm{~Hz}$, Scale Factor $=0.200 \mathrm{E}+03$ 


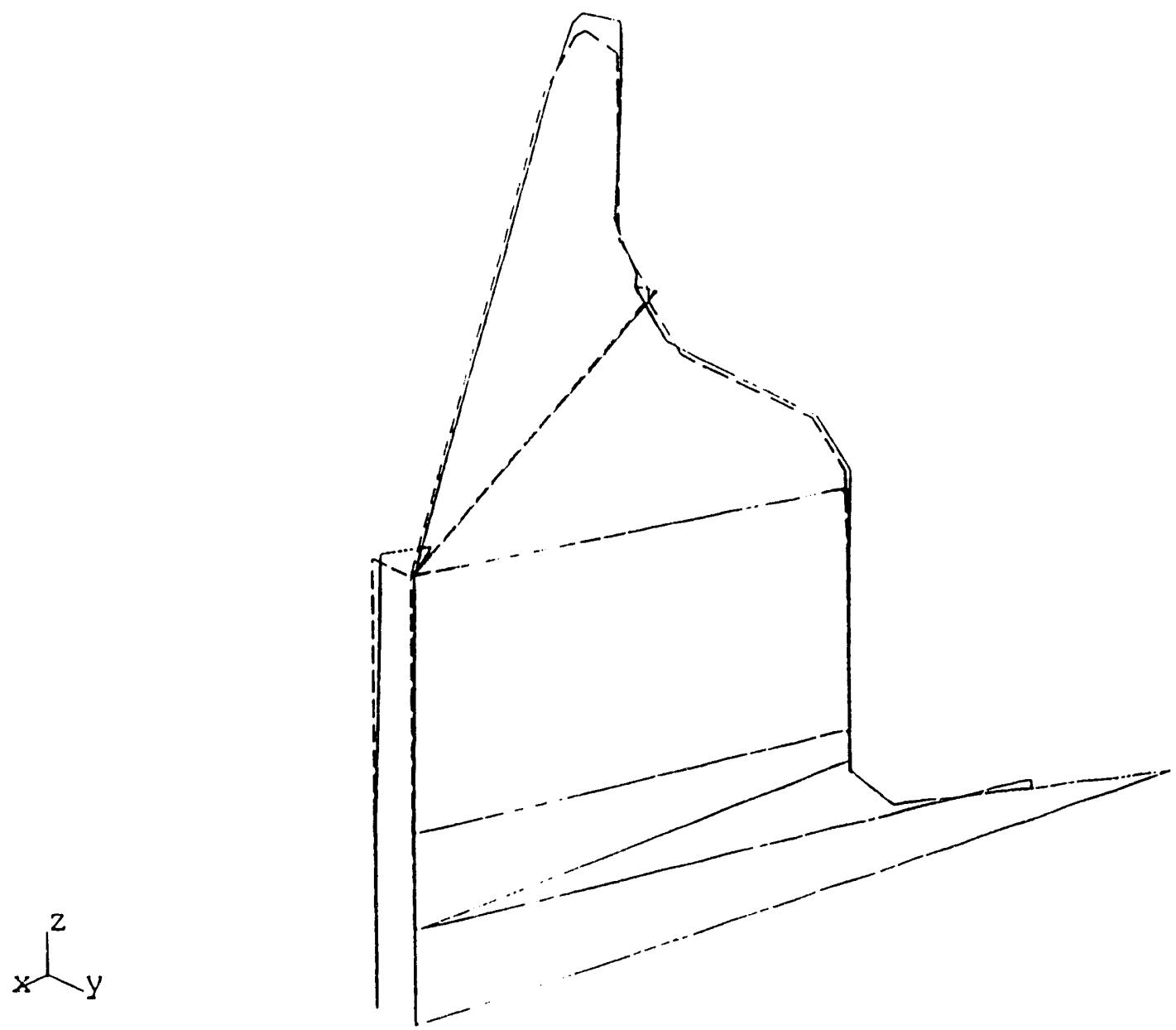

BENCHMARK PROBLEM 3: COUPLED MODEL

Mode 2, Erequency $=10.225 \mathrm{~Hz}$, Scale Factor $=0.200 \mathrm{E}+04$ 


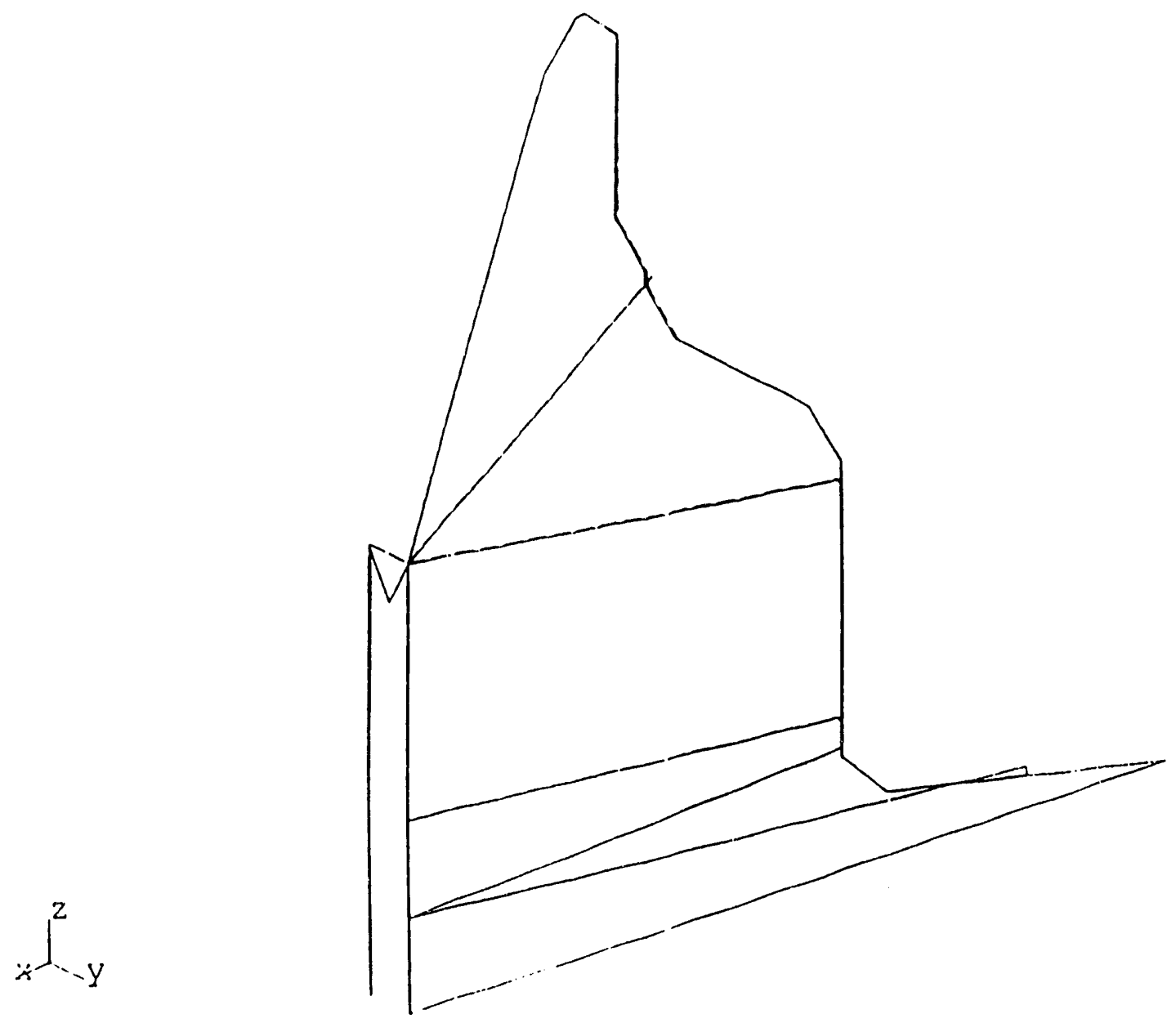

BENCHMARK PROBLEM 3: COUPLED MODEL

Mode 3, Erequency $=10.80 \% \mathrm{~Hz}$, Scale Factor $=0.200 \mathrm{E}+04$ 


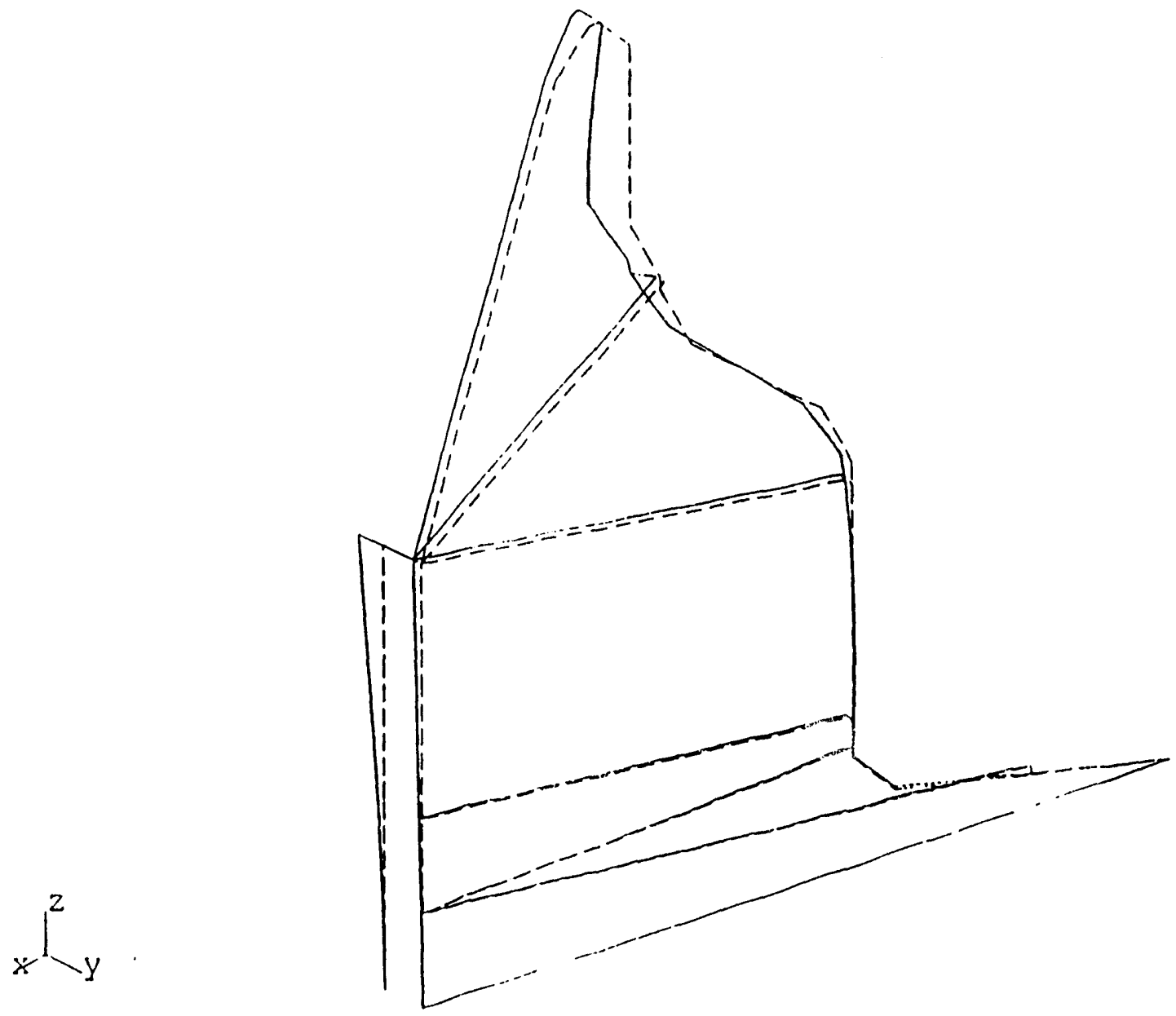

BENCHMARK PROBLEM 3: COUPLED MODEL

Mocte 4, Frequency $=12.671 \mathrm{~Hz}$, Scale Factor $=0.200 \mathrm{E}+04$ 


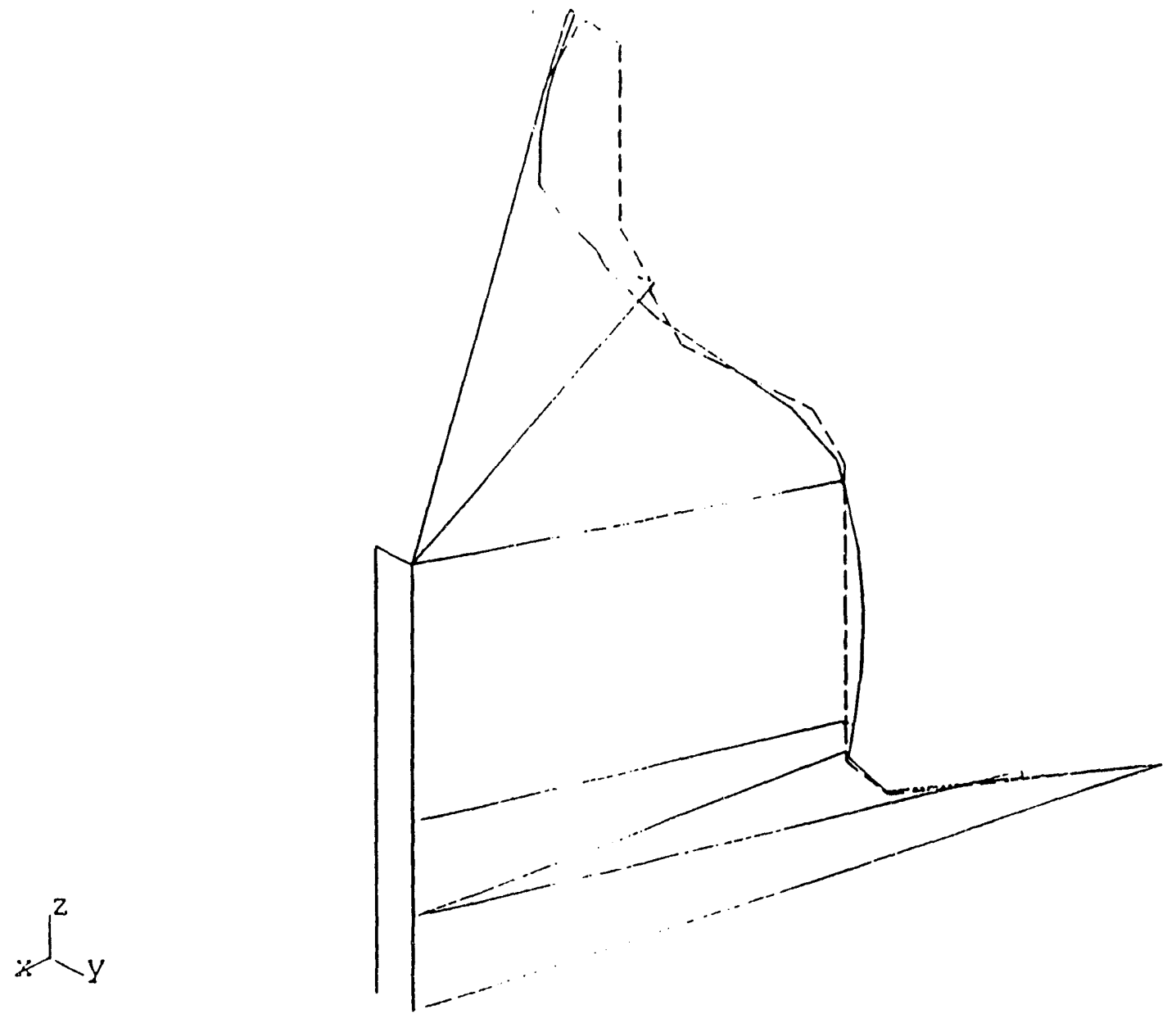

BENCIMARK PROBLEM 3: COUPLED MOUEL

Mode 5, Frequency $=14.864 \mathrm{~Hz}$, Scale Factor $=0.200 \mathrm{E}+03$ 


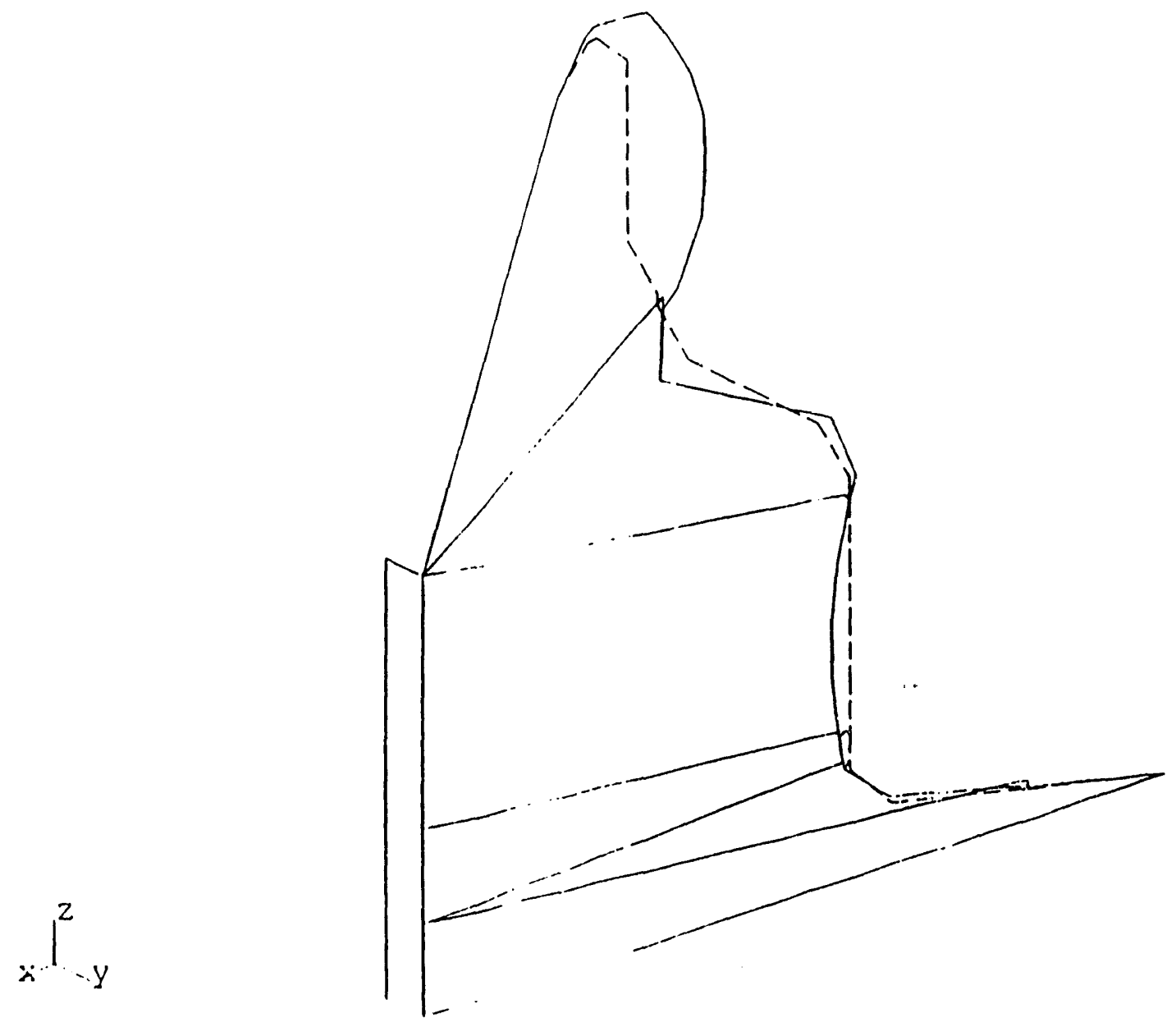

BENCHMARK ['ROBLEM 3: COUPILLI) MODEL,

Mnde 6, Frequency $=16.53 \% \mathrm{~Hz}$, Scale Factor $=0.200 \mathrm{E}+03$ 


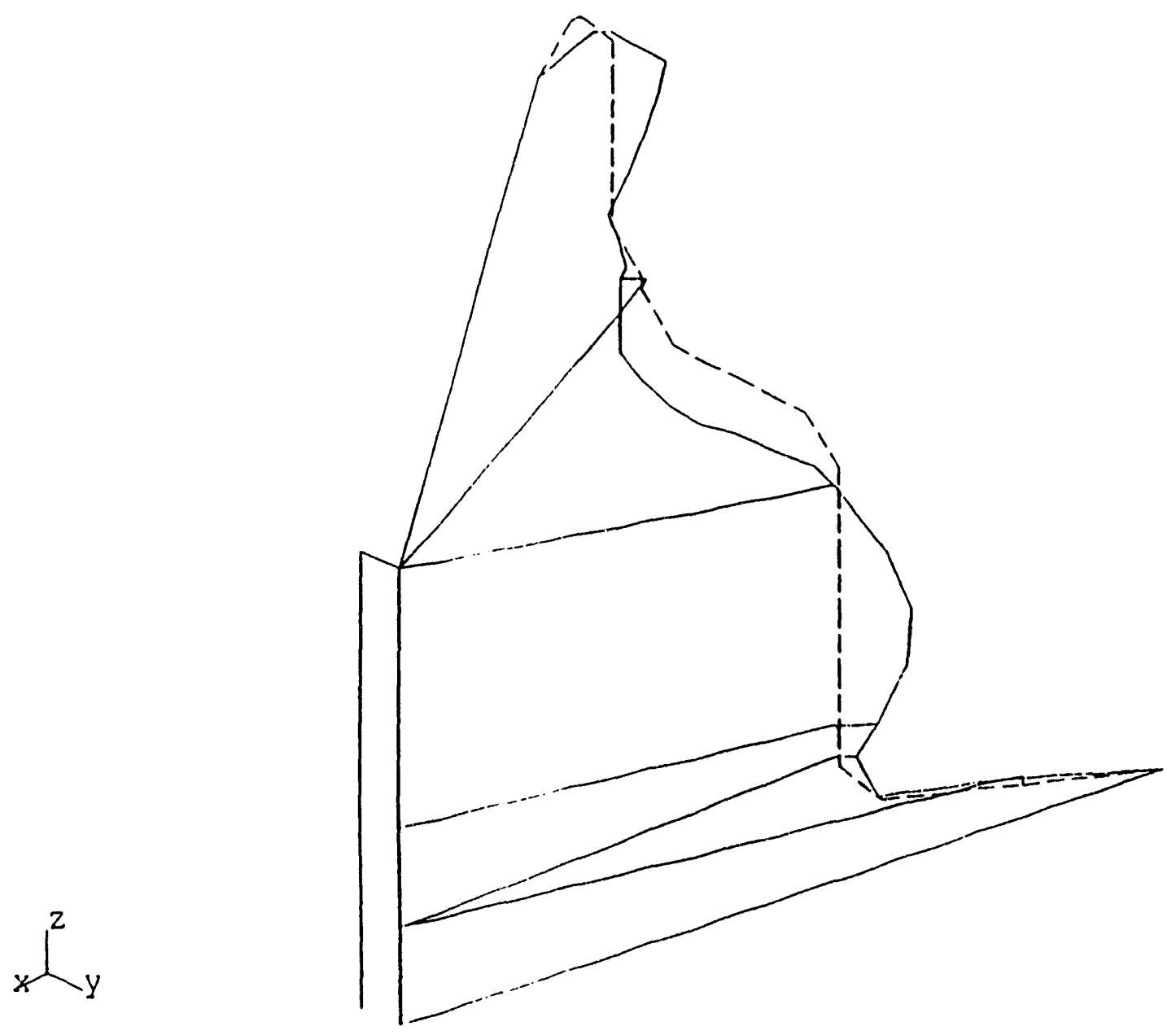

BENCHMARK PROBLEM 3: COUP LEI) MODEL

Mode 7, Frequency $=39.143 \mathrm{~Hz}$, Scale Factor $=0.200 \mathrm{E}+03$

B-7

NUREG/CR-6013 


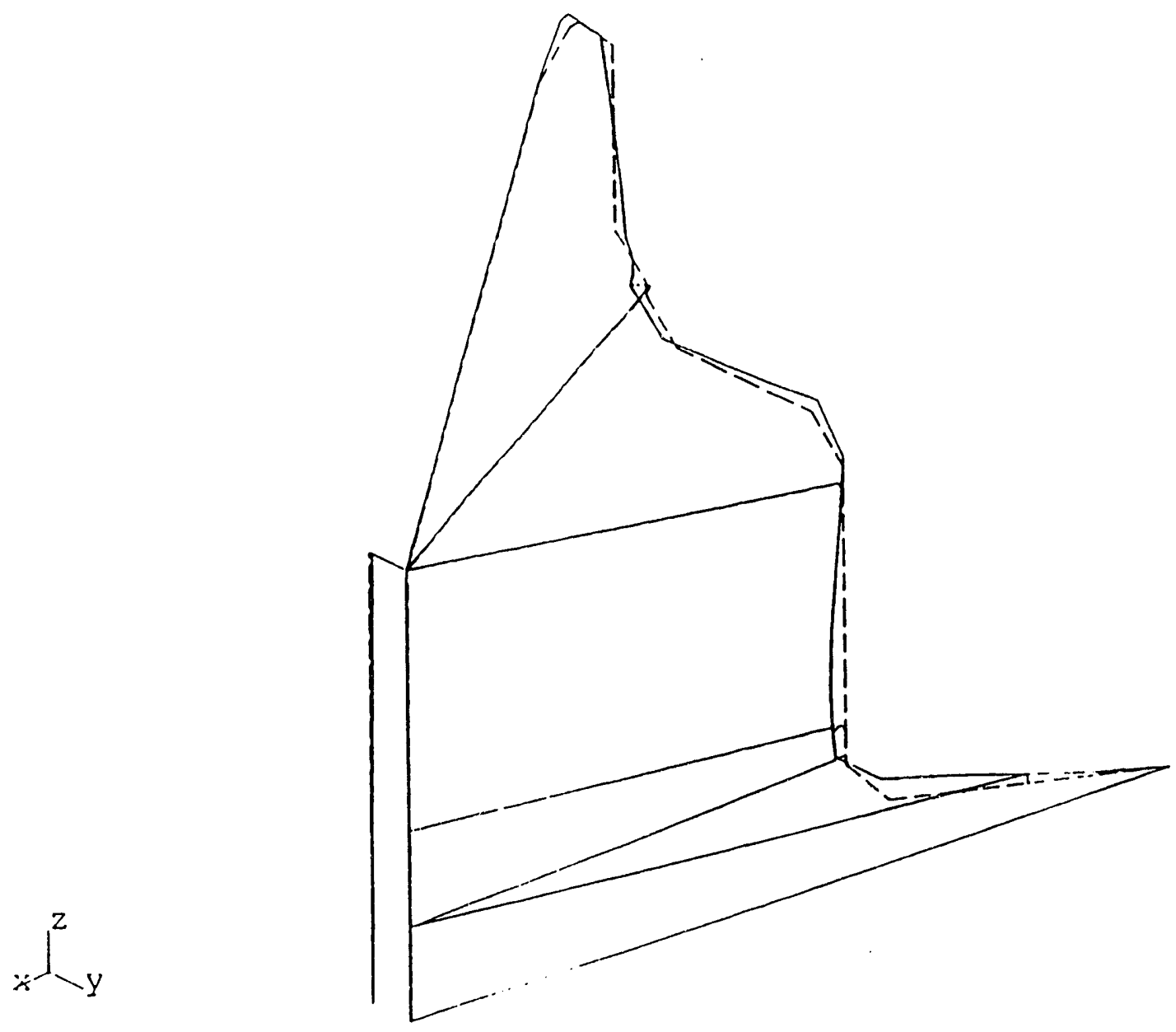

BENCHMARK PROBLEM 3: COUPLED MODEL

Mode 8, Erequency $=22.554 \mathrm{~Hz}$, Scale Eactor $=0.200 \mathrm{E}+03$ 


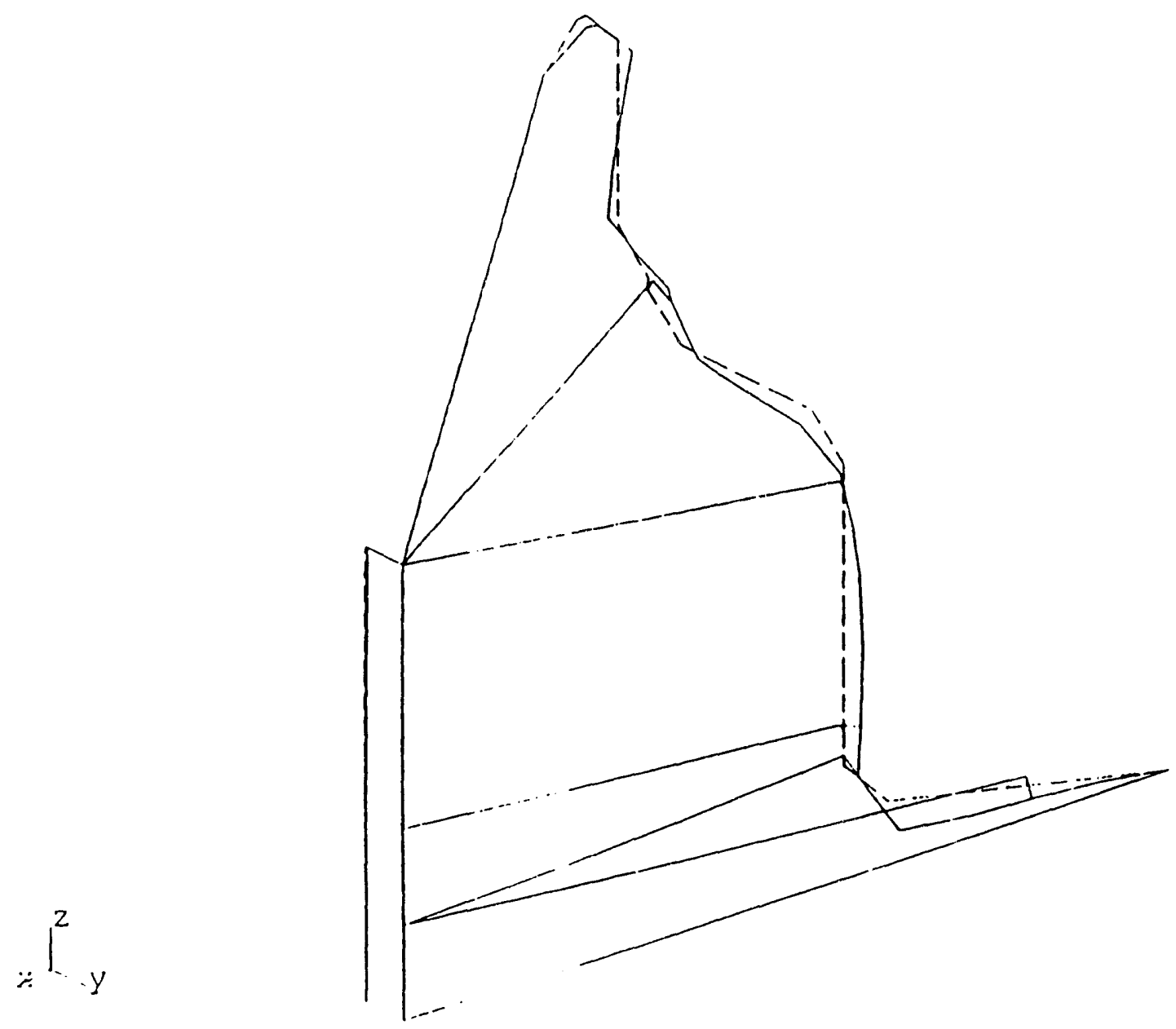

BENCHMARK PROBLEM 3: COUPLED MODEL

Mode 9, Erequency $=22.678 \mathrm{~Hz}$, Scale Factor $=0.200 \mathrm{E}+03$ 


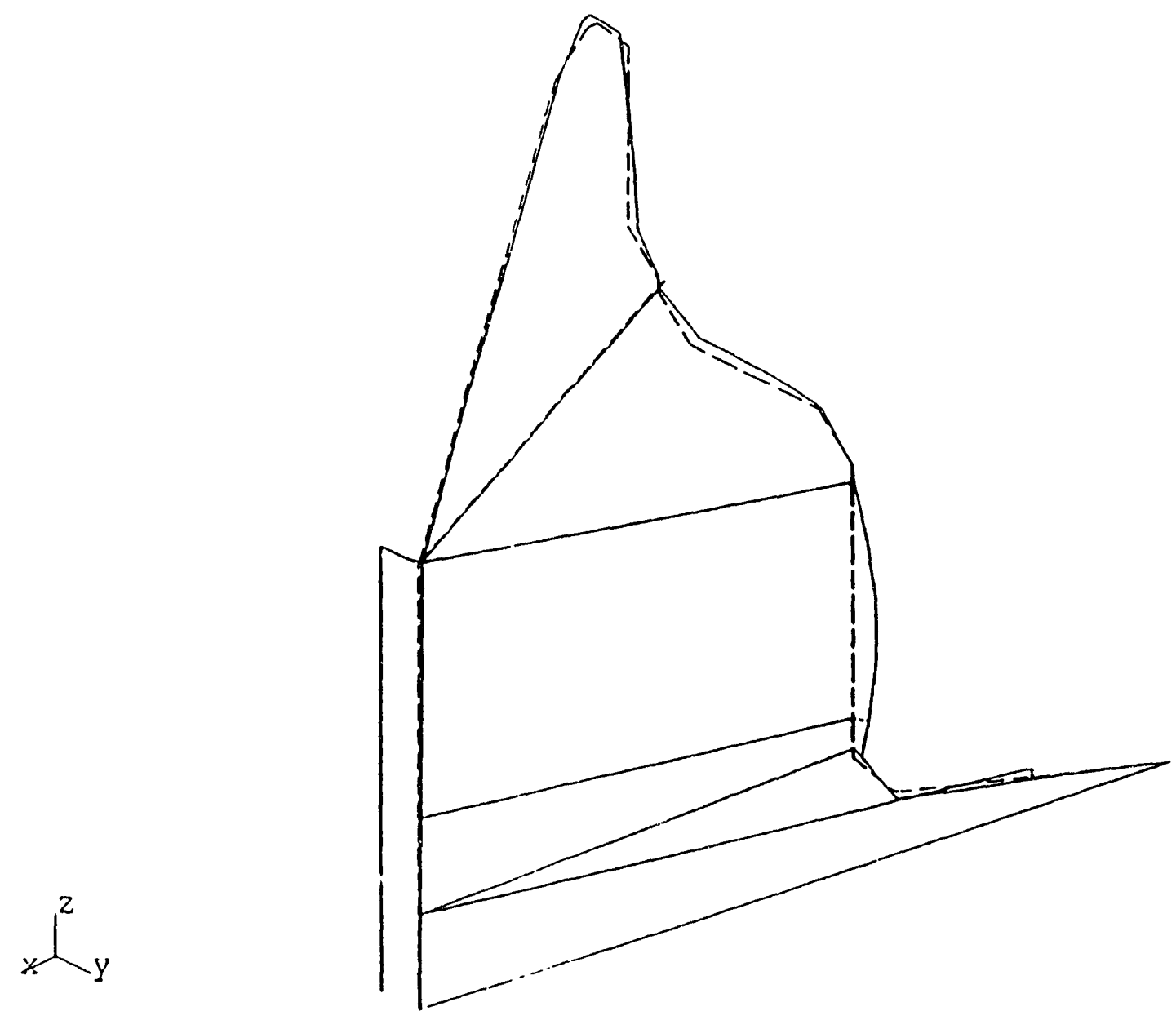

BENCHMARK PROBLEM 3: COUPLED MODEL

Mode 10, Erequency $=24.355 \mathrm{~Hz}$, Scale Eactor $=0.200 \mathrm{E}+03$ 


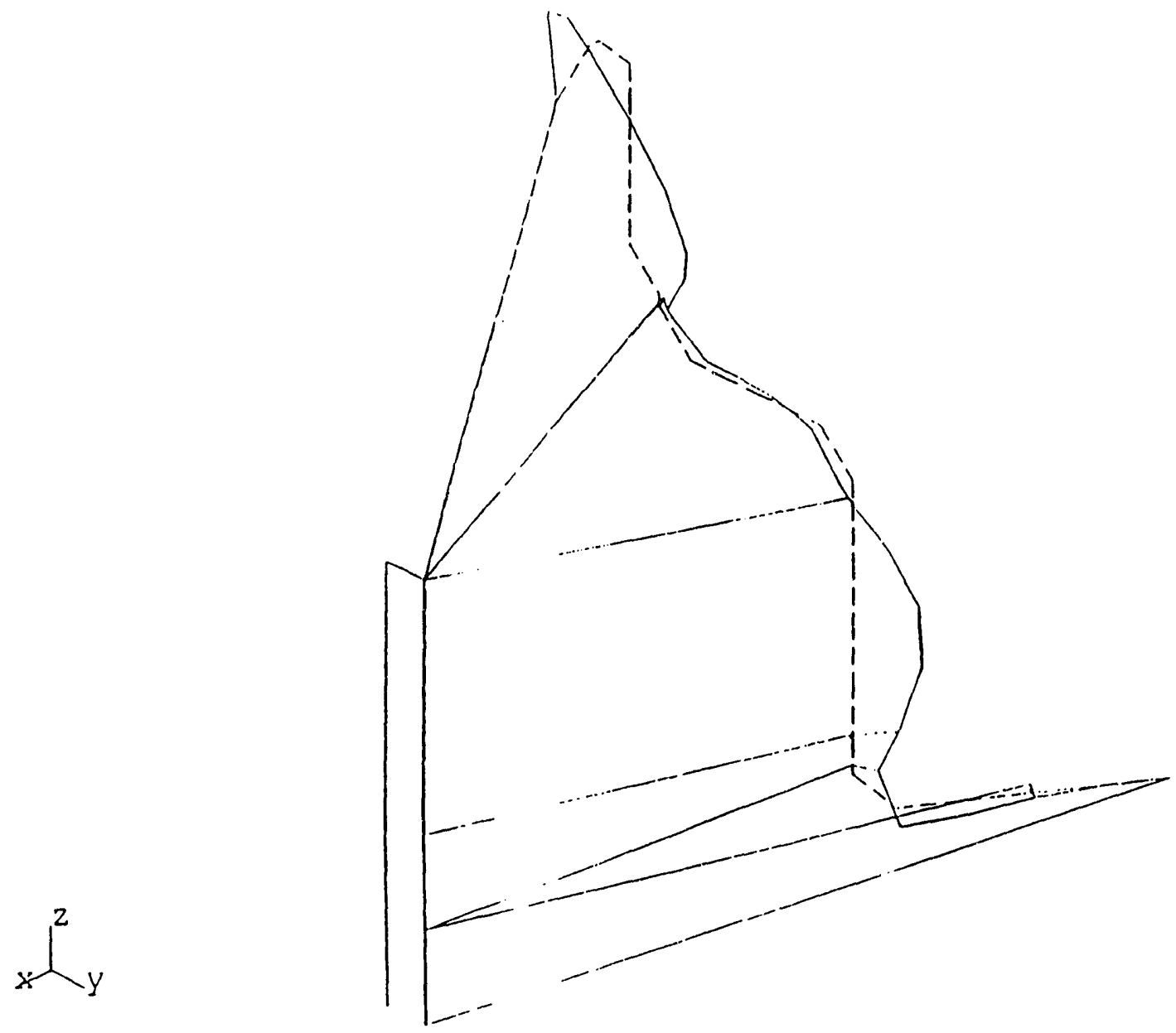

BENCHMARK PROBLEM 3: COUPLLIJ MODEL

Mode 11, Frequency $=25.11111 \mathrm{z}$, Scale Factor $=0.200 \mathrm{E}+03$ 


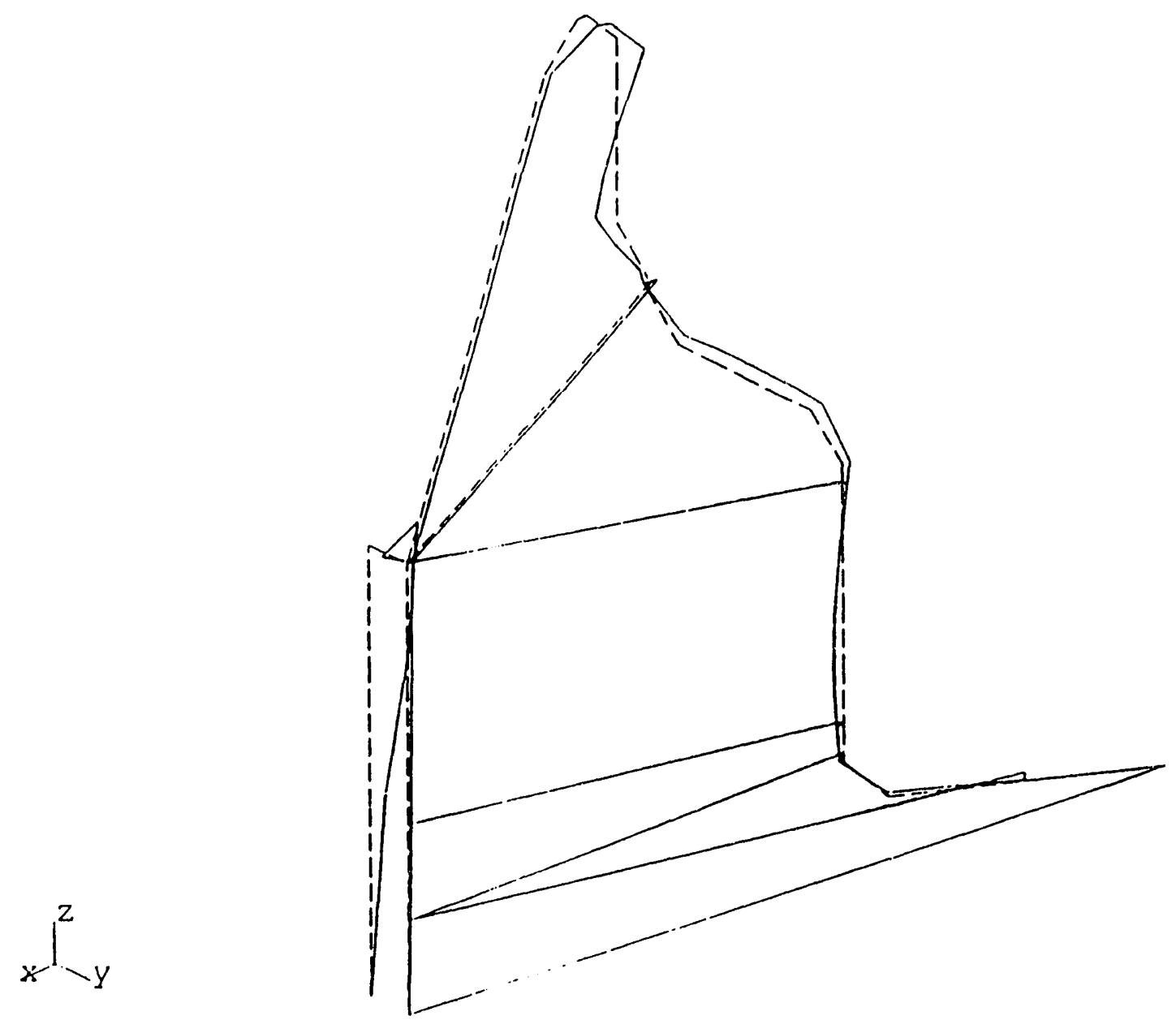

BENCHMARK PROBLEM 3: COUPLED MODEL Mode 12, Erequency $=26.635 \mathrm{~Hz}$, Scale Eactor $=0.200 \mathrm{E}+04$ 


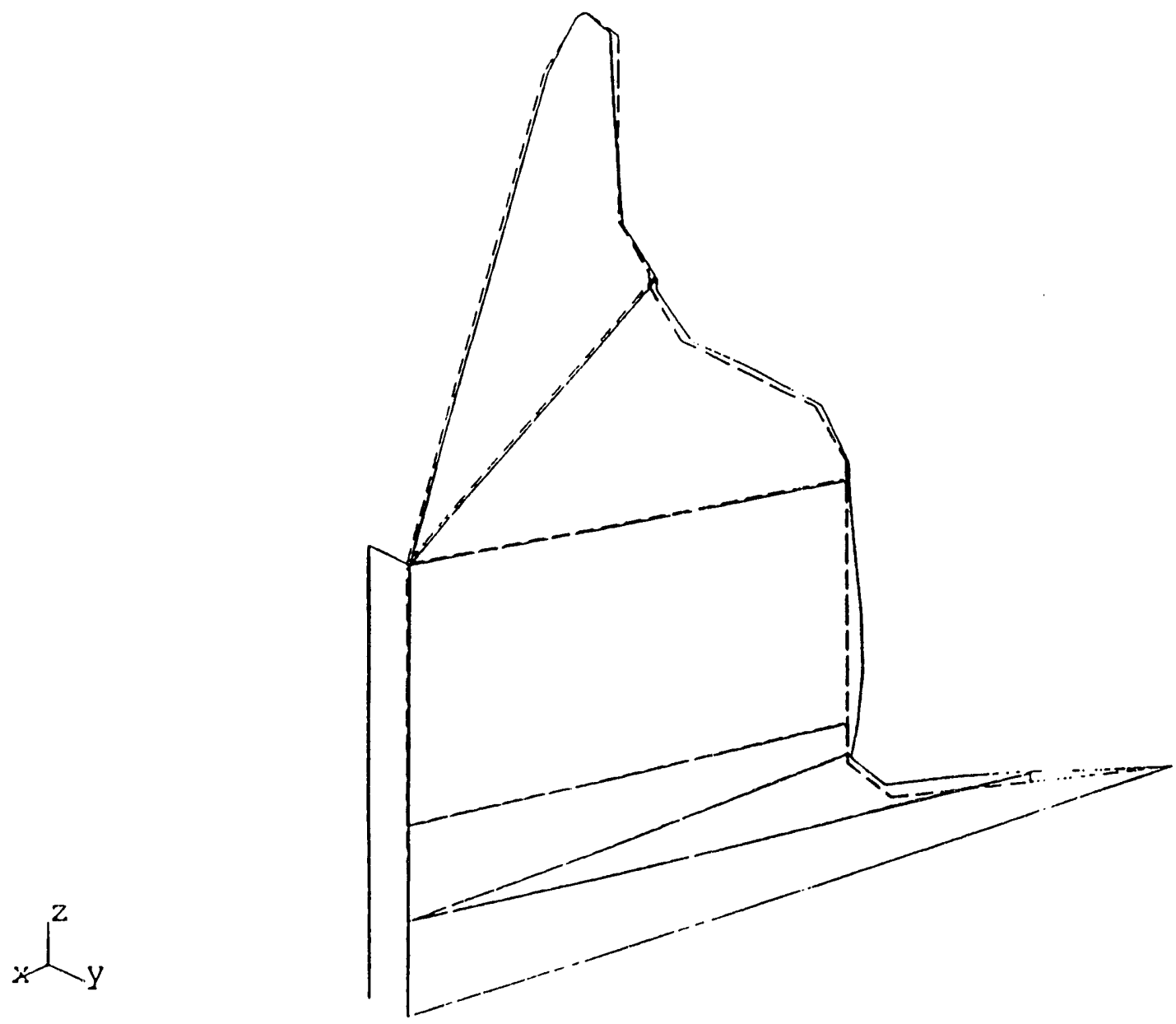

BENCHMARK PROBLEM 3: COUPLED MODEL

Mode 13, Erequency $=26.756 \mathrm{~Hz}$, Scale Eactor $=0.200 \mathrm{E}+03$ 


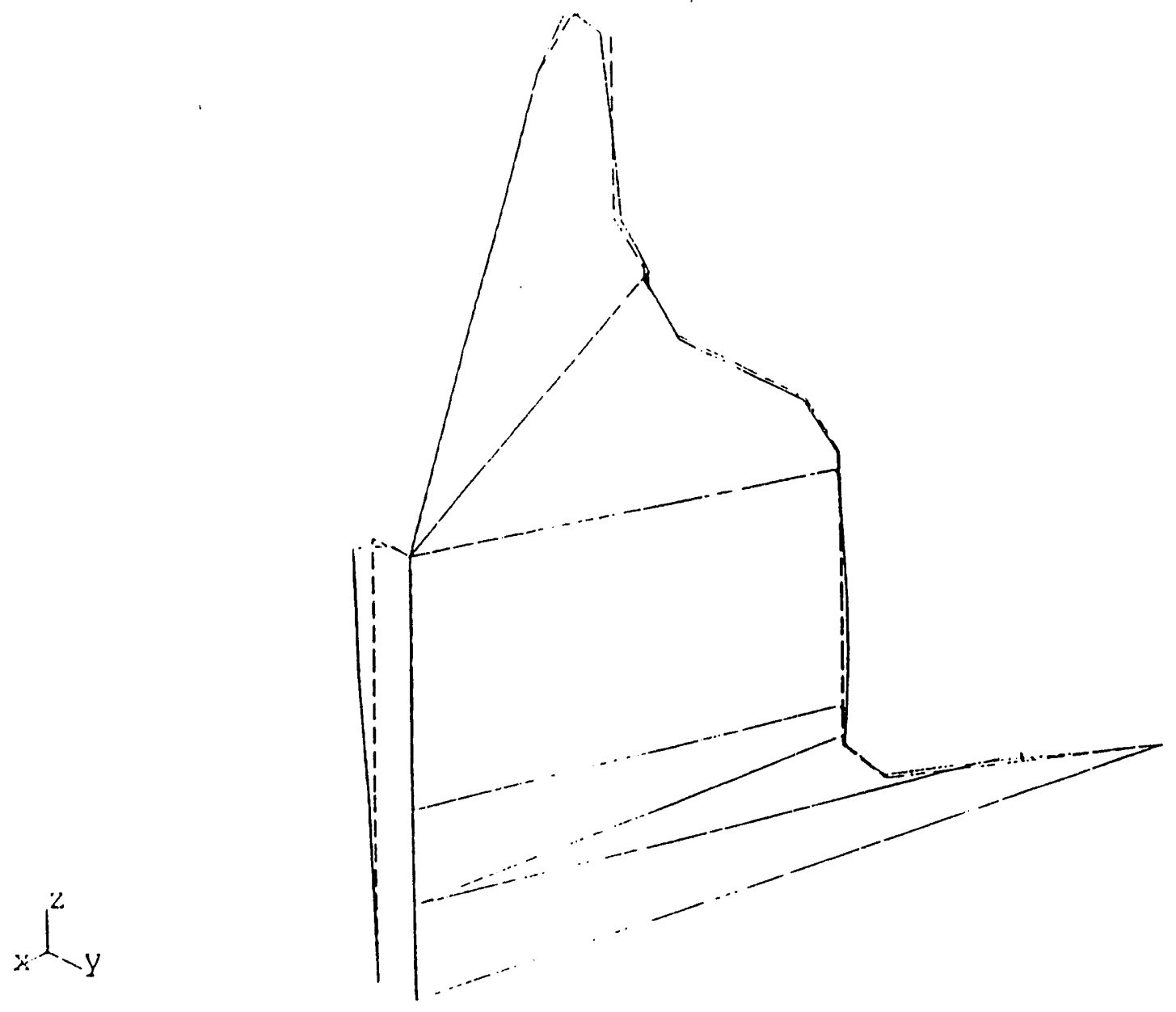

BENCHMARK PROBLEM 3: COUPLED MODEI,

Mode 14, Frequency $=26.85511 \%$, scale Eactor $=0.200 \mathrm{E}+04$

NUREG/CR-6013

B-14 


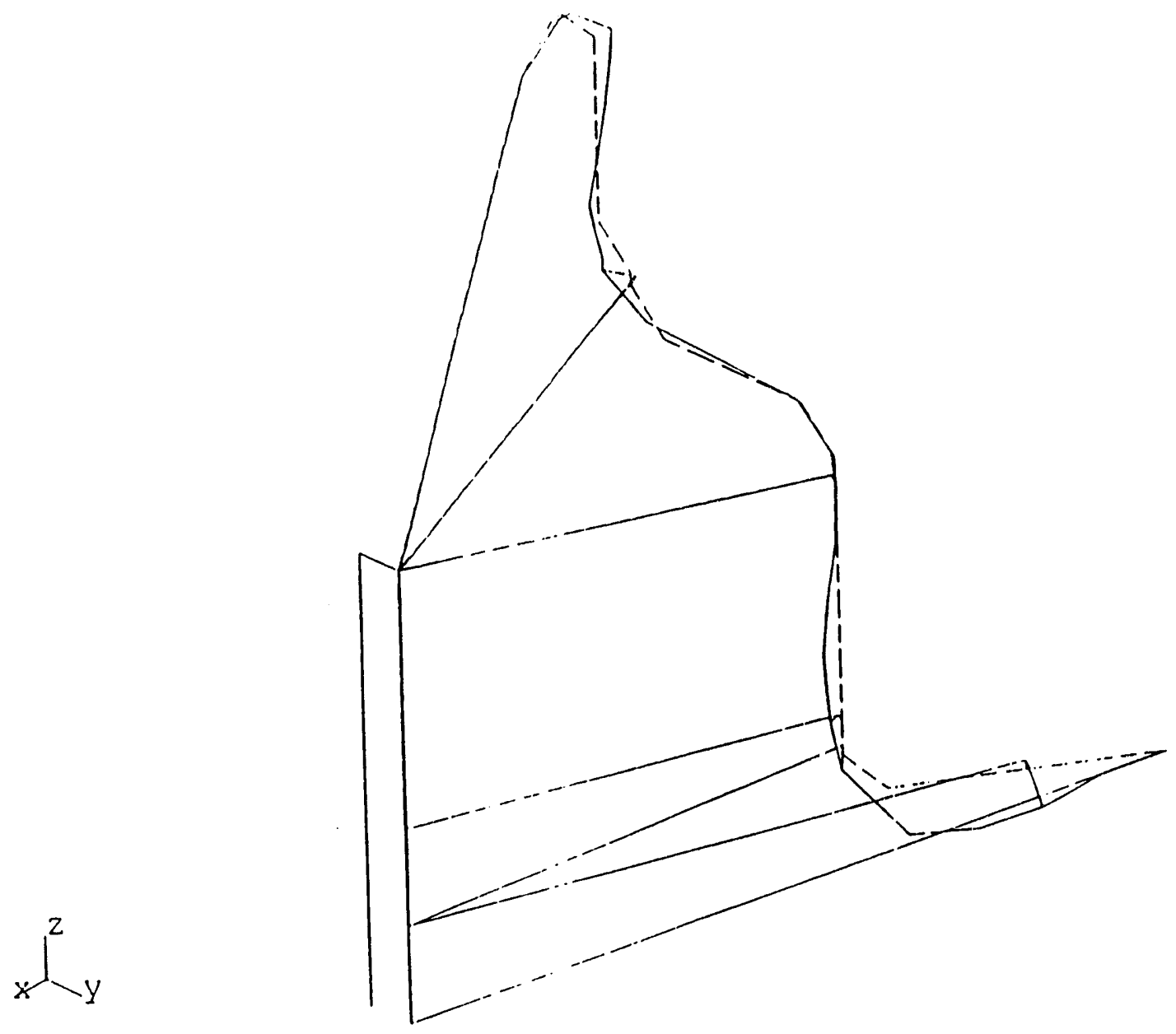

BENCHMARK PROBLEM 3: COUPLEI) MODEL Mode 15, Erequency $=27.165 \mathrm{~Hz}$, Scale Factor $=0.200 \mathrm{E}+03$ 


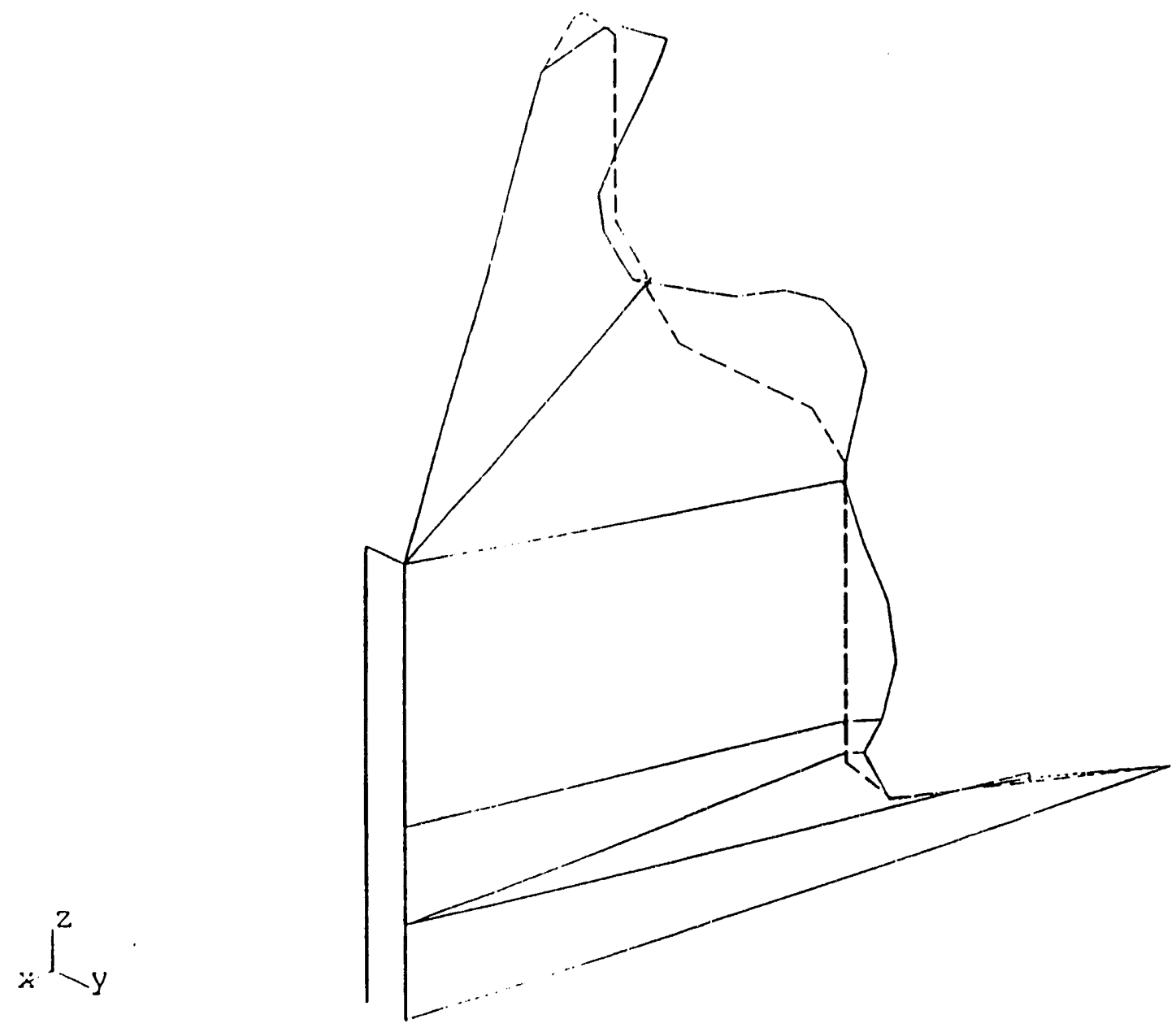

BENCHMARK PROBLEM 3: COUPLED MODEL

Mode 16, Erequency $=31.085 \mathrm{~Hz}$, Scale Eactor $=0.200 \mathrm{E}+03$ 


\begin{tabular}{|c|c|}
\hline $\begin{array}{l}\text { BIBLIOGRAPHIC DATA SHEET } \\
\text { (See instructions on the reverse) }\end{array}$ & \multirow{2}{*}{ 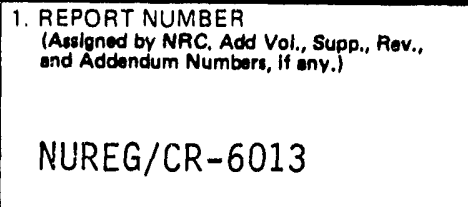 } \\
\hline \multirow{4}{*}{$\begin{array}{l}\text { 2. TITLE AND SUBTITLE } \\
\text { Methods Used for the Treatment of } \\
\text { Non-Proportionally Damped Structural Systems }\end{array}$} & \\
\hline & 3. DATE REPORT PUBLISHED \\
\hline & \begin{tabular}{|l|r|} 
MONTH & YEAR \\
May & 1993 \\
\end{tabular} \\
\hline & $\begin{array}{l}\text { 4. FIN OR GRANT NUMBER } \\
\text { D } 1730\end{array}$ \\
\hline \multirow[t]{2}{*}{$\begin{array}{l}\text { 5. AUTHOR(S) } \\
\text { J.P. Conoscente, O.R. Maslenikov, and J.J. Johnson }\end{array}$} & $\begin{array}{l}\text { 6. TYPE OF REPORT } \\
\text { Technical }\end{array}$ \\
\hline & $\begin{array}{l}\text { 7. PERIOD COVERED (Inclusive Dores) } \\
11 / 88 \text { to } 4 / 93\end{array}$ \\
\hline \multicolumn{2}{|c|}{$\begin{array}{l}\text { 8. PERFORMING ORGANIZATION - NAME AND ADDRESS (If NAC, provide Division, Office or Region, U.S. Nuclear Regulatory Commission, and maliling address; if contractor, provide } \\
\text { neme and misiling address,) }\end{array}$} \\
\hline \multicolumn{2}{|c|}{$\begin{array}{l}\text { EQE Engineering Consultants } \\
44 \text { Montgomery Street, Ste. } 3200 \\
\text { San Francisco, CA } 94104\end{array}$} \\
\hline \multicolumn{2}{|c|}{$\begin{array}{l}\text { 9. SPONSORING ORG ANIZATION - NAME AND ADDRESS IIr NRC, trpe "Same as above" if contractor, provide NRC Division, Office or Region, U.S. Nuclear Regulatory Commission, } \\
\text { and mailing address.) }\end{array}$} \\
\hline \multicolumn{2}{|c|}{$\begin{array}{l}\text { Division of Engineering } \\
\text { Office of Nuclear Regulatory Research } \\
\text { U.S. Nuclear Regulatory Commission } \\
\text { Washington, DC } 20555\end{array}$} \\
\hline \multicolumn{2}{|l|}{ 10. SUPPLEMENTARY NOTES } \\
\hline \multicolumn{2}{|c|}{$\begin{array}{l}\text { 11. ABSTRACT } 200 \text { wordsorless } \\
\text { Non-proportional or non-classical damping is defined as a form of viscous damping that } \\
\text { introduces coupling between the undamped modal coordinates of motion. Such problems } \\
\text { have practical applications in the dynamic analysis of soil-structure systems, } \\
\text { structure-equipment systems, and structural systems made of materials with different } \\
\text { energy dissipation capacities. } \\
\text { Presented in this report is a review of the methods most commonly used in structural } \\
\text { analysis for the solution of the dynamic response of systems with non-proportional } \\
\text { damping. Both rigorous and approximate methods are described. Since rigorous methods } \\
\text { usually require large computational efforts, approximate methods using undamped mode } \\
\text { shapes are often preferred. In the study described here, the accuracy of three } \\
\text { approximate methods was evaluated for three benchmark problems, with various parametric } \\
\text { variations. Results were compared with the exact solution for different combinations } \\
\text { of structural properties. } \\
\text { Based on these results, conclusions and recommendations are presented for the use of the } \\
\text { selected approximate methods. }\end{array}$} \\
\hline \multirow{6}{*}{$\begin{array}{l}\text { 12. KEY WORDS/DESCR!PTORS iList words or phrases that will assist researchers in locating the report.) } \\
\text { Structure damping, non-proportional damping, nuclear power plant } \\
\text { structures, seismic analys is }\end{array}$} & \begin{tabular}{|l|l} 
13. AVAILABILITY STATEMENT \\
\end{tabular} \\
\hline & \begin{tabular}{|l} 
Unl imited \\
14. SECURITY CLASSIFICATION
\end{tabular} \\
\hline & $\begin{array}{l}\text { (This Pogel } \\
\text { Unclassified } \\
\text { (This Report) }\end{array}$ \\
\hline & Unclassified \\
\hline & \\
\hline & \\
\hline
\end{tabular}



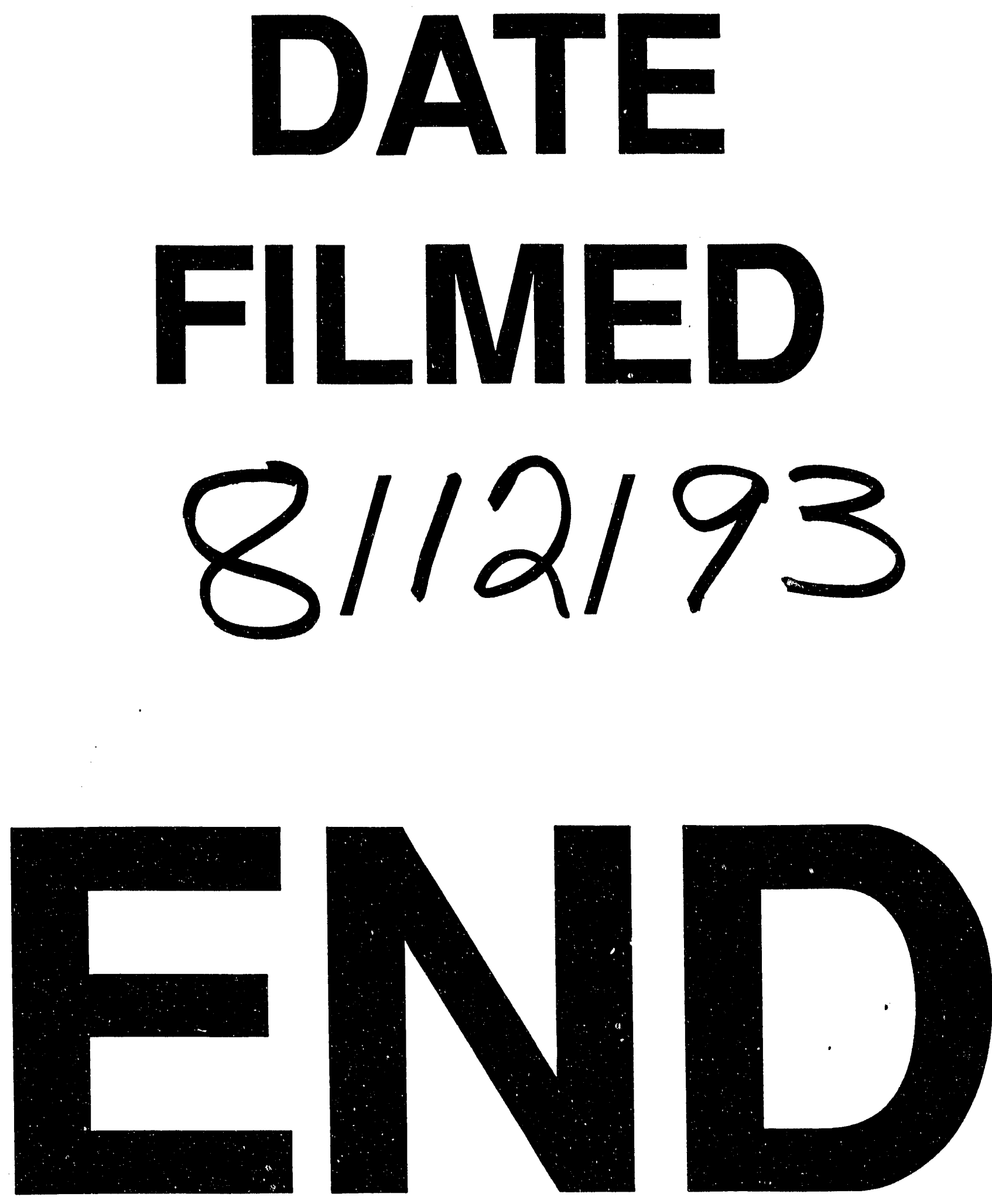
